\title{
WestVirginiaUniversity
}

THE RESEARCH REPOSITORY @ WVU

Graduate Theses, Dissertations, and Problem Reports

2014

\section{Modeling of caprock seal failure due to fluid injection}

\author{
Hari Kiran Nambu
}

Follow this and additional works at: https://researchrepository.wvu.edu/etd

\section{Recommended Citation}

Nambu, Hari Kiran, "Modeling of caprock seal failure due to fluid injection" (2014). Graduate Theses, Dissertations, and Problem Reports. 7334.

https://researchrepository.wvu.edu/etd/7334

This Thesis is protected by copyright and/or related rights. It has been brought to you by the The Research Repository @ WVU with permission from the rights-holder(s). You are free to use this Thesis in any way that is permitted by the copyright and related rights legislation that applies to your use. For other uses you must obtain permission from the rights-holder(s) directly, unless additional rights are indicated by a Creative Commons license in the record and/ or on the work itself. This Thesis has been accepted for inclusion in WVU Graduate Theses, Dissertations, and Problem Reports collection by an authorized administrator of The Research Repository @ WVU. For more information, please contact researchrepository@mail.wvu.edu. 
Hari Kiran Nambu

Thesis submitted to the

Benjamin M. Statler

College of Engineering and Mineral Resources

at West Virginia University

in partial fulfillment of the requirements for the degree of

Master of Science

in

Civil \& Environmental Engineering

Hema J. Siriwardane, Ph.D., Chair

Udaya B. Halabe, Ph.D.

John D. Quaranta, Ph.D.

Raj K. Gondle, Ph.D.

Department of Civil and Environmental Engineering

Morgantown, West Virginia

2014

Keywords: Saline aquifers, $\mathrm{CO}_{2}$ injection, seal failure, caprock fracture 
All rights reserved

INFORMATION TO ALL USERS

The quality of this reproduction is dependent upon the quality of the copy submitted.

In the unlikely event that the author did not send a complete manuscript and there are missing pages, these will be noted. Also, if material had to be removed, a note will indicate the deletion.

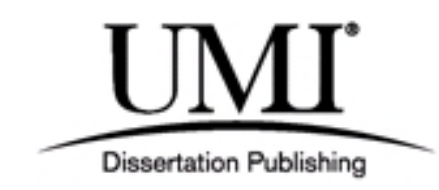

UMI 1554851

Published by ProQuest LLC (2014). Copyright in the Dissertation held by the Author.

Microform Edition () ProQuest LLC.

All rights reserved. This work is protected against unauthorized copying under Title 17, United States Code

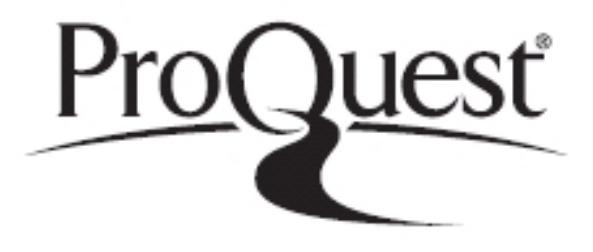

ProQuest LLC.

789 East Eisenhower Parkway

P.O. Box 1346

Ann Arbor, MI 48106 - 1346 


\section{ABSTRACT \\ Modeling of Caprock Seal Failure due to Fluid Injection}

Hari Kiran Nambu

The past, present, and projected trends of increasing carbon dioxide $\left(\mathrm{CO}_{2}\right)$ concentration levels in the atmosphere have raised serious concerns about global warming. Several efforts are being made to stabilize the current levels of $\mathrm{CO}_{2}$ emissions. Geologic sequestration of $\mathrm{CO}_{2}$ in deep saline aquifers is considered to be one of the potential options to reduce greenhouse gas emissions in the atmosphere. A tight, low-permeability caprock layer overlying the $\mathrm{CO}_{2}$-targeted reservoir limits the upward migration of $\mathrm{CO}_{2}$ and acts as a primary seal layer to trap $\mathrm{CO}_{2}$. Large volumes of fluid or $\mathrm{CO}_{2}$ injected in the subsurface may over-pressurize the reservoir and increase the potential for mechanical seal failure. Such a scenario could lead to $\mathrm{CO}_{2}$ leakage with time.

In the present study, coupled single-phase and multi-phase fluid flow and geomechanical models were constructed to investigate the fluid flow and ground deformation behavior. Axisymmetric and three-dimensional fluid flow and deformation models were constructed. Coupled multi-phase fluid flow and deformation modeling was used to estimate the maximum sustainable injection pressure. Coupled multi-phase fluid flow and geomechanical models were also used to investigate the mechanical seal failure caused by $\mathrm{CO}_{2}$ injection. A parametric study was conducted on the geomechanical failure properties that cause shear failure in the caprock layer during $\mathrm{CO}_{2}$ injection. Parametric study of geomechanical properties such as cohesion, angle of friction and permeability show that these material properties have significant influence on shear failure of caprock layer. Also, finite element techniques were used to model shear failure of an inclined fracture or a fault zone during fluid injection. Results show the development of plastic strains when injected fluid migrates to the fault zone. 


\section{This work is dedicated to}

\section{my mother, father and family}

$$
\text { for their }
$$

encouragement and unconditional

lope and support

To ohe ofamily 


\section{ACKNOWLEDGEMENTS}

I would like to express my sincere gratitude to my advisor, Dr. Hema J. Siriwardane, for his invaluable guidance, support, and encouragement. I thank Dr. Siriwardane for believing in me that I can accomplish this goal with hard work and sincere effort. I thank him for providing me that confidence which lead to completion of this research work. He taught me computational modeling work and helped me several times during this research work with his knowledge, profound insight and careful observations. I also thank my committee members, Dr. Udaya B. Halabe, Dr. John D. Quaranta, and Dr. Raj K. Gondle for their time, valuable comments, and feedback.

I gratefully acknowledge the financial support provided through a graduate research assistantship by West Virginia University through a project funded by the United States Department of Energy. The work presented in this report was performed with the funding provided by URS Energy \&Construction, Inc. to support National Energy Technology Laboratory's ongoing research in $\mathrm{CO}_{2}$ Sequestration. Special thanks to Dr. Raj K. Gondle for his suggestions and generous help during my research. I would also like to thank my friends - Sai Varre, Zainab Jawad and Carter Hulcher for their help and support during this research work. Lastly, but in no sense the least, I am thankful to all my friends who made my stay at the West Virginia University a memorable and valuable experience. 


\section{TABLE OF CONTENTS}

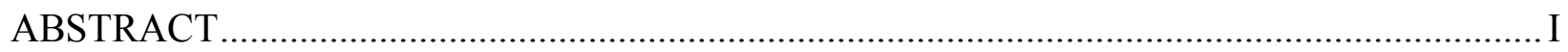

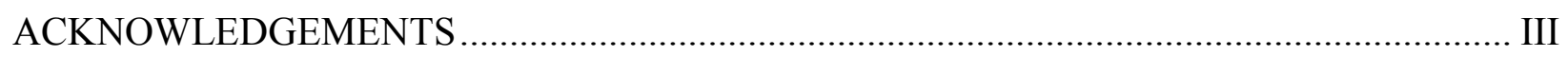

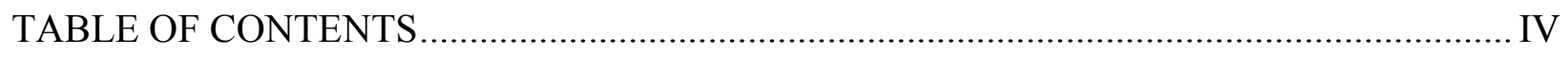

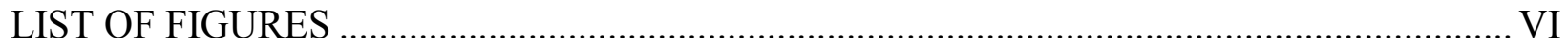

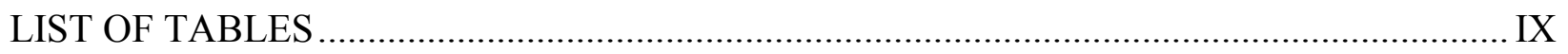

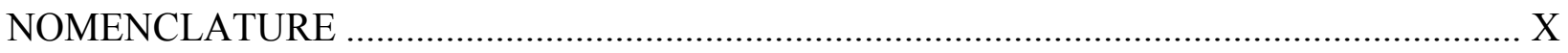

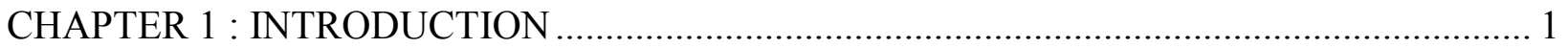

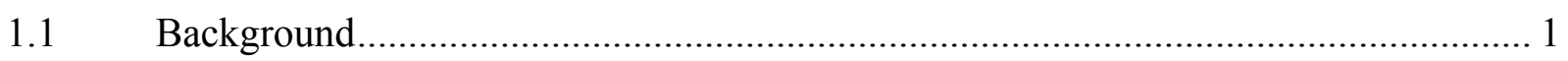

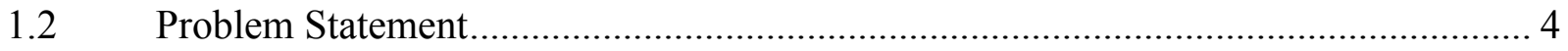

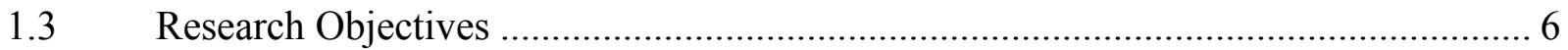

CHAPTER 2 : REVIEW OF $\mathrm{CO}_{2}$ STORAGE IN DEEP SALINE AQUIFERS ………................ 7

2.1 Introduction to Carbon Sequestration in Saline Aquifers.......................................... 7

2.2 Influence of Caprock Fracture or Fault .................................................................. 9

2.3 Caprock Seal Failure ………………………................................................ 10

2.4 Review of a few potential $\mathrm{CO}_{2}$ storage sites ...................................................... 11

2.5 Previous modeling studies ............................................................................... 14

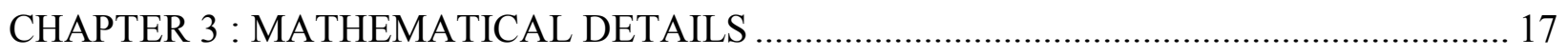

3.1 Mathematical details of single-phase fluid flow in porous media.............................. 17

3.2 Mathematical details of multi-phase fluid flow in porous media ............................... 19

3.3 Mathematical details of geomechanical modeling .................................................. 21

3.4 Implementation of aforementioned equations in computational models.................... 26

CHAPTER 4 : COUPLED FLUID FLOW AND GEOMECHANICAL MODELING................ 27

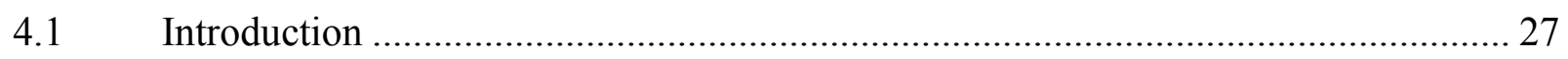

4.2 Coupled Single-phase Fluid Flow and Geomechanical Modeling ............................ 29

4.2.1 Axisymmetric modeling ......................................................................... 29

4.2.2 Three-dimensional modeling (Single-phase fluid flow)................................ 35

4.3 Coupled Multi-phase Fluid Flow and Geomechanical Modeling .............................. 38

4.3.1 Axisymmetric modeling ....................................................................... 38 


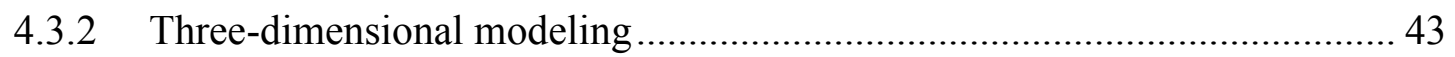

4.4 Comparison of single-phase and multi-phase fluid flow models

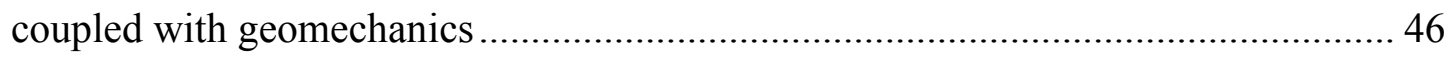

4.5 Geomechanical modeling of rock failure caused due to $\mathrm{CO}_{2}$ injection...................... 47 CHAPTER 5 : GEOMECHANICAL MODELING OF CAPROCK SEAL FAILURE ................ 51

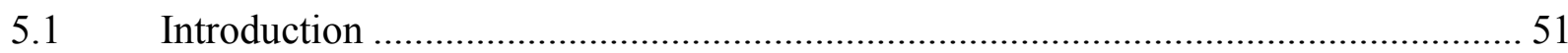

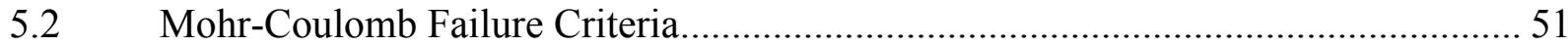

5.3 Modeling Details to Investigate Caprock Seal Failure …………………………....... 53

5.4 Parametric analysis of geomechanical properties .................................................... 58

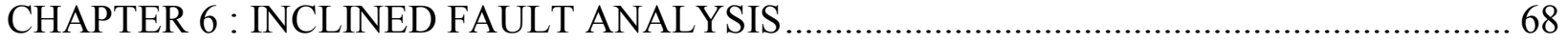

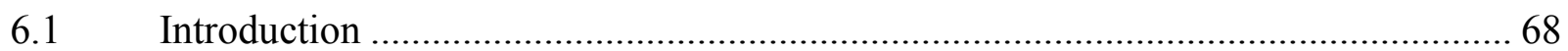

6.2 Details of Inclined Fault Model........................................................................... 72

6.3 Prediction of damage zone due to fault movement ..................................................... 76

6.3.1 Mohr-Coulombs failure criterion................................................................ 76

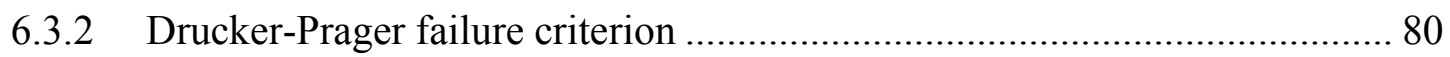

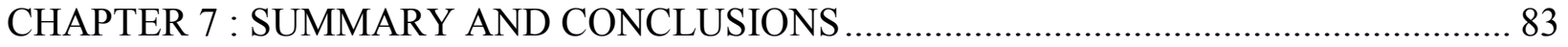

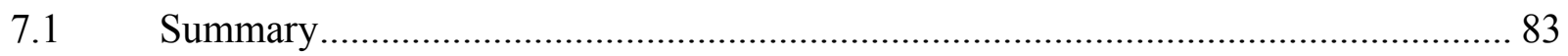

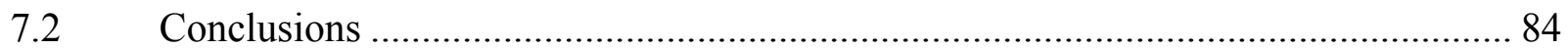

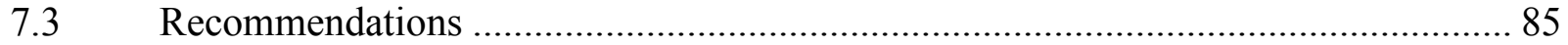

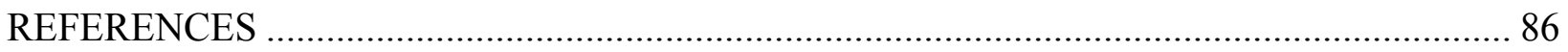




\section{LIST OF FIGURES}

Figure 1.1 : Geologic sequestration of $\mathrm{CO}_{2}$ into potential reservoirs .......................................2

Figure 1.2: Schematic diagram of a hypothetical injection site .............................................5

Figure 1.3: Schematic diagram of a fault located in the caprock layer $500 \mathrm{~m}$

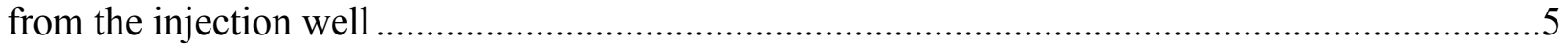

Figure 2.1: Locations of several CCS projects in USA …................................................

Figure 2.2: Schematic diagram of a caprock fracture and $\mathrm{CO}_{2}$ leakage ..................................10

Figure 4.1: Schematic diagram of a hypothetical injection site ............................................28

Figure 4.2: Geometry of the axisymmetric single-phase model .............................................31

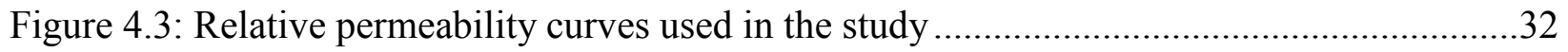

Figure 4.4: Initial fluid pressure distribution $(\mathrm{kPa})$ by using an axisymmetric

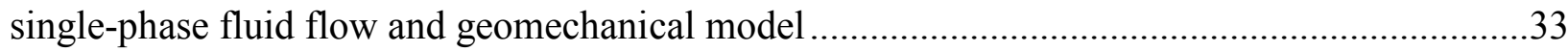

Figure 4.5: Fluid pressure distribution $(\mathrm{kPa})$ at the end of 5-years by using an axisymmetric single-phase fluid flow and geomechanical model

Figure 4.6: Computed vertical displacements $(\mathrm{cm})$ by using an axisymmetric single-phase fluid flow and geomechanical model

Figure 4.7: Computed ground displacements $(\mathrm{cm})$ by using an axisymmetric single-phase fluid flow and geomechanical model.....

Figure 4.8: Geometry of 3-D, coupled single-phase fluid flow and geomechanical model

Figure 4.9: Initial fluid pressure distribution $(\mathrm{kPa})$ by using a 3-D, single-phase

fluid flow and geomechanical model.

Figure 4.10: Computed changes in fluid pressure $(\mathrm{kPa})$ at the end of 5-year injection

by using a 3-D, single-phase fluid flow and geomechanical model

Figure 4.11: Computed vertical displacements $(\mathrm{cm})$ by using a 3-D, single-phase

fluid flow and geomechanical model

Figure 4.12: Computed ground displacements by using a 3-D, single-phase

fluid flow and geomechanical model

Figure 4.13: Geometry of axisymmetric, coupled multi-phase fluid flow

and geomechanical model.

Figure 4.14: Relative permeability curves used in the study 
Figure 4.15: Initial fluid pressure distribution $(\mathrm{kPa})$ by using an axisymmetric, coupled multi-phase fluid flow and geomechanical model

Figure 4.16: Computed fluid pressure distribution $(\mathrm{kPa})$ at the end of 5-year $\mathrm{CO}_{2}$

injection period by using an axisymmetric multi-phase flow and geomechanical model

Figure 4.17: Computed vertical displacements $(\mathrm{cm})$ by using an axisymmetric multi-phase flow and geomechanical model

Figure 4.18: Computed vertical displacements by using an axisymmetric

multi-phase flow and geomechanical model

Figure 4.19: Three-dimensional fluid flow for multi-phase flow and geomechanical model

Figure 4.20: Initial fluid pressure distribution $(\mathrm{kPa})$ by using a 3-D

multi-phase flow and geomechanical model

Figure 4.21: Computed fluid pressure distribution $(\mathrm{kPa})$ at the end

of 5 years by using a 3-D multi-phase flow and geomechanical model

Figure 4.22: Computed vertical displacements $(\mathrm{cm})$ by using a 3-D

multiphase flow and geomechanical model.

Figure 4.23: Computed vertical displacements by using a 3-D

multiphase flow and geomechanical model.

Figure 4.24: Effective plastic strains in 3-D model

Figure 4.25 : Cumulative injection volume after 5 years of $\mathrm{CO}_{2}$

injection in 3-D model

Figure 4.26: Effective plastic strains in axisymmetric model.

Figure 4.27: Cumulative injection volume after 5 years of $\mathrm{CO}_{2}$ injection

in axisymmetric model. .50

Figure 5.1: Mohr-Coulomb yield model ...........................................................................52

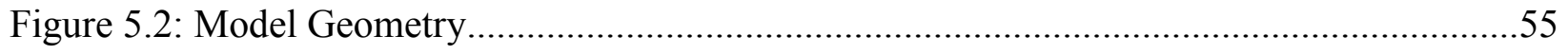

Figure 5.3: Fluid pressure distribution $(\mathrm{kPa})$ at the end of $\mathrm{CO}_{2}$ injection ...............................56

Figure 5.4: Vertical effective stress distribution $(\mathrm{kPa})$ at the end of $\mathrm{CO}_{2}$ injection ...................56

Figure 5.5: Plastic strains developed after 5 years of $\mathrm{CO}_{2}$ injection when

$\mathrm{c}=200 \mathrm{kPa}$ in the reservoir

Figure 5.6: Plastic strains developed after 5 years of $\mathrm{CO}_{2}$ injection when $\mathrm{c}=5,000 \mathrm{kPa}$ in the reservoir. .57

Figure 5.7: Plastic strains for Case 1(a) 


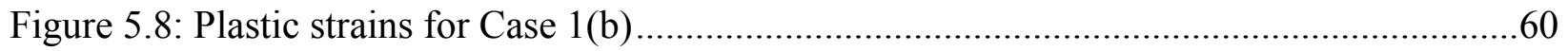

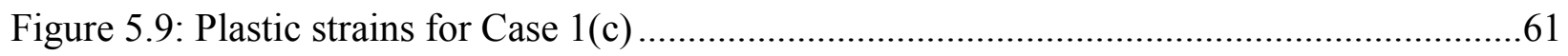

Figure 5.10: Plastic strains for Case $1(\mathrm{~d})$.........................................................................61

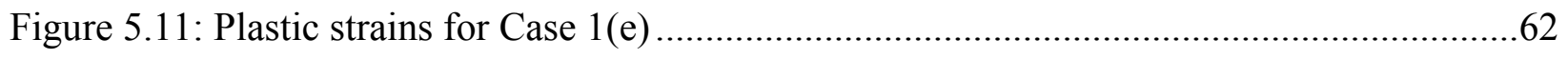

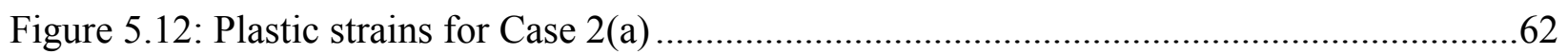

Figure 5.13: Plastic strains for Case 2(b) .......................................................................63

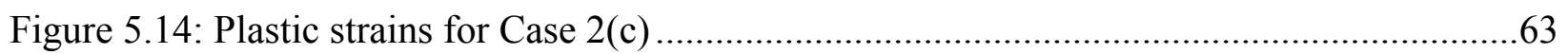

Figure 5.15: Plastic strains for Case 2(d) .......................................................................64

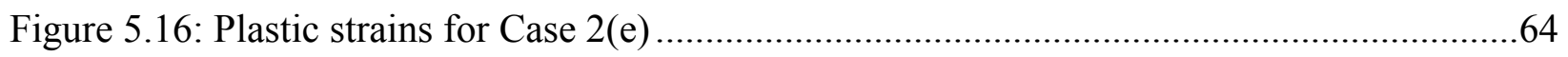

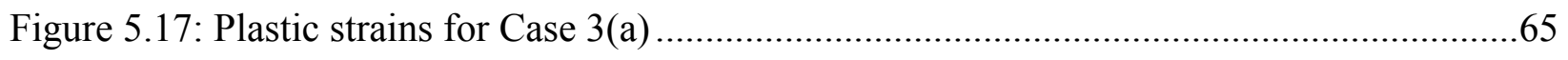

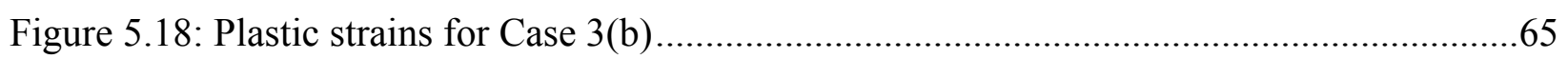

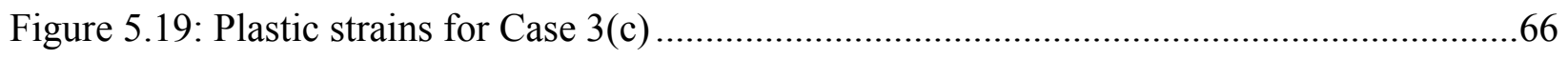

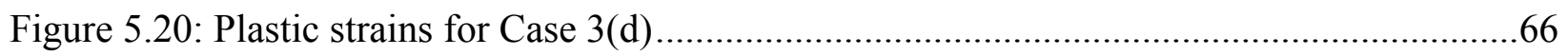

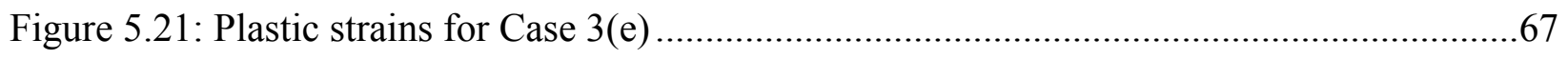

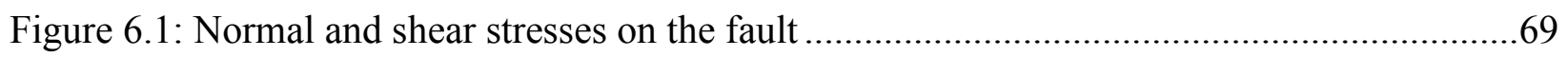

Figure 6.2: Effect of increasing pore fluid pressure on fault stability .................................... 70

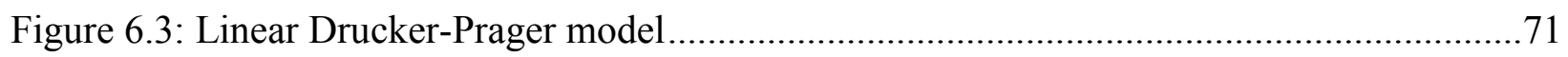

Figure 6.4: Schematic diagram of a fault located in the caprock layer $500 \mathrm{~m}$

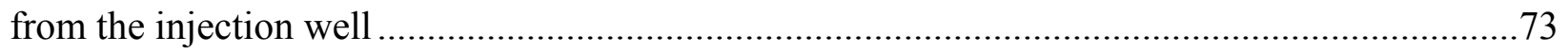

Figure 6.5: Finite element model showing the fault in the caprock layer................................75

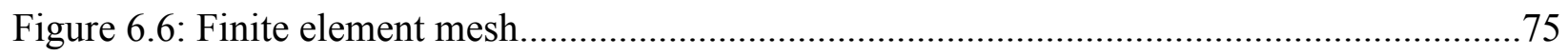

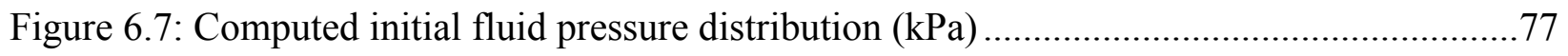

Figure 6.8: Computed pressure distribution $(\mathrm{kPa})$ after 5 years of fluid injection ......................78

Figure 6.9: Computed equivalent plastic strains after 5 years of fluid injection

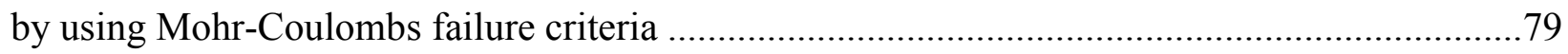

Figure 6.10: Variation of plastic strains near the fault line in the reservoir after 5 years of fluid injection by using Mohr-Coulomb criteria ............................................80

Figure 6.11: Computed equivalent plastic strains in the fault after 5 years of fluid injection by using Drucker-Prager failure criteria ...................................................81

Figure 6.12: Variation of plastic strains near the fault line in the reservoir after 5 years of fluid injection by using Drucker-Prager criteria. 


\section{LIST OF TABLES}

Table 4.1: Reservoir and geomechanical properties used in this chapter ................................28

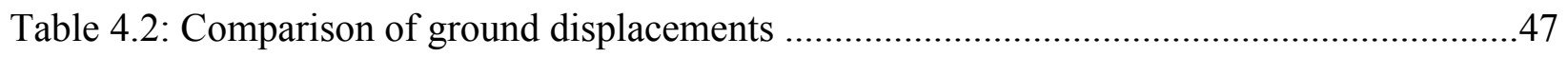

Table 5.1: Reservoir and geomechanical properties used in this chapter .................................54

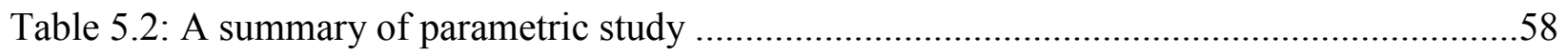

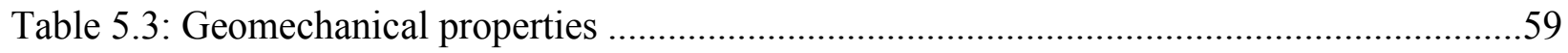

Table 6.1: Material properties used in the model with a faulted reservoir-caprock system ..........74

Table 6.2: Geomechanical properties used in the finite element analyses ...............................79 


\section{NOMENCLATURE}

\begin{tabular}{|c|c|c|}
\hline$\mu$ & $=$ & Fluid viscosity \\
\hline$n^{0}$ & $=$ & Initial porosity \\
\hline$q_{w}$ & $=$ & Mass flow rate of water \\
\hline$\sigma_{t}$ & $=$ & Total stress tensor \\
\hline$k^{o}$ & $=$ & Initial permeability \\
\hline$q_{c}$ & $=$ & Mass flow rate of $\mathrm{CO}_{2}$ \\
\hline$v_{w}$ & $=$ & Velocity of water \\
\hline$k_{r w}$ & $=$ & Relative permeability of water \\
\hline$\rho_{w}$ & $=$ & Density of water, \\
\hline$\rho$ & $=$ & Fluid density \\
\hline$v$ & $=$ & Poisson's ratio \\
\hline$v_{c}$ & $=$ & Velocity of $\mathrm{CO}_{2}$ \\
\hline$\mu_{c}$ & $=$ & Viscosity of $\mathrm{CO}_{2}$ \\
\hline$p_{w}$ & $=$ & Water pressure \\
\hline$S_{w}$ & $=$ & Water saturation \\
\hline$p_{c}$ & $=$ & $\mathrm{CO}_{2}$ pressure \\
\hline$S_{c}$ & $=$ & $\mathrm{CO}_{2}$ saturation \\
\hline$\rho_{c}$ & $=$ & Density of $\mathrm{CO}_{2}$ \\
\hline$\phi$ & $=$ & Friction angle \\
\hline$\nabla u$ & $=$ & Gradient of displacement vector \\
\hline$\nabla$ & $=$ & Gradient operator \\
\hline
\end{tabular}




\begin{tabular}{|c|c|c|}
\hline$\delta_{i j}$ & $=$ & Kronecker delta $=1$, if $\mathrm{i}=\mathrm{j} ;=0$ \\
\hline$\sigma_{1}$ & $=$ & Maximum principal stress \\
\hline$\sigma_{2}$ & $=$ & Minimum principal stress \\
\hline$\sigma_{n}$ & $=$ & Normal stress \\
\hline$k_{r c}$ & $=$ & Relative permeability of $\mathrm{CO}_{2}$ \\
\hline$\tau$ & $=$ & Shear strength \\
\hline$v_{c}$ & $=$ & Velocity of $\mathrm{CO}_{2}$ \\
\hline$\mu_{w}$ & $=$ & Viscosity of water \\
\hline $\mathrm{C}$ & $=$ & Tangential stiffness tensor \\
\hline $\mathrm{c}$ & $=$ & Cohesion \\
\hline$c_{f}$ & $=$ & Fluid compressibility \\
\hline d & $=$ & Cohesion for Drucker-Prager model \\
\hline E & $=$ & Young's modulus \\
\hline $\mathrm{F}$ & $=$ & Force per unit mass \\
\hline g & $=$ & Gravitational constant \\
\hline G & $=$ & Shear modulus \\
\hline I & $=$ & Identity matrix \\
\hline K & $=$ & Bulk modulus \\
\hline $\mathrm{k}$ & $=$ & Permeability \\
\hline $\mathrm{n}$ & $=$ & Porosity \\
\hline $\mathrm{p}$ & $=$ & Pore fluid pressure \\
\hline q & $=$ & Source or sink term \\
\hline $\mathrm{R}$ & $=$ & Rotation tensor \\
\hline $\mathrm{t}$ & $=$ & Time \\
\hline
\end{tabular}




\begin{tabular}{|c|c|c|}
\hline $\mathrm{T}$ & $=$ & Matrix transpose \\
\hline $\mathrm{T}_{\mathrm{o}}$ & $=$ & Temperature \\
\hline $\mathrm{u}$ & $=$ & Displacement vector \\
\hline$v$ & $=$ & Fluid velocity \\
\hline $\mathrm{V}$ & $=$ & Volume \\
\hline $\mathrm{z}$ & $=$ & Depth \\
\hline$\alpha$ & $=$ & Biot's constant \\
\hline$\beta_{\mathrm{r}}$ & $=$ & Linear thermal expansion coefficient of bulk volume \\
\hline$\varepsilon$ & $=$ & Strain tensor \\
\hline$\sigma^{\prime}$ & $=$ & Effective stress \\
\hline$\beta$ & $=$ & Drucker-Prager friction angle \\
\hline$t_{\mathrm{s}}$ & $=$ & Deviatoric stress plane \\
\hline $\mathrm{p}_{\mathrm{s}}$ & $=$ & Equivalent pressure tensor \\
\hline$\theta$ & $=$ & Fault angle \\
\hline$\sigma_{\mathrm{n}}-\mathrm{p}$ & $=$ & Positive effective normal stress \\
\hline$\sigma_{n}$ & $=$ & Total normal stress \\
\hline$\rho_{r}$ & $=$ & Solid grain density \\
\hline s & $=$ & Radius of the Mohr circle \\
\hline
\end{tabular}




\section{CHAPTER 1 : INTRODUCTION}

\subsection{Background}

The past, present, and projected trends of increasing atmosphere concentrations levels of greenhouse gases such as carbon dioxide $\left(\mathrm{CO}_{2}\right)$ have raised concerns about global warming. During last 20 years, the atmospheric $\mathrm{CO}_{2}$ concentration levels have increased by about $10 \%$ from 356 to 397 parts per million (ppm) which is above the acceptable or permissible limits (350 ppm) for atmospheric $\mathrm{CO}_{2}$ (Olivier et al., 2012; www.CO2NOW.org). It was reported that if the cumulative $\mathrm{CO}_{2}$ emissions do not exceed 1,500 billion tonnes in the next three decades, the average global temperature rise can be limited to $2^{0}$ Celsius above pre-industrial levels (Olivier et al., 2012). Several efforts are being made to stabilize the current levels of $\mathrm{CO}_{2}$ emissions, one of them being geological sequestration of $\mathrm{CO}_{2}$ (CO2CRC, 2008; Griffith et al., 2011; Hosa et al., 2011; IPCC, 2005; U.S.D.O.E., 2012). Storage of $\mathrm{CO}_{2}$ in geologic formations is considered to be one of the potential options to reduce greenhouse gases in the atmosphere (CO2CRC, 2008; IPCC, 2005; U.S.D.O.E., 2012).

The $\mathrm{CO}_{2}$ is separated and captured from the industrial facilities, such as power plants and petroleum refineries, and transported through pipelines for long-term storage in deep geological formations, which is referred to as geologic sequestration of $\mathrm{CO}_{2}$ (CO2CRC, 2008; IPCC, 2005; U.S.D.O.E., 2012). Some of these geologic formations that are suitable for $\mathrm{CO}_{2}$ storage include deep saline aquifers, unmineable or depleted coal seams, depleted oil and gas reservoirs, and basalt formations (CO2CRC, 2008; Hosa et al., 2011; IPCC, 2005; U.S.D.O.E., 2012). Figure 1.1 is a schematic diagram of various options available for geologic $\mathrm{CO}_{2}$ storage. In the current study, the research focus is limited to deep saline aquifers. However, some details of these reservoirs are given below: 


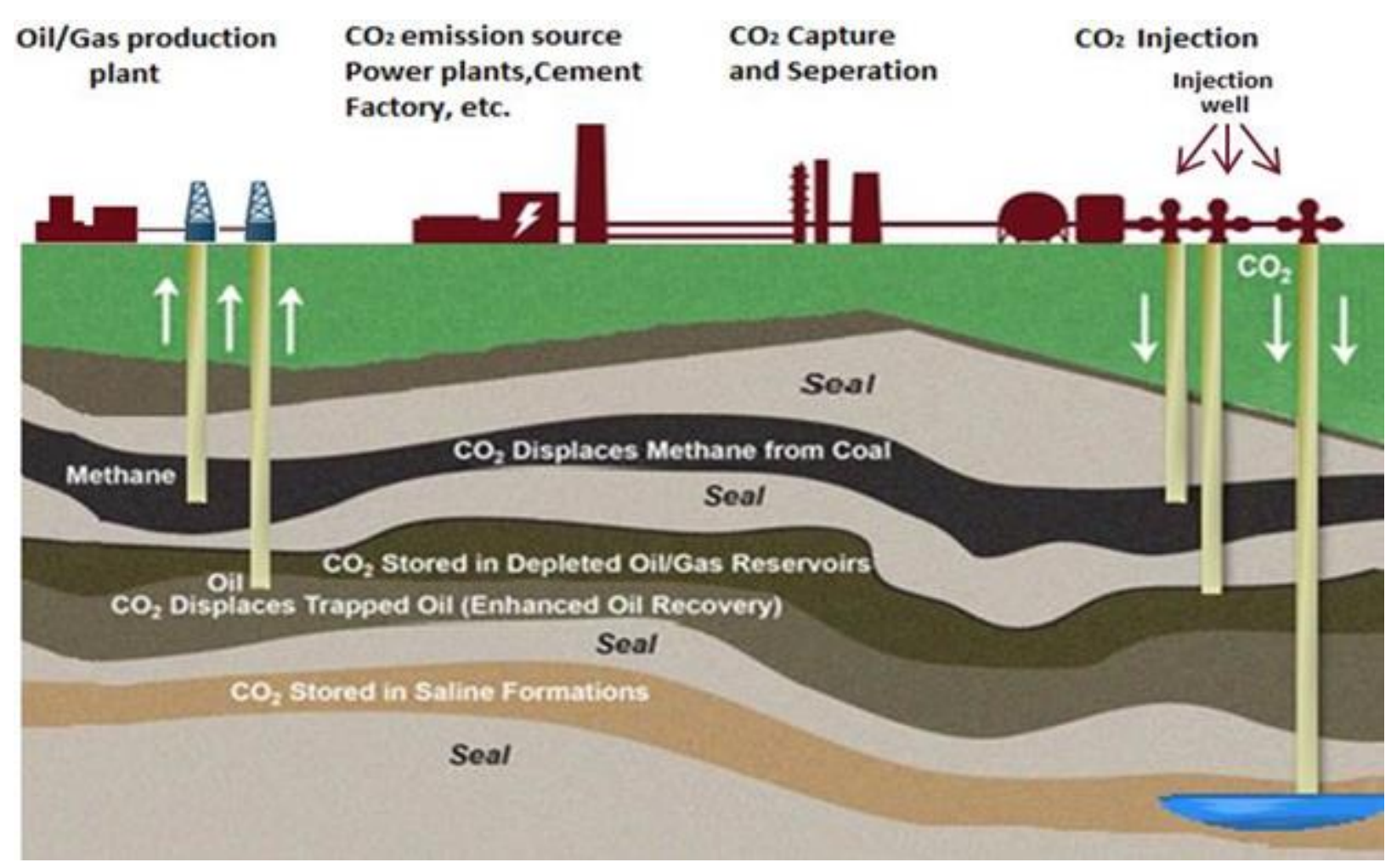

Note: This is a modified figure from a published report (U.S.D.O.E., 2007)

Figure 1.1 : Geologic sequestration of $\mathrm{CO}_{2}$ into potential reservoirs

\section{Depleted oil and gas reservoirs:}

Depleted oil and gas reservoirs can act as potential repositories for $\mathrm{CO}_{2}$ storage (CO2CRC, 2008; Holloway, 2008; Hosa et al., 2011; IPCC, 2005; Stevens et al., 2001; U.S.D.O.E., 2012). $\mathrm{CO}_{2}$ can be logically stored in oil and gas fields once they have been depleted and are no longer producing, or can be used to enhance oil or gas recovery in fields that are still producing. Advantages of storage of $\mathrm{CO}_{2}$ in depleted oil and gas fields is that the potential of the site has been proven by the retention of hydrocarbons for millions of years and there are typically large amounts of geological and industrial data available for detailed site characterization (CO2CRC, 2008; Holloway, 2008; IPCC, 2005; U.S.D.O.E., 2012). In oil and gas reservoirs, it is evident that existence of tight, impervious caprock layers above the reservoir have trapped hydrocarbons for a long time, and demonstrated the sealing efficiency of caprock layer. These reservoirs are estimated to have a storage capacity of 675-900 $\mathrm{GtCO}_{2}($ Holloway, 2008; IPCC, 2005). 


\section{Unmineable coal formations:}

Unmineable or depleted coal seams are considered to be potential reservoirs for $\mathrm{CO}_{2}$ storage (IPCC, 2005; Siriwardane and Gondle, 2011; Siriwardane et al., 2012; U.S.D.O.E., 2012). A storage estimate of 15 to $200 \mathrm{GtCO}_{2}$ was reported worldwide according to published literature (IPCC, 2005). Poor quality and extreme depths are some of the reasons that make unmineable coal seams uneconomic for mining. Due to the fact that $\mathrm{CO}_{2}$ molecules have more affinity towards coal than methane molecules, coal has the ability to sorb large amount of $\mathrm{CO}_{2}$ and desorb coalbed methane that presents in the internal surface of the coal matrix (He et al., 2013; Siriwardane et al., 2012). In addition, injection of carbon dioxide $\left(\mathrm{CO}_{2}\right)$ into coal seams can enhance coalbed methane recovery. Different aspects related to $\mathrm{CO}_{2}$ sequestration in unmineable or depleted coal seams has been investigated and can be found in published literature (He et al., 2013; Locke et al., 2011; Siriwardane et al., 2012; White et al., 2005).

\section{Deep saline formations:}

Deep saline formations suitable for $\mathrm{CO}_{2}$ storage are porous and permeable reservoir rocks that contain saline fluid in the pore spaces between the rock grains (IPCC, 2005; Martinez et al., 2013; U.S.D.O.E., 2012; Yang et al., 2010). $\mathrm{CO}_{2}$ can be trapped in saline aquifers through a combination of physical and chemical processes, which can be classified into structural and stratigraphic trapping, solubility trapping, mineral trapping, and hydrodynamic trapping (Bachu et al., 2007; Bryant et al., 2006; CO2CRC, 2008; IPCC, 2005; U.S.D.O.E., 2012). These formations are believed to have by far the largest capacity for $\mathrm{CO}_{2}$ storage (estimates exceeding 1,000 $\mathrm{GtCO}_{2}$ ) and are much more widespread than other options (Bryant et al., 2006; Holloway, 2008; IPCC, 2005). When $\mathrm{CO}_{2}$ is injected in saline reservoir, the free-phase $\mathrm{CO}_{2}$ rises to the top of the reservoir and gets physically trapped by a tight, impermeable layer of shale and clayey rock known as caprock (Birkholzer et al., 2009; IPCC, 2005; Martinez et al., 2013; Morris et al., 2011a; Rutqvist et al., 2008; Shi et al., 2012; Siriwardane et al., 2013; Tran et al., 2009; U.S.D.O.E., 2012; Vilarrasa et al., 2011; Xu et al., 2012). The current research work presented in this report deals with the injection of $\mathrm{CO}_{2}$ in deep saline aquifers. More details of the study are presented in later sections of this report. 


\subsection{Problem Statement}

Underground reservoirs such as saline aquifers have a great potential for $\mathrm{CO}_{2}$ storage and it is important to determine the various pathways that deter the safe storage of $\mathrm{CO}_{2}$ in such reservoirs during long-term $\mathrm{CO}_{2}$ injection. Viable saline aquifers for $\mathrm{CO}_{2}$ storage are capped with an impermeable caprock layer. Caprock in deep saline aquifers are water-saturated, and disposal of $\mathrm{CO}_{2}$ is likely to occur under supercritical conditions (Bachu et al., 2007; Birkholzer et al., 2009; Rutqvist et al., 2010; Shi et al., 2012; Siriwardane et al., 2013; Tran et al., 2009). Large volumes of fluid or $\mathrm{CO}_{2}$ injected in the subsurface may over-pressurize the reservoir and increase the potential for mechanical seal failure. As a result, the structural integrity of the overburden caprock layer might be compromised, and a new caprock fracture may be induced or a pre-existing dormant fracture/fault may be activated (Cappa and Rutqvist, 2011; Morris et al., 2011a; Morris et al., 2011b; Rutqvist et al., 2008; Siriwardane et al., 2013). The presence of a fractured zone in the caprock layer or activation of a dormant fracture/fault could lead to $\mathrm{CO}_{2}$ leakage with time, and influence the ground deformation behavior (Cappa and Rutqvist, 2011; Lucier and Zoback, 2008; Morris et al., 2011a; Morris et al., 2011b; Rutqvist et al., 2008; Siriwardane et al., 2013).

In the current study, a hypothetical $\mathrm{CO}_{2}$ storage site was selected to investigate the potential mechanical seal failure of caprock layer during $\mathrm{CO}_{2}$ injection. The caprock failure was modeled by considering Mohr-Coulomb and Drucker-Prager failure criteria. A parametric study was performed to investigate the influence of geomechanical properties such as cohesion and angle of friction on the caprock seal failure. Figure 1.2 shows a schematic diagram of the hypothetical $\mathrm{CO}_{2}$ storage site considered. The figure illustrates the potential shear failure of caprock layer during $\mathrm{CO}_{2}$ injection. Also, finite element modeling was performed to simulate a shear failure of inclined fracture or a fault during fluid injection. An inclined fault was considered as shown in Figure 1.3. 


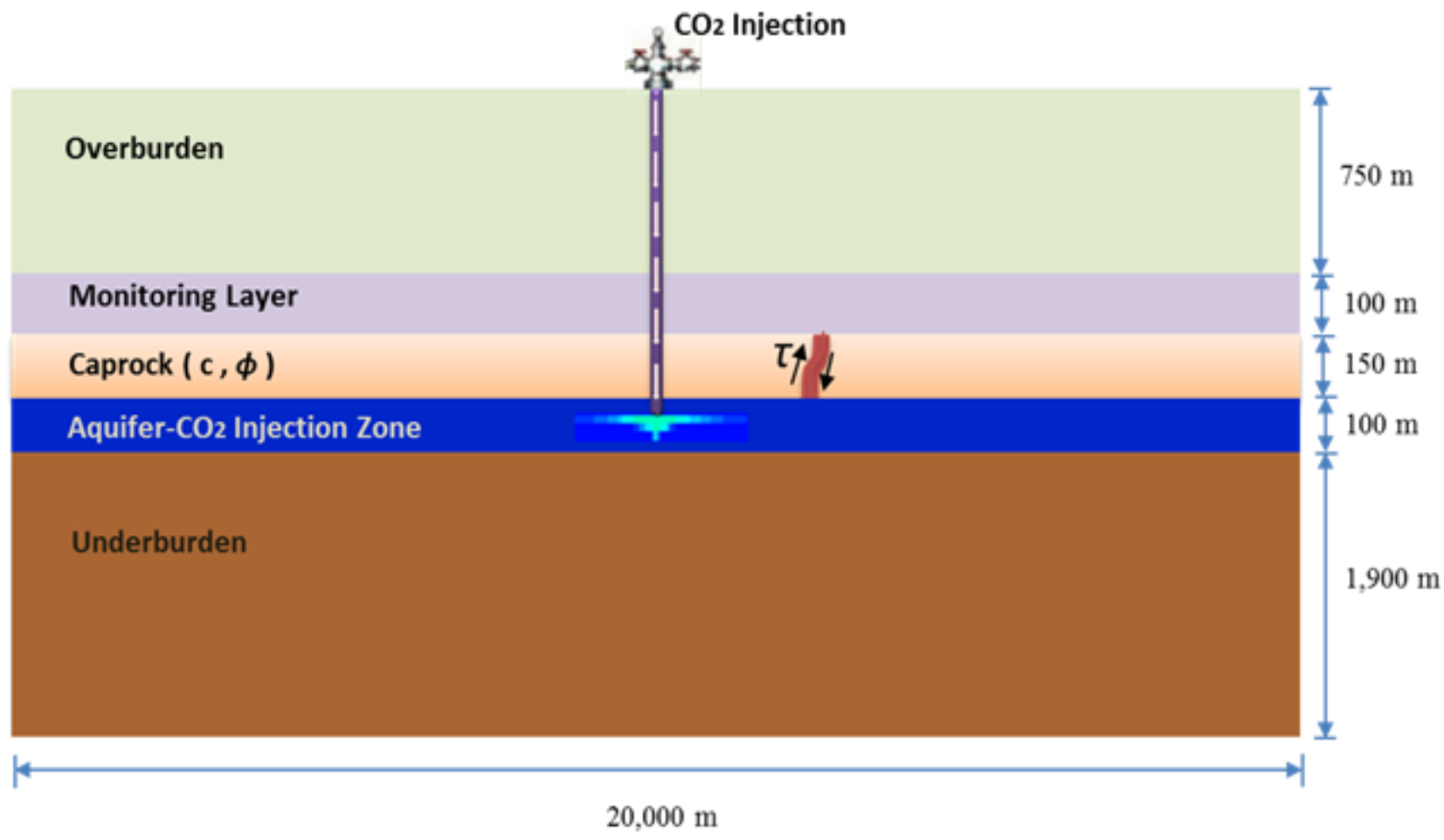

Figure 1.2: Schematic diagram of a hypothetical injection site

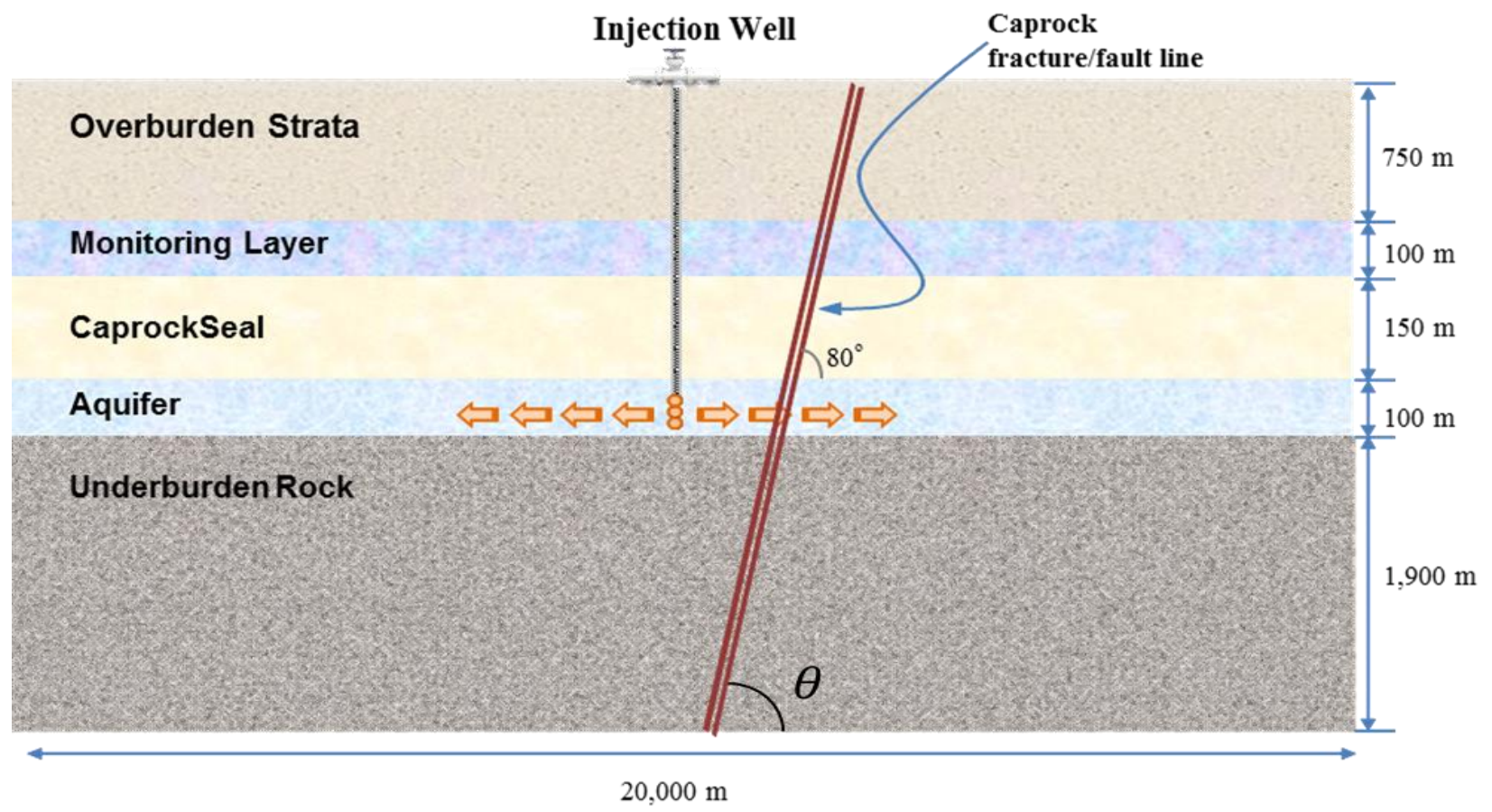

Figure 1.3: Schematic diagram of a fault located in the caprock layer 500m from the injection well 


\subsection{Research Objectives}

In the current study, deep saline aquifers were considered for potential $\mathrm{CO}_{2}$ storage. The research objectives of the current study can be listed as follows:

- Perform a comprehensive literature review on potential storage sites where $\mathrm{CO}_{2}$ injection was carried out into saline reservoirs and ground monitoring technologies were used to investigate ground deformation behavior.

- Collect literature on modeling studies where efforts were made to model shear failure of caprock layer during injection.

- Construct single-phase and multi-phase fluid flow models coupled with geomechanics to investigate the fluid flow and ground deformation behavior. Compare results from singlephase and multi-phase models.

- Construct axisymmetric and three-dimensional fluid flow and deformation models and compare results from both models were compared.

- Construct multi-phase coupled fluid flow and deformation models to investigate the shear failure in the overburden caprock layer. Mohr-Coulomb failure criterion was considered to simulate overburden shear failure.

- Conduct a parametric study on the geomechanical failure properties that cause shear failure in the caprock layer during $\mathrm{CO}_{2}$ injection.

- Use finite element method to model shear failure of inclined fracture or a fault during fluid injection. Mohr-Coulomb and Drucker-Prager failure criterions were used for the material in the fault zone to investigate the shear failure of rock during fluid injection.

Subsequent chapters present the discussion and results of the research work performed to achieve the above mentioned objectives. 


\section{CHAPTER 2 : REVIEW OF $\mathrm{CO}_{2}$ STORAGE IN DEEP SALINE AQUIFERS}

\subsection{Introduction to Carbon Sequestration in Saline Aquifers}

Saline aquifers are porous and permeable reservoir formations. These geologic formations are believed to have by far the largest capacity for $\mathrm{CO}_{2}$ storage and are much more widespread than other options available for $\mathrm{CO}_{2}$ storage (Griffith et al., 2011; Hosa et al., 2011; Holloway, 2008; IPCC, 2005; U.S.D.O.E., 2012). A storage capacity of at least $1,000 \mathrm{GtCO}_{2}$ is estimated in deep saline formations (Bryant et al., 2006; Holloway, 2008; IPCC, 2005). Several large-scale $\mathrm{CO}_{2}$ sequestration projects involve saline aquifers, and some of these projects include the In Salah project, Algeria (estimated storage capacity of 17 million tons) (Hosa et al., 2011; Chadwick et al., 2008; IEA GHG, 2008; Michael et al., 2010; Riddiford et al., 2003; Ringrose et al., 2009), the Sleipner project, North Sea (storage capacity of $25 \mathrm{Mt}$ ) (Hosa et al., 2011; Chadwick et al., 2004; Chadwick et al., 2008; IEA GHG, 2008; Michael et al., 2010), North Sea Basin, UK (storage capacity of $18 \mathrm{Gt}$ ) (Hosa et al., 2011), Snohvit, Norway (storage capacity of 23 Mt) (Hosa et al., 2011; IEA GHG, 2008; Michael et al., 2010), and Gorgon project, Australia (storage capacity of 129 Mt) (Hosa et al., 2011; IEA GHG, 2008; Michael et al., 2010). A few storage sites in the U.S.A. are shown in the Figure 2.1 and these details can be found elsewhere (Fischietto et al., 2009; Hosa et al., 2011; IEA GHG, 2008; IPCC, 2005; Litynski et al., 2009; Michael et al., 2010). 


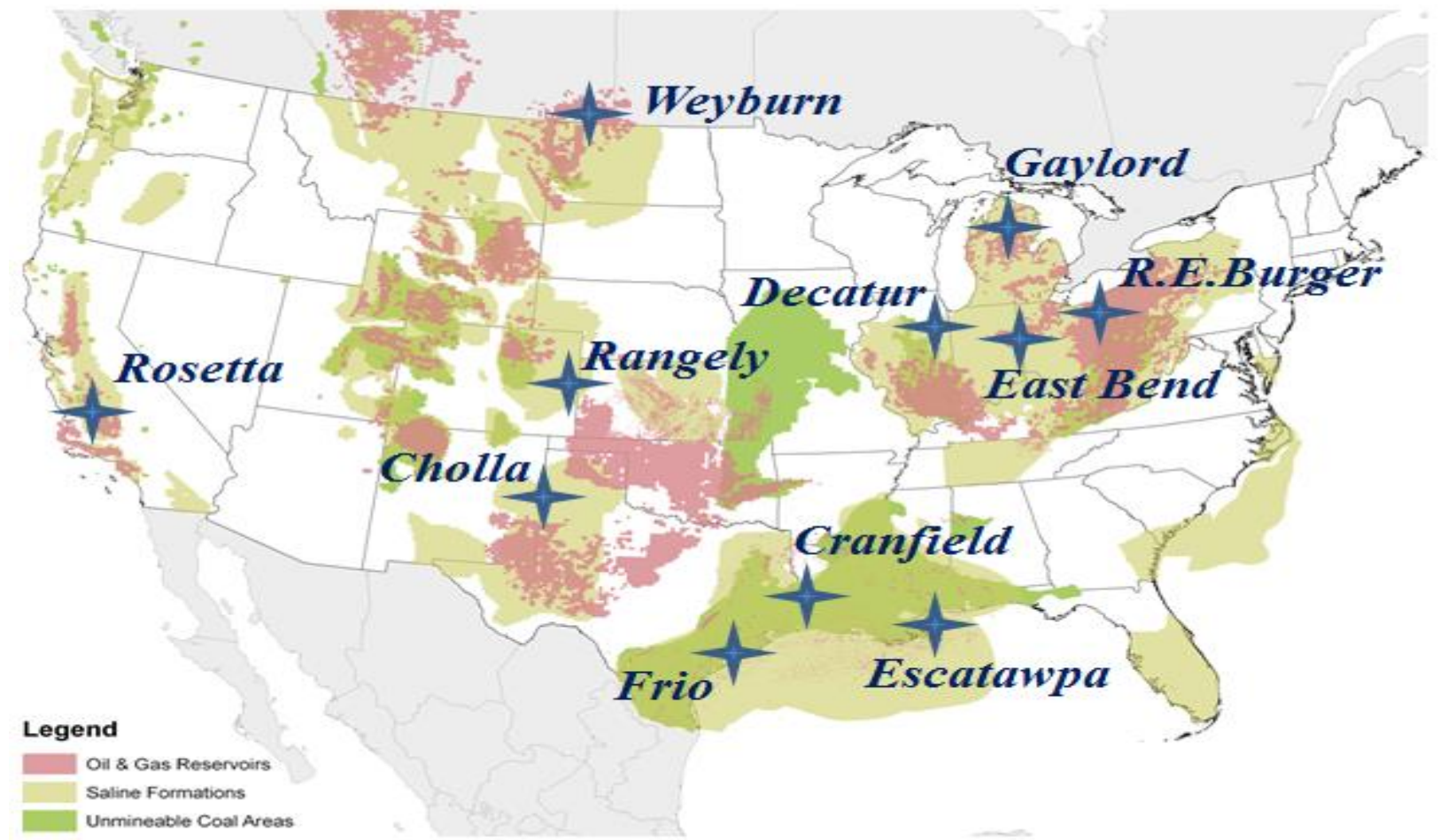

Note: This is a modified figure from www.natcarb.org

Figure 2.1: Locations of several CCS projects in USA

When $\mathrm{CO}_{2}$ is injected into a brine formation, it is trapped through a combination of physical and chemical processes. Tight, impermeable shale and clayey rock above the reservoir physically trap $\mathrm{CO}_{2}$ and limit upward migration of injected $\mathrm{CO}_{2}$. These impervious layer(s) are referred to as 'caprock layer(s)', and the presence of such layers above the reservoir helps reduce leakage risks. When $\mathrm{CO}_{2}$ is injected, the free-phase $\mathrm{CO}_{2}$ rises to the top of the aquifer and gets physically trapped by these tight, impervious caprock layers (Bachu et al., 2007; Birkholzer et al., 2009; Bryant et al., 2006; IPCC, 2005; Martinez et al., 2013; Siriwardane et al., 2013; U.S.D.O.E., 2012; Vilarrasa et al., 2011; Xu et al., 2012).

The evaluation of the $\mathrm{CO}_{2}$ storage capacity in deep saline aquifers is very complex as there are multiple trapping mechanisms acting simultaneously at different rates (Bachu et al., 2007; Birkholzer et al., 2009; Bryant et al., 2006; Chadwick et al., 2008; Chang et al., 2008; CO2CRC, 2008; Ennis-King and Paterson, 2005; Griffith et al., 2011; IPCC, 2005; Kumar et al., 
2004; Siriwardane et al., 2013). In the context of $\mathrm{CO}_{2}$ storage in aquifers, the involved trapping mechanisms are:

1. Structural (hydrodynamic) trapping, where the upward migrating buoyant $\mathrm{CO}_{2}$ is suppressed by an impermeable cap rock. In this case $\mathrm{CO}_{2}$ can be considered as free gas; and, will rise up due to buoyancy effect until it approaches the geologic seal layers (Bachu et al., 2007; Birkholzer et al., 2009; Bryant et al., 2006; Chadwick et al., 2008; Siriwardane et al., 2013).

2. Residual saturation trapping, where injected $\mathrm{CO}_{2}$ breaks up into immobile form in deep saline aquifers due to the petrophysical property of flow phases (Bachu et al., 2007; Bryant et al., 2006; Chadwick et al., 2008; Kumar et al., 2004).

3. During long-term injection of $\mathrm{CO}_{2}$, some of the injected $\mathrm{CO}_{2}$ dissolves with formation brine and gets trapped through a several geochemical changes. Solubility trapping is significant in deep saline aquifers (Bachu et al., 2007; Bryant et al., 2006; Chadwick et al., 2008; Ennis-King and Paterson, 2005).

4. Mineral trapping, where dissolved $\mathrm{CO}_{2}$ reacts with rock minerals and yields carbonate mineral precipitation (Bachu et al., 2007; Bryant et al., 2006; Chadwick et al., 2008; Chang et al., 2008).

\subsection{Influence of Caprock Fracture or Fault}

Fractures play an important role in nearly all geologic settings during hydrocarbon migration and entrapment (Berkowitz, 2002). Natural and artificially-induced fractures/faults may have impact on safe $\mathrm{CO}_{2}$ storage (Berkowitz, 2002; Birkholzer et al., 2009; Cappa and Rutqvist, 2011; Martinez et al., 2013; Morris et al., 2011a; Rutqvist et al., 2008; Siriwardane et al., 2013). Site characterization of fracture network and monitoring of such storage sites helps ensure low leakage risks. In porous geologic formations with tight overlying caprock material, the fluid flow and storage efficiency is controlled by faults and fractures. The spatial distribution, orientation, and conductivity/permeability of faults/fractures in the caprock layer are some influencing factors on fluid flow behavior. These fractures could act as potential leakage pathways and could possibly hinder the prospective storage ability of a sequestration site (Morris et al., 2011b; Rutqvist et al., 2008; Siriwardane et al., 2013). Fractures have high permeability 
compared to surrounding rock matrix, and could allow $\mathrm{CO}_{2}$ to escape to the overburden. The presence of a caprock fracture or activation of a dormant fracture/fault in the caprock layer could lead to high risk of $\mathrm{CO}_{2}$ leakage, and may have significantly different $\mathrm{CO}_{2}$ transport behavior and overburden geomechanical response. Figure 2.2 shows a schematic diagram of a caprock fracture and $\mathrm{CO}_{2}$ leakage in the presence of a caprock fracture.

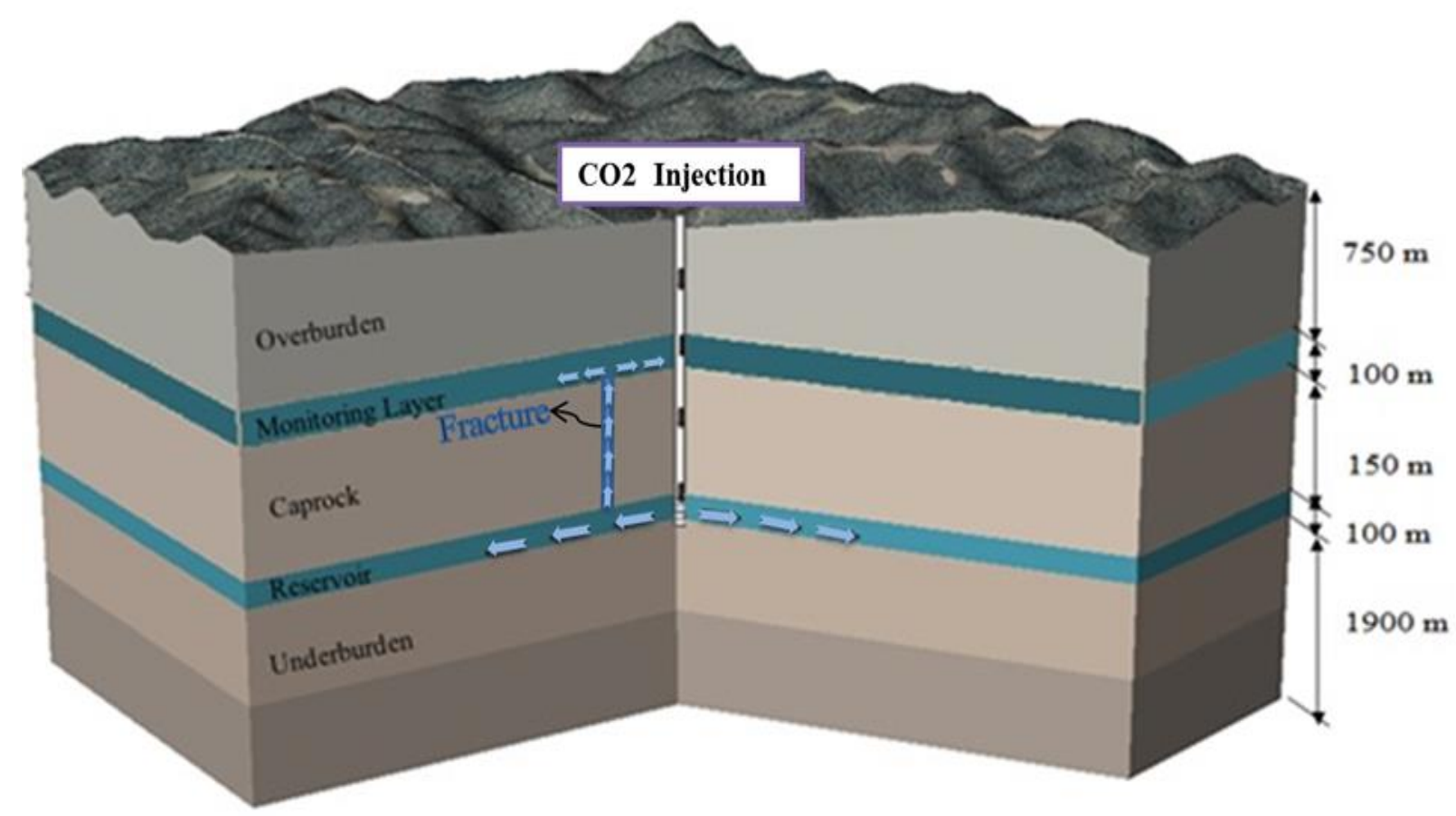

Figure 2.2: Schematic diagram of a caprock fracture and $\mathrm{CO}_{2}$ leakage

\subsection{Caprock Seal Failure}

Caprock integrity is thought to be one of the most important factors in the safety assessment of long term greenhouse gas storage in deep aquifers (Chang et al., 2008; Martinez et al., 2013; Morris et al., 2011a; Rutqvist et al., 2002; Siriwardane et al., 2013; Xu et al., 2012). The effectiveness of the seal over geological time periods controls its ability to prevent migration into potential overburden strata, or migration eventually back into the atmosphere. Lithology, thickness, and fracture density are all factors that influence the seal properties (Griffith et al., 
2011; IPCC, 2005). The most common caprock lithologies are mudstones, clays, and shales (Griffith et al., 2011). Deep saline aquifers are water-saturated, and disposal of $\mathrm{CO}_{2}$ is likely to occur under supercritical conditions (Bachu et al., 2007; IPCC, 2005; Siriwardane et al., 2013).

Leakage through caprock seals are influenced by many factors such as capillary properties, relative permeability and wettability (Griffith et al., 2011; Bryant et al., 2006). These properties are discussed extensively in the literature (Bennion and Bachu, 2005; Bryant et al., 2006; Chang et al., 2008; Griffith et al., 2011; Kumar et al., 2004). Uncertainties remain around the mechanisms which promote the formation of microfractures in argillaceous materials, and evidence of their formation is largely inferred by the behavior of fluid pressures in reservoirs as described by leakoff tests (Dewhurst et al., 1999).

\subsection{Review of a few potential $\mathrm{CO}_{2}$ storage sites}

The Sleipner Project (Chadwick et al., 2004; Hellevang et al., 2005; Holloway, 2008; Hosa et al., 2011; IEA GHG, 2008; Michael et al., 2010; Torp and Gale, 2004; van der Meer and van Wees, 2006): At the Sleipner site located in the central North Sea, about $1 \mathrm{Mt}$ (million tonne) $\mathrm{CO}_{2}$ per year was injected in the highly porous and permeable Utsira Sand formation, and the injection was monitored periodically to gain insight into migration of $\mathrm{CO}_{2}$ at different trapping levels for the safe storage of $\mathrm{CO}_{2}$ (Holloway, 2008; Torp and Gale, 2004). It was the first commercial-scale project dedicated to geological $\mathrm{CO}_{2}$ storage. The operation started in October 1996 and over the lifetime of the project a total of $25 \mathrm{Mt} \mathrm{CO}_{2}$ is expected to be stored (Chadwick et al., 2004; Holloway, 2008; Hosa et al., 2011; Torp and Gale, 2004). The Utsira aquifer is located at depths between $800 \mathrm{~m}$ and $1,100 \mathrm{~m}$ below sea level, with reservoir thickness up to $250 \mathrm{~m}$ near the injection zone (Chadwick et al., 2004; Holloway, 2008). It was reported that the Utsira Sand consists of weakly consolidated sandstone with uncemented fine grains dominated by quartz and other minerals such as feldspar and calcite (Chadwick et al., 2004). The Utsira Sand is capped by geologic layers of shale, clayey silt or silty sand (Nordland Formation) with thickness ranging between $200 \mathrm{~m}$ and $300 \mathrm{~m}$ (Hosa et al., 2011; Torp and Gale, 2004). The transport of the $\mathrm{CO}_{2}$ plume in the storage formation has been monitored by field monitoring studies such as seismic time-lapse surveys so that $\mathrm{CO}_{2}$ remained in the target reservoir without migrating in the overburden layers (Hellevang et al., 2005). The injected $\mathrm{CO}_{2}$ moved upward to 
the top of the aquifer due to buoyancy and then moved literally beneath the caprock (Hellevang et al., 2005). The seismic surveys at different times show that the caprock is an effective seal that prevents $\mathrm{CO}_{2}$ migration out of the storage formation (Torp and Gale, 2004). A few modeling studies were performed and results show that the free-phase, immiscible injected $\mathrm{CO}_{2}$ moves upward through geologic discontinuities up to the aquifer top, and then spreads laterally below the impervious caprock layers (Hellevang et al., 2005; Torp and Gale, 2004).

The In Salah Gas Project (Gourmelen et al., 2011; Hosa et al., 2011; IEA GHG, 2008; IPCC, 2005; Michael et al., 2010; Morris et al., 2011b; Riddiford et al., 2003; Ringrose et al., 2009; Rutqvist et al., 2009; Shi et al., 2012): The In Salah Gas Project located in the central Saharan region of Algeria, is one of the large-scale $\mathrm{CO}_{2}$ storage project in a gas reservoir (Riddiford et al., 2003; Shi et al., 2012). Carbon dioxide injection started in April 2004 and, over the life of the project, it is estimated that $17 \mathrm{Mt}$ (million tonnes) $\mathrm{CO}_{2}$ will be geologically stored (Hosa et al., 2011; Shi et al., 2012). Natural gas containing up to $9 \% \mathrm{CO}_{2}$ produces from Krechba field at In Salah project site (Morris et al., 2011b; Rutqvist et al., 2009). The project involves re-injecting the $\mathrm{CO}_{2}$ into a sandstone reservoir at a depth of $1,800 \mathrm{~m}$ and storing up to 1 $\mathrm{Mt}$ (million tonne) $\mathrm{CO}_{2} /$ year (Hosa et al., 2011). The top seal is a thick caprock layer up to 950 $\mathrm{m}$ thick. At this storage site, ground deformations are being monitored by using InSAR technology (Gourmelen et al., 2011; Morris et al., 2011b; Ringrose et al., 2009; Shi et al., 2012).

The Weyburn Project (Hosa et al., 2011; IEA GHG, 2008; Preston et al., 2005; Verdon et al., 2011): The Weyburn $\mathrm{CO}_{2}$-enhanced oil recovery $\left(\mathrm{CO}_{2}\right.$-EOR) project is located in the Williston Basin, a geological structure extending from south-central Canada into north-central United States (Preston et al., 2005; Verdon et al., 2011). Over the life of the $\mathrm{CO}_{2}$-EOR project (20-25 years), it is expected that some $20 \mathrm{Mt} \mathrm{CO}_{2}$ will be stored in the field, under current economic conditions and oil recovery technology (Hosa et al., 2011; Preston et al., 2005). The field has been designed with a combination of vertical and horizontal wells to optimize the sweep efficiency of the $\mathrm{CO}_{2}$. Since $\mathrm{CO}_{2}$ injection began in late 2000, the EOR project has performed largely as predicted. $\mathrm{CO}_{2}$ injection was carried out with an injection rate of approximately 3 million tonnes of $\mathrm{CO}_{2}$ each year in a supercritical state (Verdon et al., 2011). 
The Mt.Simon project (Barnes et al., 2009; Fischietto et al., 2009; Leetaru et al., 2005; Liu et al., 2011; Medina et al., 2011; Rodosta et al., 2011): The Mt. Simon sandstone is recognized as a highly promising reservoir for carbon sequestration (Medina et al., 2011). The Mt. Simon sandstone serves as a significant gas storage reservoir in areas of Illinois Basin. Storage capacity for all the Cambrian age basal sandstones in the Midwest (Indiana, Kentucky, Michigan, and Ohio) has been estimated to range from 50 to 200 billion metric tons (Barnes et al., 2009; Medina et al., 2011; U.S.D.O.E., 2007). This formation has been chosen due to its favorable depth, thickness, permeability, and the presence of caprocks that have low permeability. Mt. Simon sandstone is overlain by three thick impermeable shale layers (Eau Claire, Maquoketa and New Albany) and numerous thinner shale-rich strata (Leetaru et al., 2005; Liu et al., 2011; Medina et al., 2011; U.S.D.O.E., 2007). Former gas storage fields in the formation indicate that the Eau Claire, the cap that immediately overlays the sandstone, is an effective seal for natural gas containment (Barnes et al., 2009; Leetaru et al., 2005; Medina et al., 2011). Seasonal natural gas storage (for over 50 years) was used at the Mt. Simon in the portions of Illinois Basin (Medina et al., 2011). Several studies have been reported in the published literature with reference to carbon sequestration in Mt. Simon sandstone (Barnes et al., 2009; Fischietto et al., 2009; Liu et al., 2011; Medina et al., 2011; U.S.D.O.E., 2007).

The Fort Nelson project (Crockford and Telmer, 2009; Hickin, 2009; IEA GHG, 2008; Laundry, 2011): Approximately 1.1 million tons of sour $\mathrm{CO}_{2}$ (mixture of $\mathrm{CO}_{2}$ and hydrogen sulfide, H2S) is injected annually (Crockford and Telmer, 2009; Laundry, 2011). The sour $\mathrm{CO}_{2}$ is compressed and transported in supercritical state through a pipeline to the target injection location (Crockford and Telmer, 2009; Hickin, 2009; Laundry, 2011). The storage site is the Devonian-age Elk Point carbonate rock formation located in relatively close proximity to the gas plant at a depth of over 2,200 meters (Crockford and Telmer, 2009; Laundry, 2011).

Tuscaloosa/Paluxy project (IEA GHG, 2008; Koperna et al., 2011; Litynski et al., 2009; Mancini and Goddard, 2006; Michael et al., 2010; Rodosta et al., 2011; SECARB, 2013): Approximately 3,000 tons of $\mathrm{CO}_{2}$ was injected in lower Tuscaloosa formation at Escatawpa, Mississippi plant (IEA GHG, 2008; Litynski et al., 2009; Rodosta et al., 2011). SECARB (Southeast Regional Carbon Sequestration) proposed a two-step, large-volume injection test in the lower Tuscaloosa Formation at Gulf Coast Wedge. In the first step, it was proposed to inject 
1.4 million tonnes of $\mathrm{CO}_{2}$ per year for 18 months and in the second step it was proposed to inject 100,000 to 250,000 tonnes of $\mathrm{CO}_{2}$ per year for four years (IEA GHG, 2008; Litynski et al., 2009). A low permeable $150 \mathrm{~m}$ thick shale layer above the Tuscaloosa formations acts as a caprock layer. A Southern Company power plant located near the injection site supply's the $\mathrm{CO}_{2}$ (IEA GHG, 2008).

\subsection{Previous modeling studies}

$\mathrm{CO}_{2}$ migration during injection and post injection was examined by several researchers using compositional reservoir simulators (Birkholzer et al., 2009; Chadwick et al., 2004; Kumar et al., 2004; Morris et al., 2011b; Rutqvist et al., 2010; Tran et al., 2009; Vilarrasa et al., 2010). The permanence of $\mathrm{CO}_{2}$ storage depends entirely on the integrity of the seal over long periods of time (Chang et al., 2008; Kumar et al., 2004; Martinez et al., 2013; Morris et al., 2011a; Rutqvist et al., 2002; Siriwardane et al., 2013; Xu et al., 2012). Modeling results show that $\mathrm{CO}_{2}$ leakage could be controlled by injection operations (Kumar et al., 2004). While injection can be controlled, there are still leakage risks posed by factors such as geologic fractures/faults and wellbore failure (Berkowitz, 2002; Birkholzer et al., 2009; Cappa and Rutqvist, 2011; Martinez et al., 2013; Morris et al., 2011a; Rutqvist et al., 2008; Siriwardane et al., 2013). Bryant (2008) studied buoyancy dominated flow of $\mathrm{CO}_{2}$ in a storage aquifer, a further examination of the injection strategies proposed by Kumar et al., (2004). The conclusions drawn included that buoyant instability has only a small effect on the displacement front. However, $\mathrm{CO}_{2}$ follows preferential flow paths because of heterogeneity in permeability, drainage capillary pressure curve and anisotropy. As a result, reservoir characterization is critical to the injection strategy proposed by Bryant (2008).

The maximum amount of $\mathrm{CO}_{2}$ that can be injected depends on the maximum acceptable pressure increase without fracturing the formation and activating the existing dormant faults (Cappa and Rutqvist, 2011; Martinez et al., 2013; Morris et al., 2011a; Morris et al., 2011b; Nacht et al., 2010; Rutqvist et al., 2007; Rutqvist et al., 2010; Streit and hills, 2004; van der Meer and van Wees, 2006). Thus, in a storage operation, it is important to determine a pressure threshold to avoid causing geomechanical instability (Morris et al., 2011a; Rutqvist et al., 2007; Streit and Hillis, 2004; van der Meer and van Wees, 2006; Vidal-Gilbert et al., 2010). Coupled 
flow and geomechanical modeling of $\mathrm{CO}_{2}$ injection in saline aquifers was carried out by several researchers to investigate geomechanical issues related to the caprock, and to investigate injection-induced overburden deformations (Cappa and Rutqvist, 2011; Martinez et al., 2013; Morris et al., 2011a; Morris et al., 2011b; Nacht et al., 2010; Rutqvist et al., 2008; Rutqvist et al., 2009; Tran et al., 2009). In addition to coupled hydromechanical modeling of $\mathrm{CO}_{2}$ storage, field monitoring studies have been carried out at potential storage sites to measure ground deformations (Gourmelen et al., 2011; Morris et al., 2011b; Ringrose et al., 2009; Rutqvist et al., 2010; Shi et al., 2012; Siriwardane and Gondle, 2011). The increase in the fluid pressure due to injection of $\mathrm{CO}_{2}$ may initiate a new fracture or activating a dormant fracture/fault in the overburden caprock layers (Cappa and Rutqvist, 2011; Morris et al., 2011a; Morris et al., 2011b; Nacht et al., 2010; Rohmer and Bouc, 2010; Rutqvist et al., 2007; Shi et al., 2012; Siriwardane et al., 2013; Streit and Hillis, 2004; Vidal-Gilbert et al., 2010; Wiprut and Zoback, 2000). Fluid flow along such fault zones, caprock damage zones and fracture regions are discussed elsewhere (Cappa and Rutqvist, 2011; Chang et al., 2008; Morris et al., 2011a; Morris et al., 2011b; Rutqvist et al., 2008; Siriwardane et al., 2013; Tran et al., 2009; Wiprut and Zoback, 2000).

Advanced modeling techniques have been developed by several researchers to understand caprock integrity and the fate of injected $\mathrm{CO}_{2}$ (Birkholzer et al., 2009; Cappa and Rutqvist, 2011; Liu et al., 2011; Morris et al., 2011a; Morris et al., 2011b; Nacht et al., 2010; Rutqvist et al., 2007; Shi et al., 2012; Siriwardane et al., 2013; Tran et al., 2009; Vidal-Gilbert et al., 2010). The success of commercial-scale $\mathrm{CO}_{2}$ sequestration projects requires development of monitoring techniques and modeling approaches to investigate $\mathrm{CO}_{2}$ migration in the reservoir and its influence on the overlying geologic media (Gourmelen et al., 2011; Morris et al., 2011b; Rutqvist et al., 2010; Shi et al., 2012; Siriwardane et al., 2013; Siriwardane and Gondle, 2011; Vilarrasa et al., 2010). The ability to detect the activation of a pre-existing dormant fault in the caprock seal during $\mathrm{CO}_{2}$ injection, which could act as a conduit for $\mathrm{CO}_{2}$ leakage, would be essential (Siriwardane et al., 2013). The detection of an existing fracture or fault being activated during $\mathrm{CO}_{2}$ injection can act as an early warning system so that storage site operations can be modified before leaking $\mathrm{CO}_{2}$ in the overburden (Siriwardane et al., 2013). The pressure signatures and displacement patterns may vary depending on the number of caprock fractures/faults and their respective locations in the overburden formations (Siriwardane et al., 2013). Numerical modeling work and ground monitoring tools can be useful in identifying the 
presence of geologic features such as a caprock fracture or activation of an existing dormant fault that could potentially lead to $\mathrm{CO}_{2}$ leakage (Siriwardane et al., 2013; Tran et al., 2009; VidalGilbert et al., 2010).

Coupled reservoir and geomechanical simulations were carried out as reported in the published literature (Rutqvist et al., 2008) to investigate the potential for shear and tensile failure caused due to injection of $\mathrm{CO}_{2}$. Results from this study show that a higher potential for shear failure (e.g., activation for dormant faults/fractures) compared to tensile failure. In this study (Rutqvist et al., 2008), multiple low-permeable caprock layers were considered in the multilayered geologic system to investigate the upward migration of $\mathrm{CO}_{2}$. Results show that multiple caprock layers can delay the upward migration of $\mathrm{CO}_{2}$. The $\mathrm{CO}_{2}$ rising to the top of the reservoir increases the fluid pressure near the caprock layer causing mechanical stress changes, which may lead to the potential of mechanical seal failure (Rutqvist et al., 2008). 


\section{CHAPTER 3 : MATHEMATICAL DETAILS}

\subsection{Mathematical details of single-phase fluid flow in porous media}

The governing equations for the single-phase fluid flow in a porous medium are given by the conservation of mass, Darcy's law, and an equation of state. Darcy's law describes the migration of fluids through porous media. It states that the fluid flow is proportional to the pressure gradient (Chang et al., 2008; Chen et al., 2006; Das, 2007). This law indicates a linear relationship between the fluid velocity relative to the solid and the pressure head gradient. The single-phase flow equation derived from conservation of mass and Darcy's law is given by (Chang et al., 2008; Chen et al., 2006; Minkoff et al., 2003).

Mass consevation equation (Chang et al., 2008; Chen et al., 2006; Minkoff et al., 2003).

$$
\frac{\partial(n \rho)}{\partial t}=-\nabla \cdot(\rho v)+q
$$

where

$$
\begin{aligned}
& \mathrm{n}=\text { porosity, } \\
& \mathrm{q}=\text { source or sink term, } \\
& \mathrm{t}=\text { time, } \\
& v=\text { fluid velocity, } \\
& \rho=\text { fluid density, and } \\
& \nabla=\text { gradient operator. }
\end{aligned}
$$

Darcy's law indicates a linear relationship between the fluid velocity and the pressure head gradient (Chang et al., 2008; Chen et al., 2006; Minkoff et al., 2003).

$$
v=-\frac{1}{\mu} k(\nabla p-\rho g \nabla z)
$$


where

$$
\begin{aligned}
& \mathrm{k}=\text { permeability } \\
& \mathrm{g}=\text { gravitational constant, } \\
& \mathrm{p}=\text { pore fluid pressure, } \\
& \mathrm{z}=\text { depth vector, } \\
& \mu=\text { fluid viscosity, and } \\
& \nabla=\text { gradient operator. }
\end{aligned}
$$

Substituting the Equation 3.2 into Equation 3.1, the following equation can be derived (Chang et al., 2008; Chen et al., 2006).

$$
\frac{\partial}{\partial t}(n \rho)=\nabla \cdot \frac{\rho k}{\mu}(\nabla p-\rho g \nabla z)+q
$$

where

$$
\begin{aligned}
& \mathrm{g}=\text { gravitational constant, } \\
& \mathrm{k}=\text { permeability } \\
& \mathrm{n}=\text { porosity } \\
& \mathrm{p}=\text { pore fluid pressure } \\
& \mathrm{q}=\text { source or sink term. } \\
& \mathrm{z}=\text { depth vector } \\
& \rho=\text { fluid density, } \\
& \mu=\text { fluid viscosity, and } \\
& \nabla=\text { gradient operator. }
\end{aligned}
$$

An equation of state is expressed in term of the fluid compressibility $c_{f}$ (Chen et al., 2006): 


$$
c_{f}=-\left.\frac{1}{V} \frac{\partial V}{\partial p}\right|_{T_{o}}=-\left.\frac{1}{V} \frac{\partial \rho}{\partial p}\right|_{T_{o}}
$$

where

$$
\begin{aligned}
& \mathrm{C}_{\mathrm{f}}=\text { fluid compressibility, } \\
& \mathrm{p}=\text { pore fluid pressure, } \\
& \mathrm{T}_{\mathrm{o}}=\text { temperature, } \\
& \mathrm{V}=\text { volume occupied by the fluid at reservoir conditions, and } \\
& \rho=\text { fluid density. }
\end{aligned}
$$

\subsection{Mathematical details of multi-phase fluid flow in porous media}

For both water (w) and $\mathrm{CO}_{2}$ (c) phases, multi-phase fluid flow equations can be found in published literature (Chen et al., 2006; Martinez et al., 2013; Das and Hassanizadeh, 2005). The basic equation of continuity for two-phase fluid flow in a porous medium is (Chen et al., 2006; Martinez et al., 2013; Das and Hassanizadeh, 2005):

For water:

$$
\begin{gathered}
\frac{\partial\left(n \rho_{w} S_{w}\right)}{\partial t}=-\nabla \cdot\left(\rho_{w} v_{w}\right)+q_{w} \\
v_{w}=-\frac{k_{r w}}{\mu_{w}} k\left(\nabla p_{w}-\rho_{w} g \nabla z\right)
\end{gathered}
$$

where

$$
\begin{aligned}
& k=\text { permeability, } \\
& \mathrm{n}=\text { porosity, } \\
& \mathrm{t}=\text { time, } \\
& z=\text { depth, } \\
& k_{r w}=\text { relative permeability of water, }
\end{aligned}
$$


$p_{w}=$ water pressure

$q_{w}=$ mass flow rate of water,

$S_{w}=$ water saturation,

$v_{w}=$ velocity of water,

$\mu_{w}=$ viscosity of water,

$\mathrm{g}=$ gravitational constant,

$\nabla=$ gradient operator, and

$\rho_{w}=$ density of water.

For $\mathrm{CO}_{2}$ :

$$
\begin{gathered}
\frac{\partial\left(n \rho_{c} S_{c}\right)}{\partial t}=-\nabla \cdot\left(\rho_{c} v_{c}\right)+q_{c} \\
v_{c}=-\frac{k_{r c}}{\mu_{c}} k\left(\nabla p_{c}-\rho_{c} g \nabla z\right)
\end{gathered}
$$

where

$k=$ permeability,

$\mathrm{n}=$ porosity,

$\mathrm{t}=$ time,

$z=$ depth,

$k_{r c}=$ relative permeability of $\mathrm{CO}_{2}$,

$p_{c}=\mathrm{CO}_{2}$ pressure,

$q_{c}=$ mass flow rate of $\mathrm{CO}_{2}$,

$S_{c}=\mathrm{CO}_{2}$ saturation, 


$$
\begin{aligned}
& v_{c}=\text { velocity of } \mathrm{CO}_{2}, \\
& \mu_{c}=\text { viscosity of } \mathrm{CO}_{2}, \\
& \mathrm{~g}=\text { gravitational constant, } \\
& \nabla=\text { gradient operator, and } \\
& \rho_{c}=\text { density of } \mathrm{CO}_{2} .
\end{aligned}
$$

Since the pore space is filled with water or $\mathrm{CO}_{2}$, it should fulfill the following condition.

$$
S_{w}+S_{c}=1
$$

where

$$
\begin{aligned}
& S_{w}=\text { water saturation, and } \\
& S_{c}=\mathrm{CO}_{2} \text { saturation. }
\end{aligned}
$$

It is assumed that permeability is proportional to the cube of porosity based on the KozenyCarman model (CMG, 2012; Siriwardane et al., 2013). The relationship is given below (CMG, 2012; Siriwardane et al., 2013):

$$
\frac{k}{k^{o}}=\left(\frac{n}{n^{o}}\right)^{3}\left(\frac{1-n^{2}}{1-n}\right)^{2}
$$

where $k^{o}$ and $n^{o}$ are the initial permeability and porosity, respectively.

\subsection{Mathematical details of geomechanical modeling}

Mechanical behavior of a deformable porous, homogeneous and isotropic media can be written as follows (Martinez et al., 2013; Minkoff et al., 2003; Tran et al., 2005; Tran et al., 2009):

(a) Force equilibrium equation: 


$$
\nabla . \sigma_{t}-\rho_{r} F=0
$$

where

$$
\begin{aligned}
& F=\text { body force per unit mass of solid grain that accounts for gravity, } \\
& \nabla=\text { gradient operator, } \\
& \sigma_{t}=\text { total stress tensor, and } \\
& \rho_{r}=\text { solid grain density. }
\end{aligned}
$$

(b) Strain-displacement relationships:

The gradient of displacement vector $(\nabla \mathrm{u})$ in a deformable body consists of two parts. The first part is a symmetric matrix equivalent to strain tensor, $\boldsymbol{\varepsilon}$ and the second part is a skew symmetric matrix equivalent to rotation tensor, $\mathbf{R}$ (Tran et al., 2005). Therefore, the gradient of displacement vector $(\nabla \mathrm{u})$ can be written as (Tran et al., 2005):

$$
\nabla u=\varepsilon+R
$$

where

$$
\begin{aligned}
& \nabla \mathrm{u}=\text { gradient of displacement vector, } \\
& \boldsymbol{\varepsilon}=\text { strain tensor, and } \\
& R=\text { rotation tensor } \\
& \qquad \nabla u=\frac{1}{2}\left[\nabla u+(\nabla u)^{T}\right]+\frac{1}{2}\left[\nabla u-(\nabla u)^{T}\right]
\end{aligned}
$$

where

$$
\begin{aligned}
& \mathrm{u}=\text { displacement vector, } \\
& \mathrm{T}=\text { matrix transpose, and } \\
& \nabla \mathbf{u}=\text { gradient of displacement vector. }
\end{aligned}
$$


(c) Effective stress calculations:

Effective stress $\left(\sigma^{\prime}\right)$ in a fluid saturated porous media increases during fluid production and decreases during fluid injection due to change in pore fluid pressure. Effective stress can be expressed in terms of total stress $\left(\sigma_{t}\right)$ and pore fluid pressure $(p)$ as shown below (Martinez et al., 2013; Tran et al., 2005; Tran et al., 2009; Vilarrasa et al., 2011):

$$
\sigma^{\prime}=\sigma_{t}-\alpha p I
$$

where

$$
\begin{aligned}
& \alpha=\text { Biot's constant }(\mathrm{n} \leq \alpha \leq 1) \text { where } \mathrm{n}=\text { porosity, } \\
& \mathrm{I}=\text { identity matrix, } \\
& \sigma^{\prime}=\text { effective stress, } \\
& \sigma_{\mathrm{t}}=\text { total stress, and } \\
& \mathrm{p}=\text { pore fluid pressure. }
\end{aligned}
$$

(d) Constitutive relation for solid rock:

The constitutive relationship between stress, strain and temperature can be expressed as shown below (Tran et al., 2005; Tran et al., 2009):

$$
\sigma^{\prime}=C: \varepsilon-\eta \nabla T_{O} I
$$

where

$$
\begin{aligned}
& \eta=\frac{E \beta_{r}}{(1-2 v)} \text { for } 3 D \text { and plane strain } \\
& =\frac{E \beta_{r}}{(1-v)} \text { for plane stress } \\
& \mathrm{C}=\text { tangential stiffness tensor, } \\
& \mathrm{E}=\text { Young's modulus, }
\end{aligned}
$$




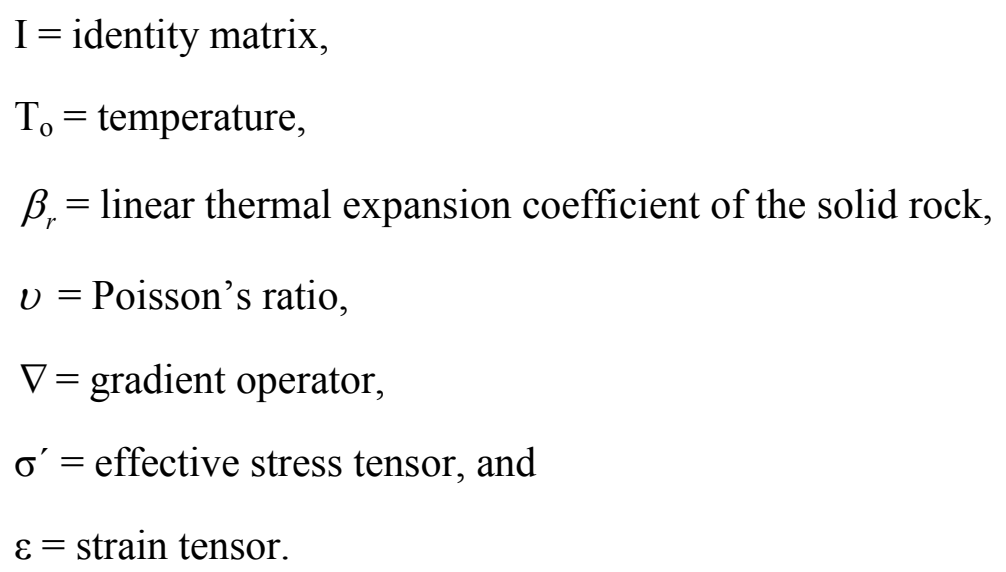

The displacement equation can be obtained by substituting Equations 3.12, 3.13 and 3.14 into Equation 3.10 (Tran et al., 2005). The displacement equation can be expressed as given below (Tran et al., 2005):

$$
\nabla \cdot\left[C: \frac{1}{2}\left(\nabla u+(\nabla u)^{T}\right)\right]+\nabla \cdot\left[C: \frac{1}{2}\left(\alpha p-\eta \Delta T_{O}\right) I\right]=\rho_{r} F
$$

where

$$
\begin{aligned}
& \mathrm{C}=\text { tangential stiffness tensor, } \\
& \mathrm{I}=\text { identity matrix, } \\
& \mathrm{F}=\text { force per unit mass that accounts for gravity, } \\
& \mathrm{T}=\text { matrix transpose, } \\
& \mathrm{T}_{\mathrm{o}}=\text { temperature, } \\
& \mathrm{p}=\text { pore fluid pressure, } \\
& \mathrm{u}=\text { displacement vector, } \\
& \nabla=\text { gradient operator, } \\
& \nabla \mathrm{u}=\text { gradient of displacement vector, } \\
& \alpha=\text { Biot's constant, and } \\
& \rho_{r}=\text { solid grain density. }
\end{aligned}
$$


The constitutive equation for the stress-strain relationship can be written as (Desai and Siriwardane, 1984; Siriwardane et al., 2012; Siriwardane et al., 2013; Vilarrasa et al., 2011):

$$
\sigma_{i j}=2 G \varepsilon_{i j}+\left(K-\frac{2 G}{3}\right) \varepsilon_{k k} \delta_{i j}+\alpha p \delta_{i j}
$$

where

$$
\begin{aligned}
& \mathrm{G}=\text { shear modulus, } \\
& \mathrm{K}=\text { bulk modulus, } \\
& p=\text { pore fluid pressure, } \\
& \alpha=\text { Biot's constant, } \\
& \sigma_{\mathrm{ij}}=\text { stress tensor, } \\
& \varepsilon_{\mathrm{ij}}=\text { strain tensor, and } \\
& \delta_{i j}=\text { Kronecker delta }=1, \text { if } \mathrm{i}=\mathrm{j} ;=0, \text { otherwise } .
\end{aligned}
$$

The bulk modulus and the shear modulus can be expressed as (Desai and Siriwardane, 1984; Helwany, 2007):

$$
\begin{gathered}
K=\frac{E}{3(1-2 v)} \\
G=\frac{E}{2(1+v)}
\end{gathered}
$$

where

$$
\begin{aligned}
& \mathrm{E}=\text { Young's modulus, } \\
& \mathrm{G}=\text { shear modulus, } \\
& \mathrm{K}=\text { bulk modulus, and } \\
& v=\text { Poisson's ratio. }
\end{aligned}
$$




\subsection{Implementation of aforementioned equations in computational models}

In the current study, CMG-GEM and ABAQUS were used to construct the coupled fluid flow and geomechanical models. CMG-GEM is a commercially available finite difference based simulator that can be used to construct multi-phase fluid flow models (CMG, 2012). Geomechanics module built in CMG-GEM was used to couple geomechanics with multi-phase fluid flow models. Iterative coupling (two-way coupling) methods were used to couple geomechanics with the fluid flow models as reported in the literature (Tran et al., 2009). The data is exchanged back and forth in the flow simulator and geomechanics module. Geomechanics module uses a finite element based approach to independently solve the basic constitutive equations for fluid flow and deformations (Tran et al., 2004; Tran et al., 2005; Tran et al., 2010). ABAQUS is a commercially available finite element code that can handle fully coupled geomechanics with single-phase fluid flow (ABAQUS, 2012; Helwany, 2007). More details about the coupling geomechanics to flow simulators can be found elsewhere (ABAQUS, 2012; CMG, 2012; Minkoff et al., 2003; Siriwardane et al., 2013; Tran et al., 2004; Tran et al., 2009; Tran et al., 2010; Vilarrasa et al., 2010). 


\section{CHAPTER 4 : COUPLED FLUID FLOW AND GEOMECHANICAL MODELING}

\subsection{Introduction}

In the current study, coupled single-phase and multi-phase fluid flow and geomechanical modeling were performed to investigate the changes in fluid pressure and ground deformation behavior caused by fluid injection. A hypothetical injection scenario in a multi-layered geologic media was considered for modeling, and ground response due to single-phase injection and multi-phase injection were investigated. Results corresponding to single-phase and multi-phase fluid flow coupled with geomechanics were compared and presented in this chapter. Figure 4.1 shows the geometric details and a schematic diagram of the hypothetical injection site considered in this study. Five geologic layers were considered, including the monitoring layer, the caprock (or seal), the target reservoir, the overburden and the underburden layer. Table 4.1 shows the assumed reservoir and geomechanical properties for each layer. Geomechanical properties were assumed based on those reported in the published literature (Rutqvist et al., 2008; Siriwardane et al., 2013). Axisymmetric and three-dimensional coupled fluid flow and geomechanical modeling were performed, and results of fluid pressure changes and ground response are presented. The model extends vertically from 0 to 3,000 $\mathrm{m}$ depth and horizontally far enough from the injection zone $(10,000 \mathrm{~m})$. Reservoir temperature of $120^{\circ} \mathrm{F}$ was assumed. The model consists of a storage aquifer $100 \mathrm{~m}$ in thickness, bounded at top by a low-permeable $150 \mathrm{~m}$ thick caprock, which in turn, is surrounded by a monitoring layer of $100 \mathrm{~m}$ thickness above, respectively (Figure 4.1). 


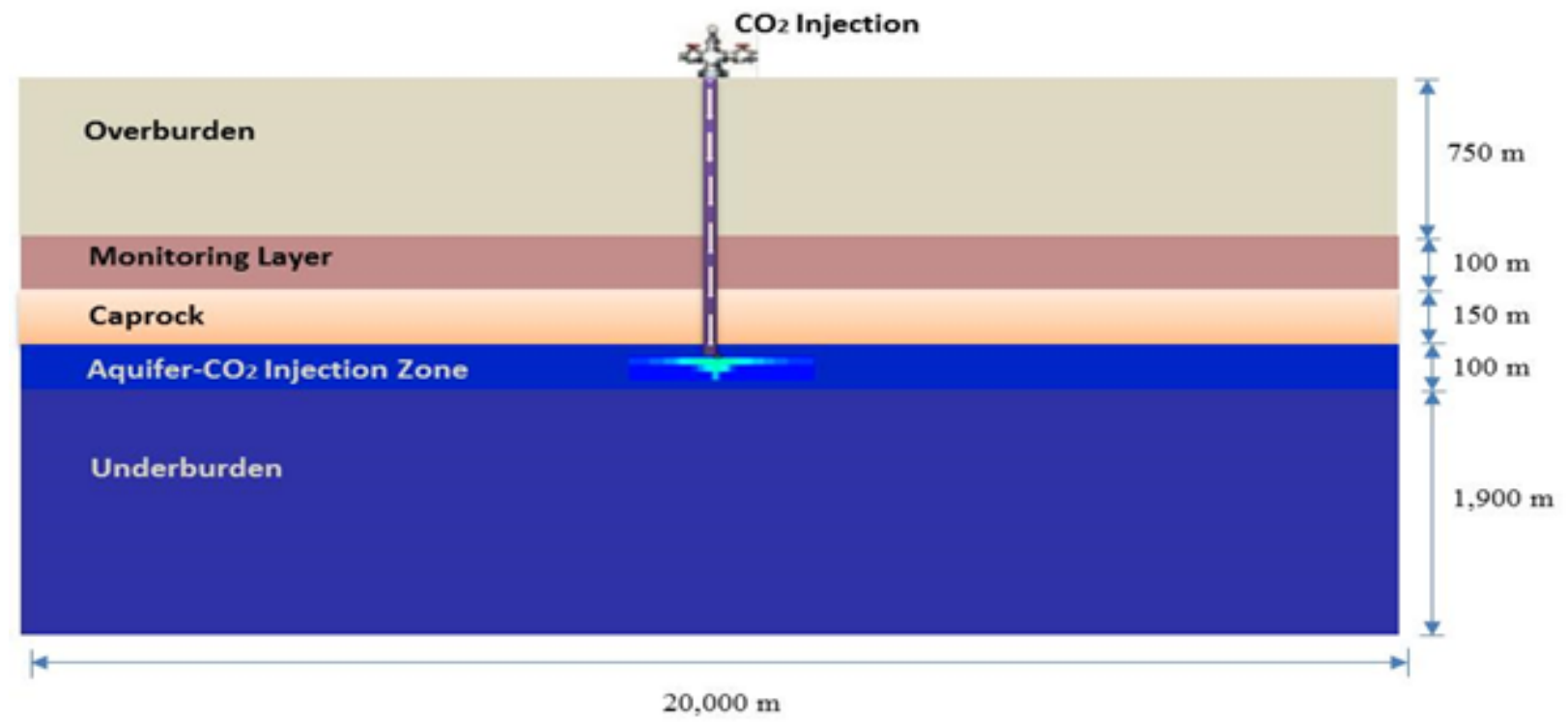

Figure 4.1: Schematic diagram of a hypothetical injection site

Table 4.1: Reservoir and geomechanical properties used in this chapter

\begin{tabular}{|c|c|c|c|c|c|}
\hline Material Property & $\begin{array}{c}\text { Overburden } \\
\text { Layer }\end{array}$ & $\begin{array}{c}\text { Monitoring } \\
\text { Layer }\end{array}$ & $\begin{array}{c}\text { Caprock } \\
\text { Seal }\end{array}$ & Aquifer & $\begin{array}{c}\text { Underburden } \\
\text { Layer }\end{array}$ \\
\hline Layer Thickness (m) & 750 & 100 & 150 & 100 & 1900 \\
\hline Grid Top (m) & 0 & 750 & 850 & 1000 & 1100 \\
\hline Stress gradient (kPa/m) & 22.62 & 22.62 & 22.62 & 22.62 & 22.62 \\
\hline Elastic Modulus (kPa) & $5 \mathrm{E}+06$ & $5 \mathrm{E}+06$ & $5 \mathrm{E}+06$ & $5 \mathrm{E}+06$ & $5 \mathrm{E}+06$ \\
\hline Poisson's Ratio & 0.25 & 0.25 & 0.25 & 0.25 & 0.25 \\
\hline Permeability (mD) & 0.0001 & 100 & 0.000001 & 100 & 0.0001 \\
\hline Porosity (fraction) & 0.02 & 0.1 & 0.005 & 0.1 & 0.02 \\
\hline Cohesion (kPa) & $5 \mathrm{E}+05$ & $5 \mathrm{E}+05$ & $5 \mathrm{E}+05$ & $5 \mathrm{E}+05$ & $5 \mathrm{E}+05$ \\
\hline Friction Angle & 30 & 30 & 30 & 30 & 30 \\
\hline
\end{tabular}




\subsection{Coupled Single-phase Fluid Flow and Geomechanical Modeling}

CMG simulator (CMG, 2012) was used in the study presented in this section. Axisymmetric and three-dimensional models were constructed to simulate fluid injection in a targeted aquifer at a hypothetical injection site as shown in Figure 4.1. In the present section, modeling details and results of coupled single-phase fluid flow and geomechanical modeling are presented. Fluid flow behavior and vertical displacements caused due to fluid injection from these models (axisymmetric and three-dimensional) were compared.

\subsubsection{Axisymmetric modeling}

Computer Modeling Group's GEM simulator (CMG, 2012) was used to construct the single-phase fluid flow model and to understand fluid transport behavior. Based on the hypothetical injection site (as shown in Figure 4.1), an axisymmetric model (45 x 1 x 16 grid blocks) was constructed to simulate fluid injection in an aquifer. Single-phase fluid flow modeling coupled with geomechanics was performed to investigate changes in fluid pressure and compute vertical displacements caused due to fluid injection.

- In a single-phase fluid flow model, water was used as the injection component as described in the published literature (Siriwardane et al., 2013). CMG-GEM is a multi-phase fluid flow simulator, and water and $\mathrm{CO}_{2}$ were selected as two components in the fluid flow model. Water is a default component in CMG-GEM (CMG, 2012; Siriwardane et al., 2013). A small percentage (negligible composition) of $\mathrm{CO}_{2}$ was considered in the initialization and the model was assumed to be fully saturated with water. However, the water saturation can be controlled in CMG-GEM. Also, relative permeability curves were used and more details are presented in the forthcoming sections.

- In a multi-phase fluid flow analyses where modeling of $\mathrm{CO}_{2}$ injection is planned, the injection component is changed from water to $\mathrm{CO}_{2}$.

GEM's in-built geomechanics module was used to perform geomechanical modeling. The grid block volumes of boundary elements in the monitoring, reservoir, and caprock layers were 
modified with large volume multipliers to model the infinitely large lateral extent of these layers and to ensure that boundaries have minimal effects on geomechanical models. The bottom and lateral boundaries of the geomechanical model were fixed. Figure 4.2 shows the two-dimensional and three-dimensional view of the axisymmetric model considered in this study. As shown in Figure 4.2, refined grid blocks were used near the injection point and coarser grid blocks were used far from injection near the boundaries. A lateral distance of 10,000 m was considered away from injection point with a model thickness of 3,000 m. 


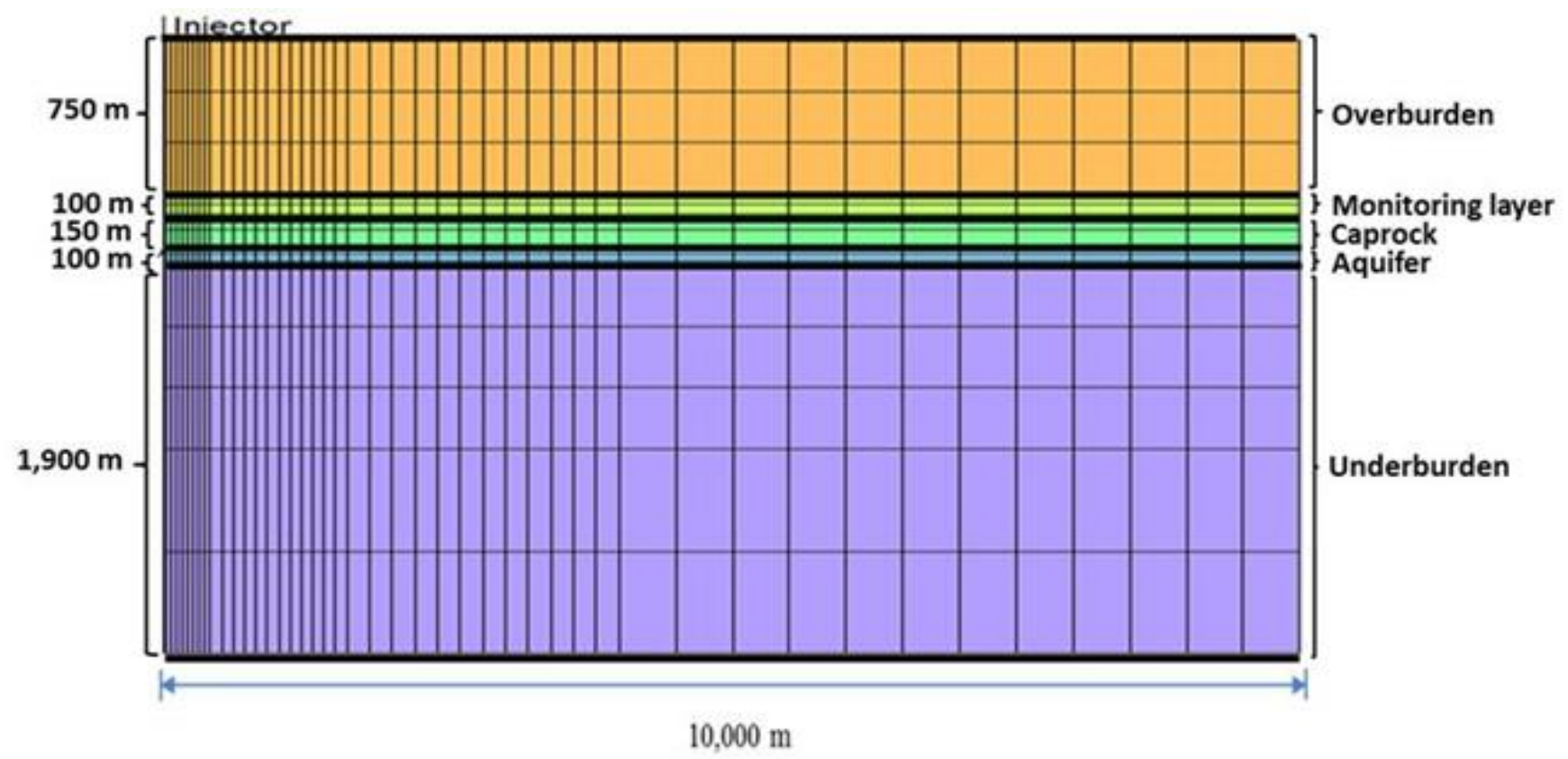

(a) Two-dimensional view

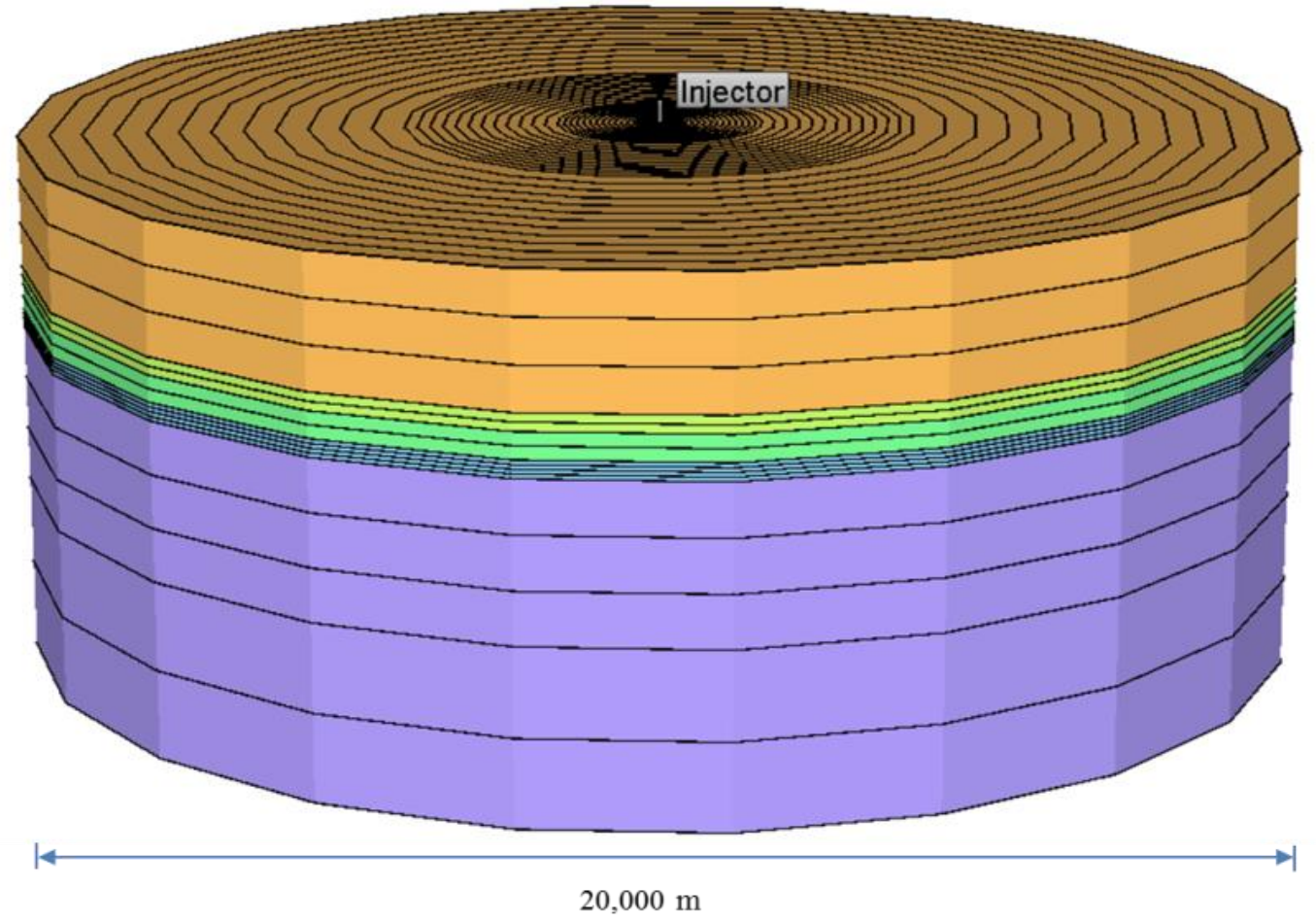

(b) Three - dimensional view

Figure 4.2: Geometry of the axisymmetric single-phase model 
Single-phase fluid injection (water injection) was carried out at a depth of $1,050 \mathrm{~m}$ at an injection rate of 100,000 tonnes/year injection rate (primary constraint) for a time period of five years. Initial fluid pressure was computed by assuming a fluid pressure gradient of $9.81 \mathrm{kPa} / \mathrm{m}$ ( $0.43 \mathrm{psi} / \mathrm{ft})$. Figure 4.3 shows the relative permeability curves used when water was used as an injection fluid. The relative permeability curves used in this study are in the similar range identified for different rock formations (Bennion and Bachu, 2005; Siriwardane et al., 2013). Figure 4.4 show the initial fluid pressure distribution and Figure 4.5 show the changes in fluid pressure at the end of 5-year fluid injection period. Results show an increase in the fluid pressure due to 5 years of continuous injection. Figure 4.6 shows the vertical displacements caused due to single-phase fluid injection. Figure 4.7 shows the plot between vertical displacements and radial distance. The maximum vertical uplift was computed as $1.9 \mathrm{~cm}$ was observed when single-phase injection (water injection) was carried out.

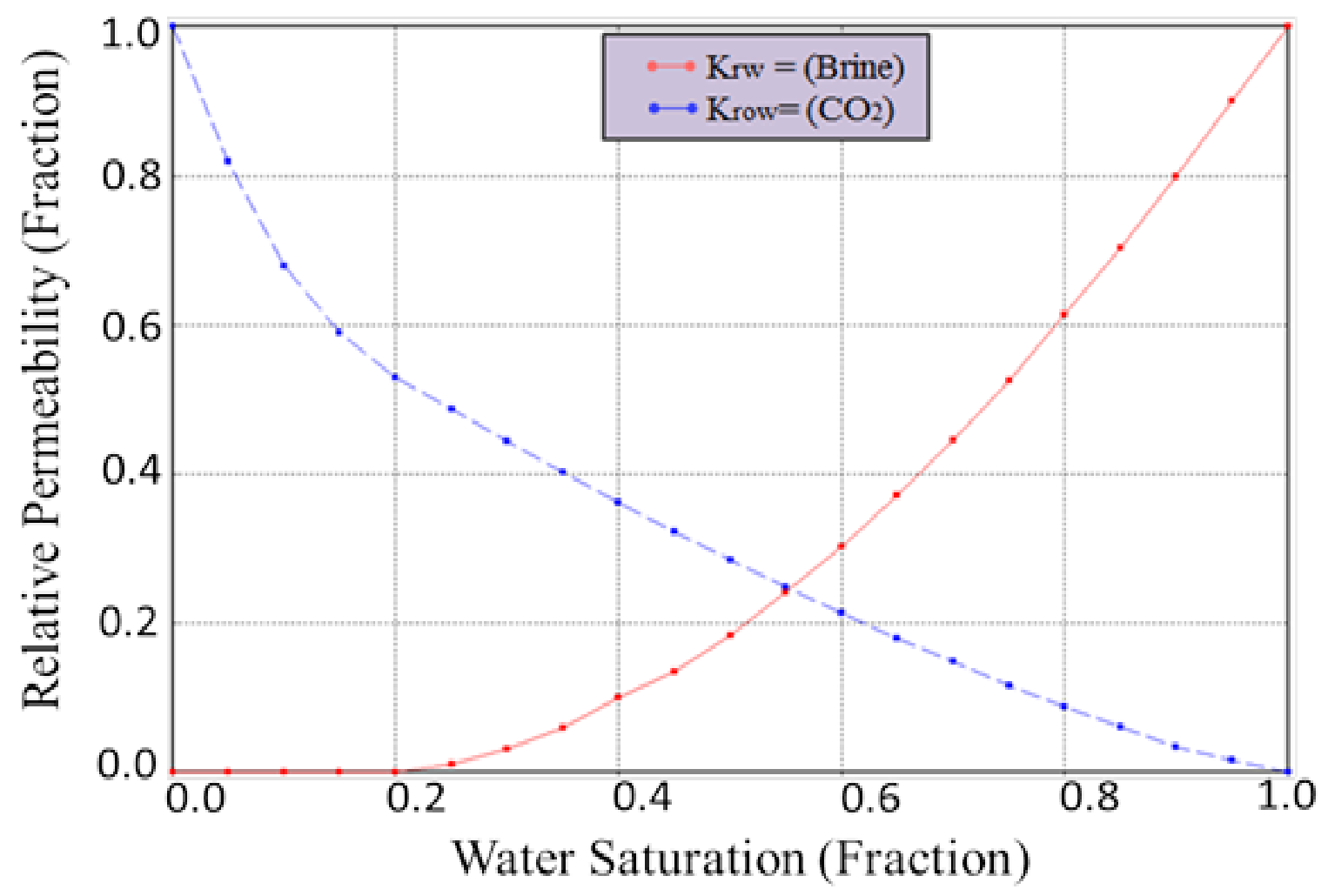

Note: Obtained from published literature (Bennion and Bachu, 2005; Siriwardane et al., 2013) Figure 4.3: Relative permeability curves used in the study 

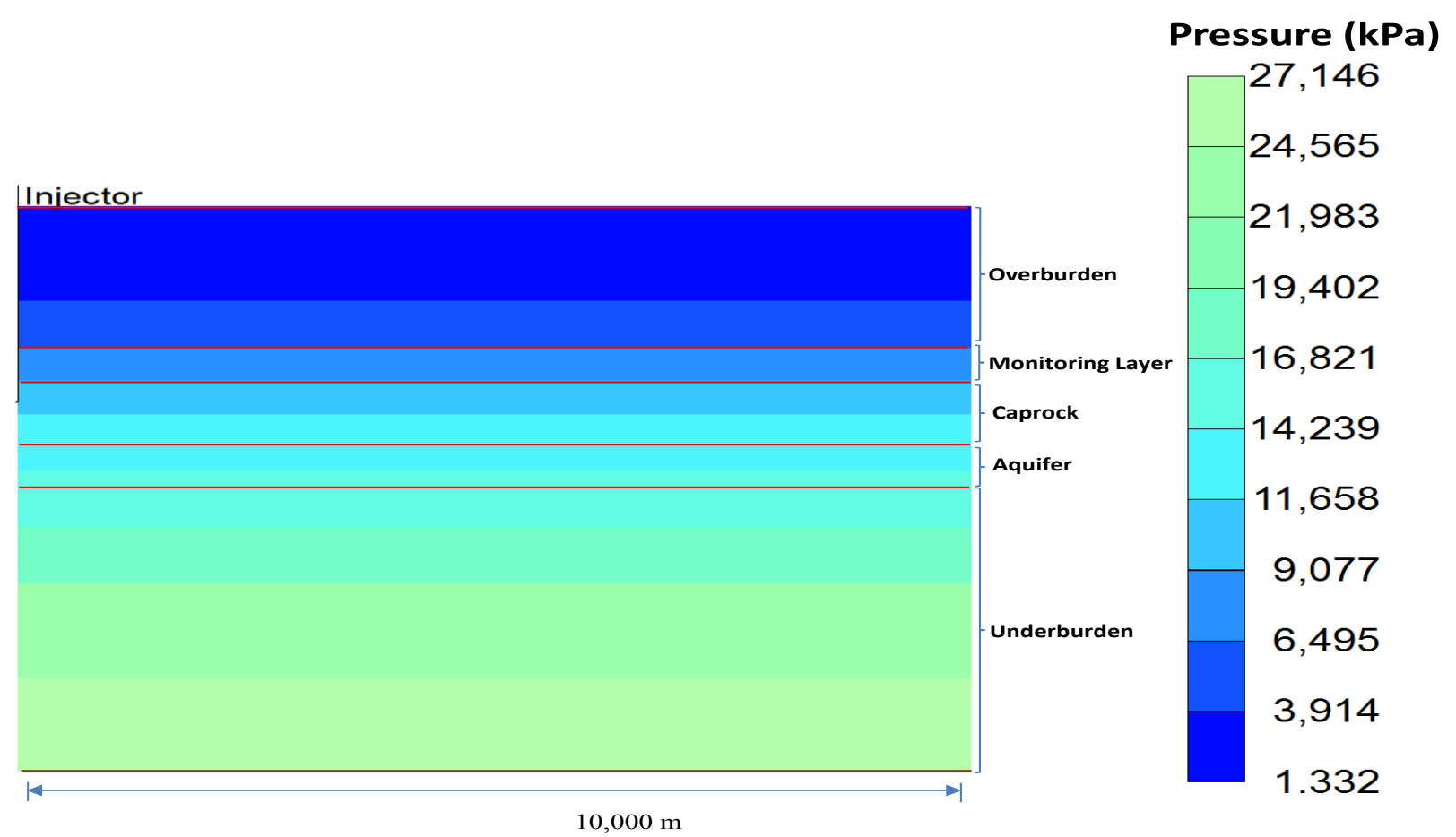

Figure 4.4: Initial fluid pressure distribution $(\mathrm{kPa})$ by using an axisymmetric single-phase fluid flow and geomechanical model
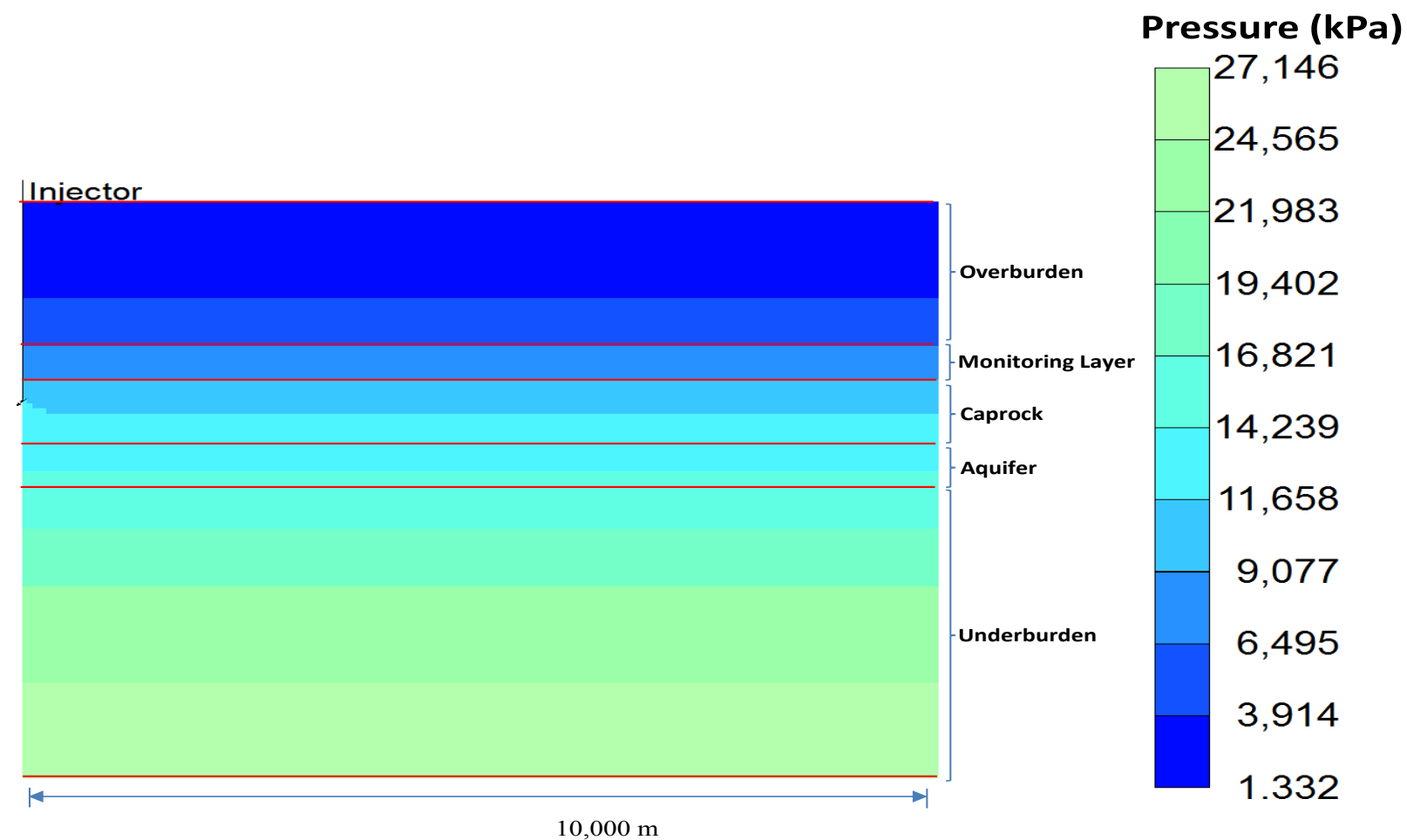

Figure 4.5: Fluid pressure distribution $(\mathrm{kPa})$ at the end of 5-years by using an axisymmetric single-phase fluid flow and geomechanical model 


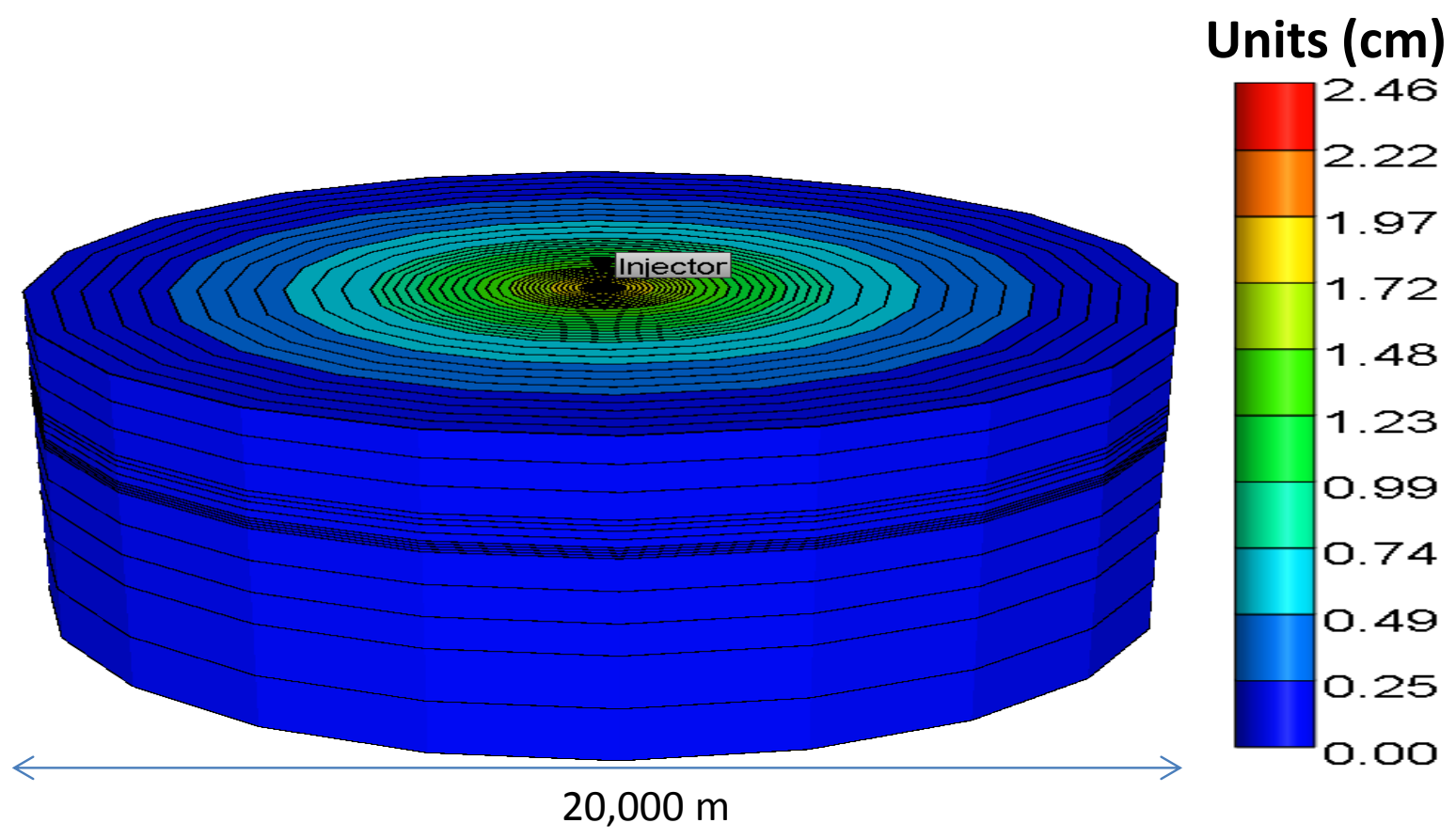

Figure 4.6: Computed vertical displacements $(\mathrm{cm})$ by using an axisymmetric single-phase fluid flow and geomechanical model

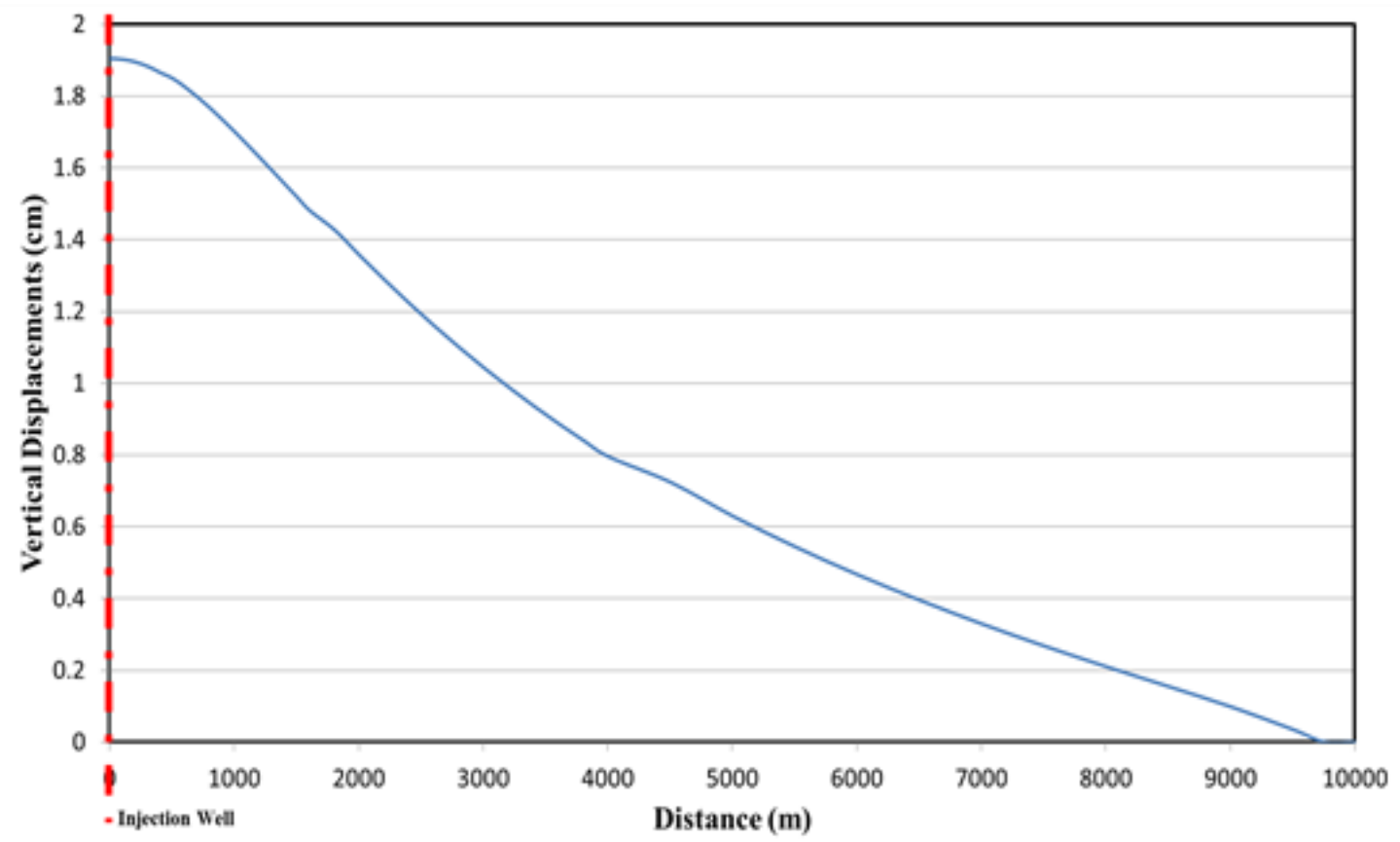

Figure 4.7: Computed ground displacements $(\mathrm{cm})$ by using an axisymmetric single-phase fluid flow and geomechanical model 


\subsubsection{Three-dimensional modeling (Single-phase fluid flow)}

Computer Modeling Group's GEM simulator (CMG, 2012) was used to construct the three-dimensional, single-phase coupled fluid flow and geomechanical model. The threedimensional model is shown in Figure 4.8. A grid block configuration of 89 x 89 x 16 was used. Similar to axisymmetric model, a refined grid block configuration was assumed near the injection zone. The boundary elements in the monitoring layer, caprock and reservoir layer were modified with large volume multipliers to model infinitely large extent of the reservoir and to ensure that boundaries have minimal effects on geomechanical model as described in the published literature (Siriwardane et al., 2013; Tran et al., 2009). The volume modifiers in this model were assumed to be $1 \mathrm{e}+07$. The fluid injection was carried out with a flow rate constraint of 100,000 tonnes/year at a depth of 1,050 m. Initial fluid pressure was computed by assuming a fluid pressure gradient of $9.81 \mathrm{kPa} / \mathrm{m}(0.43 \mathrm{psi} / \mathrm{ft})$. Figure 4.9 shows the initial fluid pressure distribution of the geomechanical model. Figure 4.10 shows the changes in the fluid pressure at the end of 5-year fluid injection period. Results show an increase in the fluid pressure near the injection region and surrounding geologic media. Figure 4.11 shows the vertical displacements caused due to fluid injection. Figure 4.12 shows the vertical displacements plotted with lateral distance. The maximum vertical displacement was computed as $1.9 \mathrm{~cm}$ after a 5-year fluid injection period. The magnitude of the computed maximum ground displacement from the threedimensional model is similar to displacement results obtained from the axisymmetric model. 


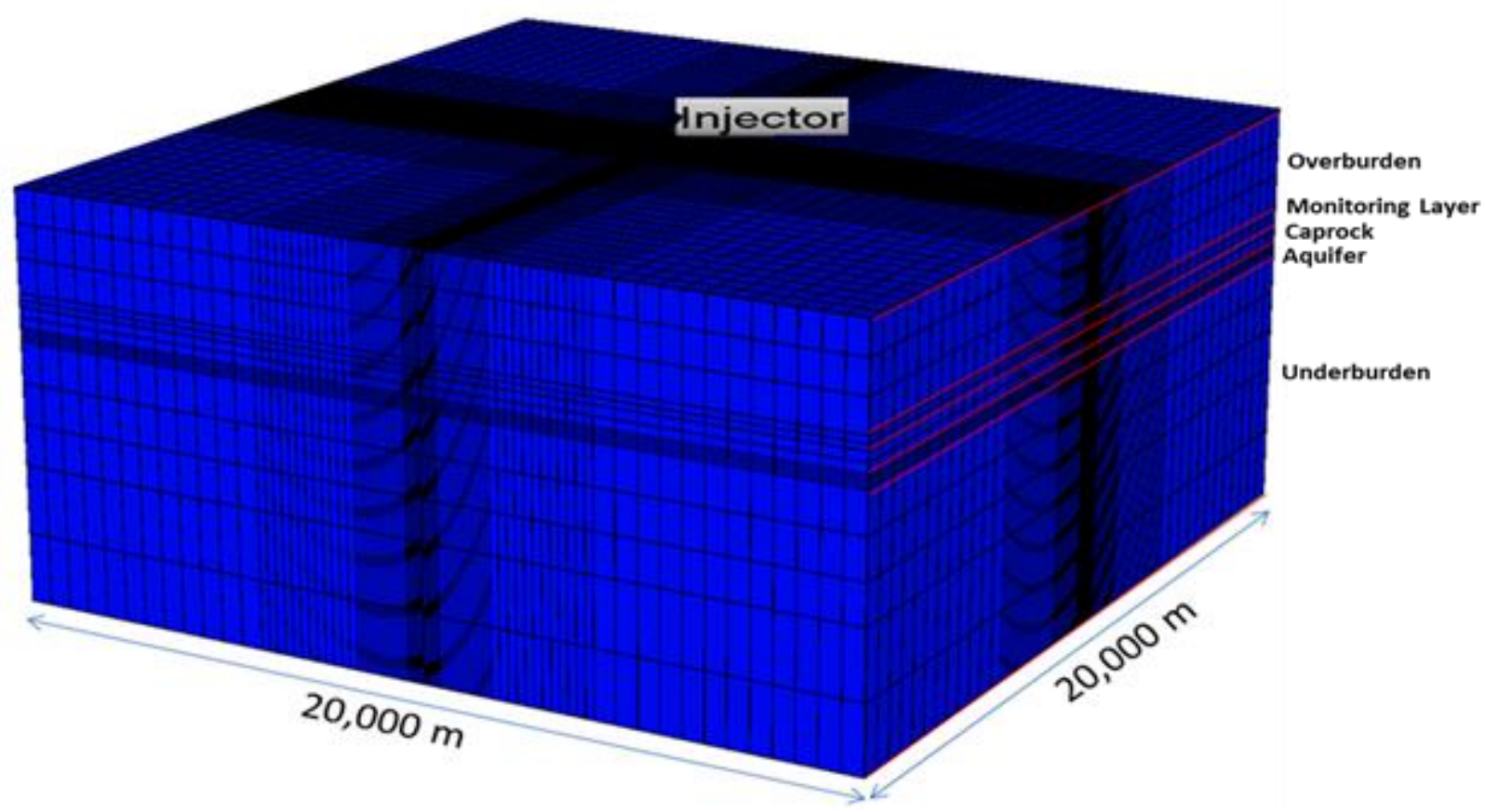

Figure 4.8: Geometry of 3-D, coupled single-phase fluid flow and geomechanical model

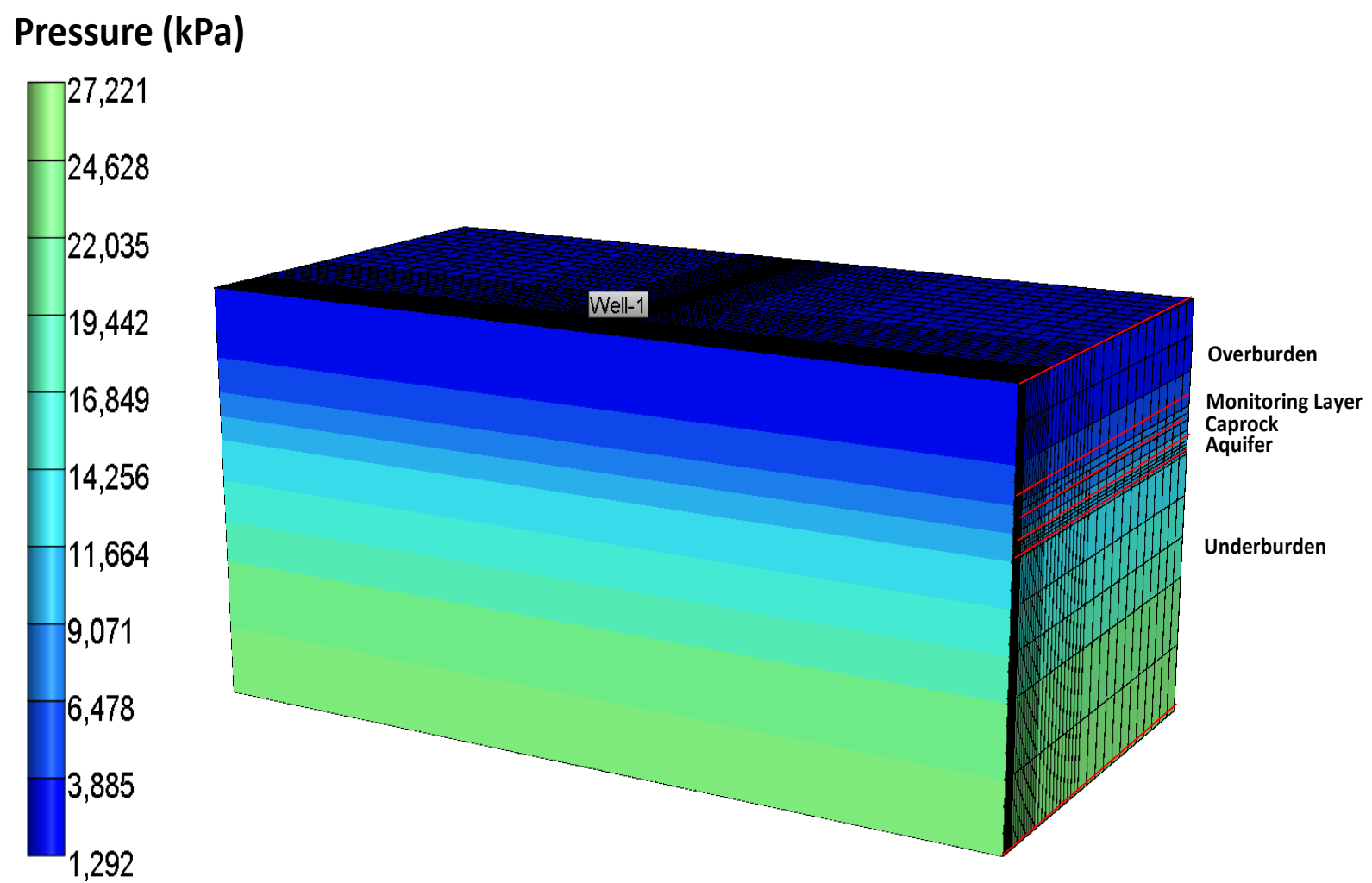

Figure 4.9: Initial fluid pressure distribution $(\mathrm{kPa})$ by using a 3-D, single-phase fluid flow and geomechanical model 


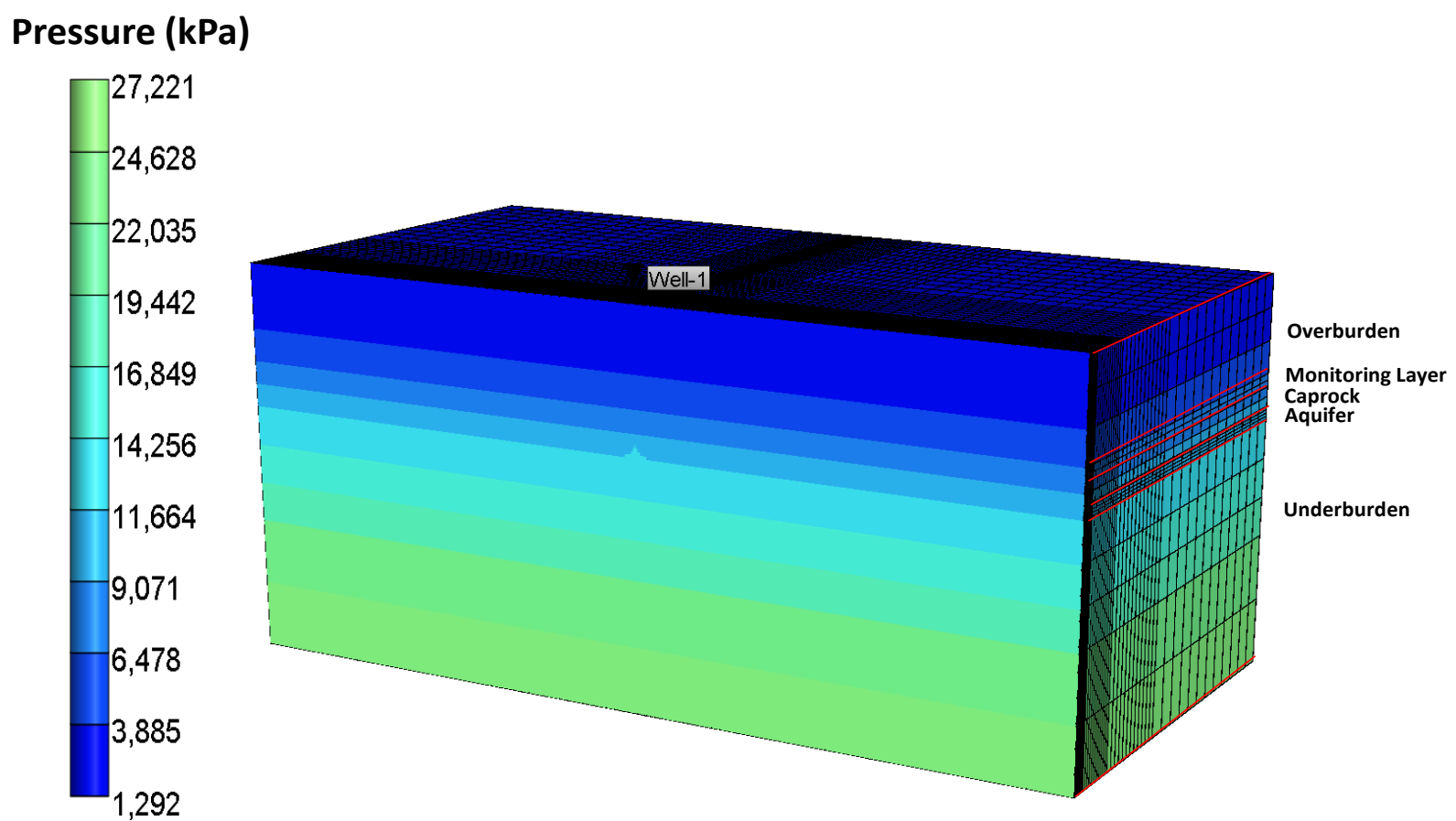

Figure 4.10: Computed changes in fluid pressure $(\mathrm{kPa})$ at the end of 5-year injection by using a 3 -D, single-phase fluid flow and geomechanical model

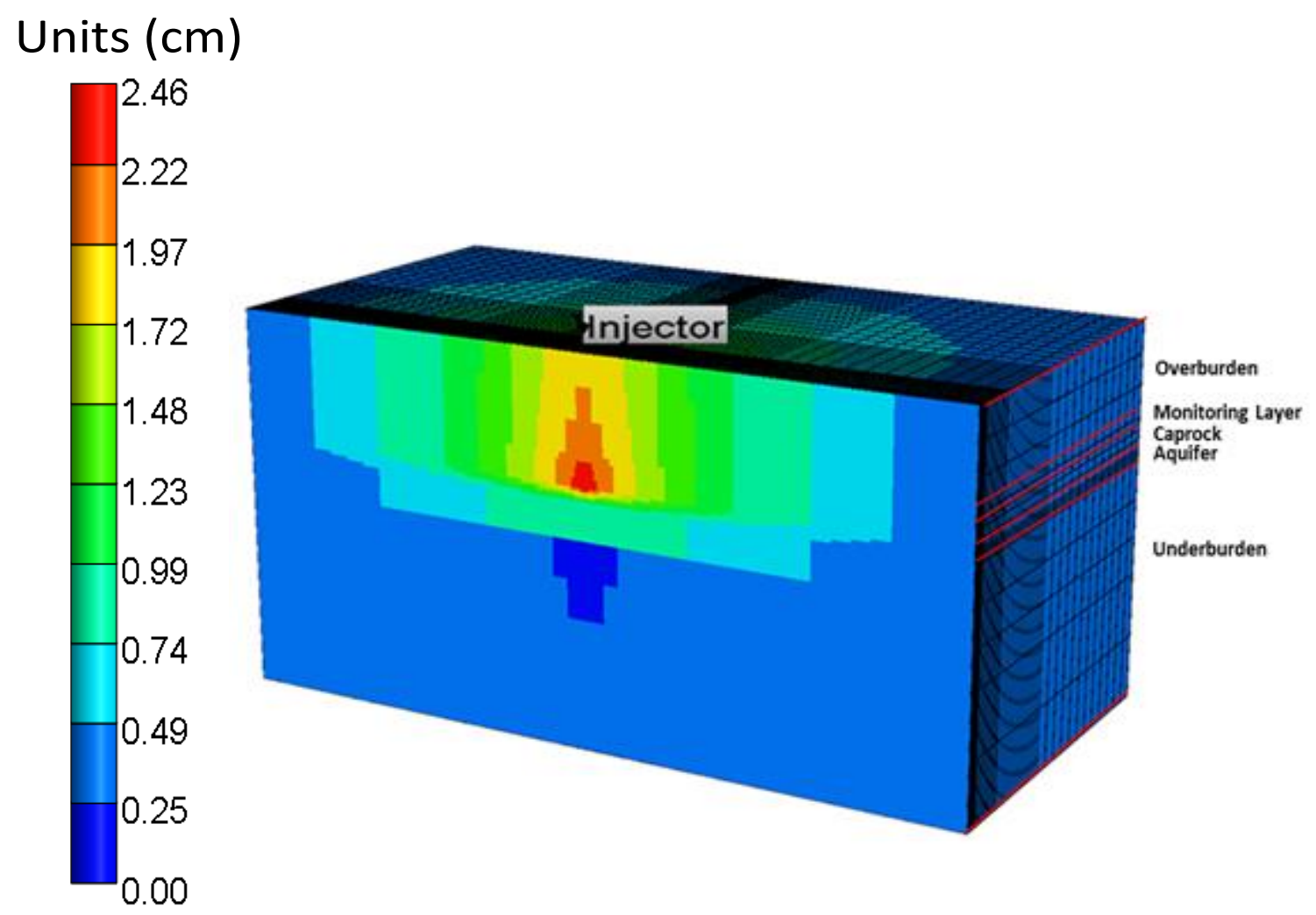

Figure 4.11: Computed vertical displacements $(\mathrm{cm})$ by using a 3-D, single-phase fluid flow and geomechanical model 


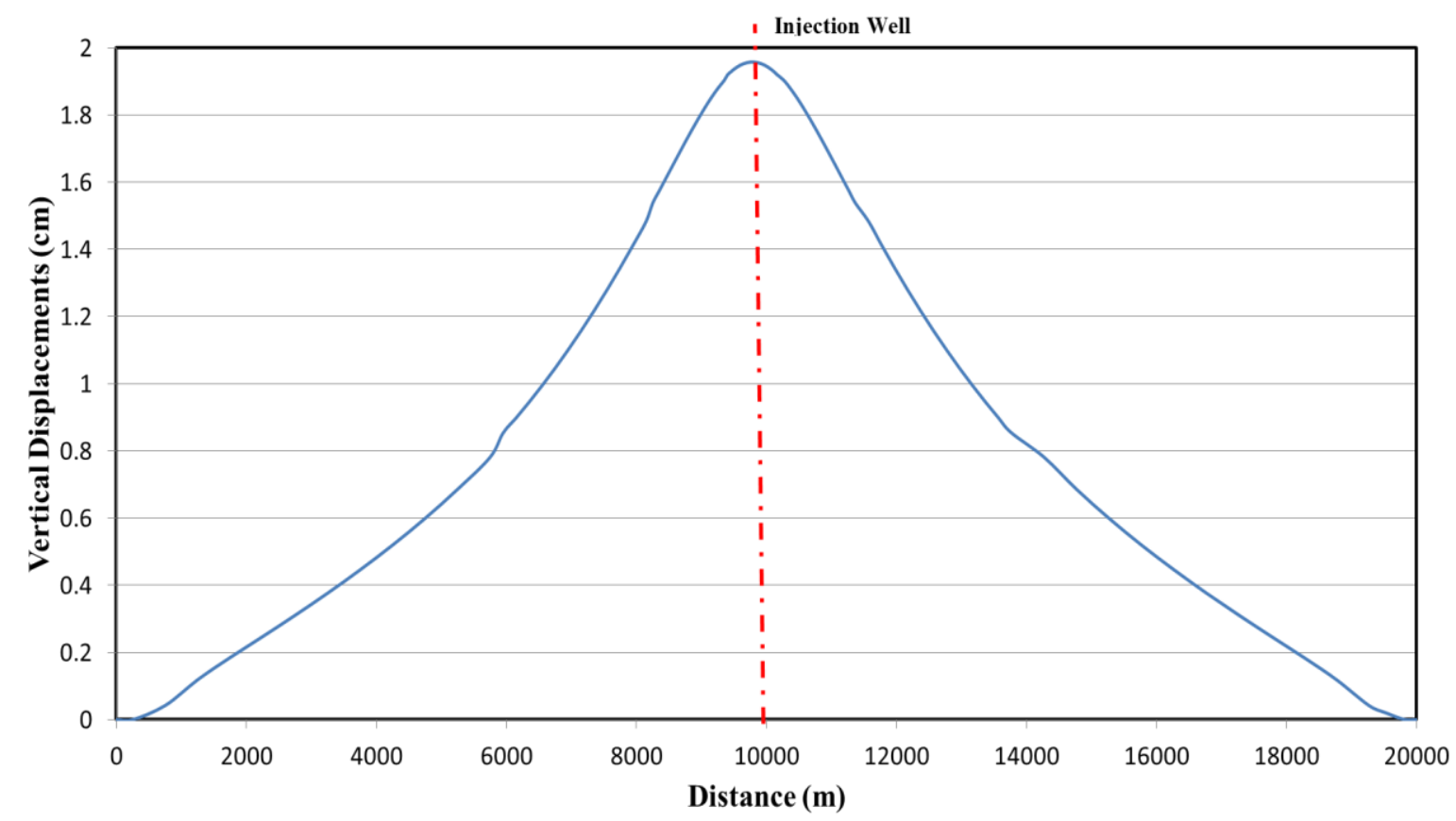

Figure 4.12: Computed ground displacements by using a 3-D, single-phase fluid flow and geomechanical model

\subsection{Coupled Multi-phase Fluid Flow and Geomechanical Modeling}

Computer Modeling Group's GEM simulator (CMG, 2012) was used in the study presented in this section. Axisymmetric and three-dimensional models were constructed to simulate $\mathrm{CO}_{2}$ injection in a targeted aquifer at a hypothetical injection site as shown in Figure 4.1. Coupled multi-phase fluid flow and geomechanical models were considered, and results of axisymmetric and three-dimensional models were compared. Changes in fluid flow behavior and vertical displacements caused due to fluid injection from these models were compared and are presented in this section.

\subsubsection{Axisymmetric modeling}

CMG-GEM simulator (CMG, 2012) was used to construct the multi-phase fluid flow model and understand $\mathrm{CO}_{2}$ transport behavior. Axisymmetric, multi-layered, coupled multiphase fluid flow and geomechanical model was constructed (45 x 1 x 16 grid blocks) to simulate $\mathrm{CO}_{2}$ injection in an aquifer. Figure 4.13 shows the two-dimensional and three-dimensional view 
of the axisymmetric model considered in this study. Refined grid blocks were used near the injection point and coarser grid blocks were used far from injection near the boundaries. Lateral distance of 10,000 $\mathrm{m}$ was considered away from injection point with a model thickness of 3,000 m. Material properties were assumed based on published literature (Rutqvist et al., 2008; Siriwardane et al., 2013) and are shown in Table 4.1. Similar to single-phase fluid flow models, the grid block volumes of boundary elements in the monitoring, reservoir, and caprock layers were modified with large multipliers to model the infinitely large lateral extent of these layers. The bottom and lateral boundaries of the geomechanical model were fixed.

Injection of $\mathrm{CO}_{2}$ was carried out at a depth of $1,050 \mathrm{~m}$ at an injection rate of 100,000 tonnes/year injection rate for a time period of five years. Figure 4.14 shows the relative permeability curves used when $\mathrm{CO}_{2}$ was used as an injection fluid. The relative permeability curves used in this study are in the similar range identified for different rock formations (Bennion and Bachu, 2005; Siriwardane et al., 2013). Initial fluid pressure was computed by assuming a fluid pressure gradient of $9.81 \mathrm{kPa} / \mathrm{m}(0.43 \mathrm{psi} / \mathrm{ft})$. Figure 4.15 shows the initial fluid pressure distribution and Figure 4.16 shows the changes in fluid pressure at the end of 5-year $\mathrm{CO}_{2}$ injection period. Results show an increase in the fluid pressure due to injection of $\mathrm{CO}_{2}$. Figure 4.17 shows the vertical displacements caused due to $\mathrm{CO}_{2}$ injection. Figure 4.18 shows the plot between vertical displacements and radial distance. A maximum vertical uplift as $2.62 \mathrm{~cm}$ was observed. 


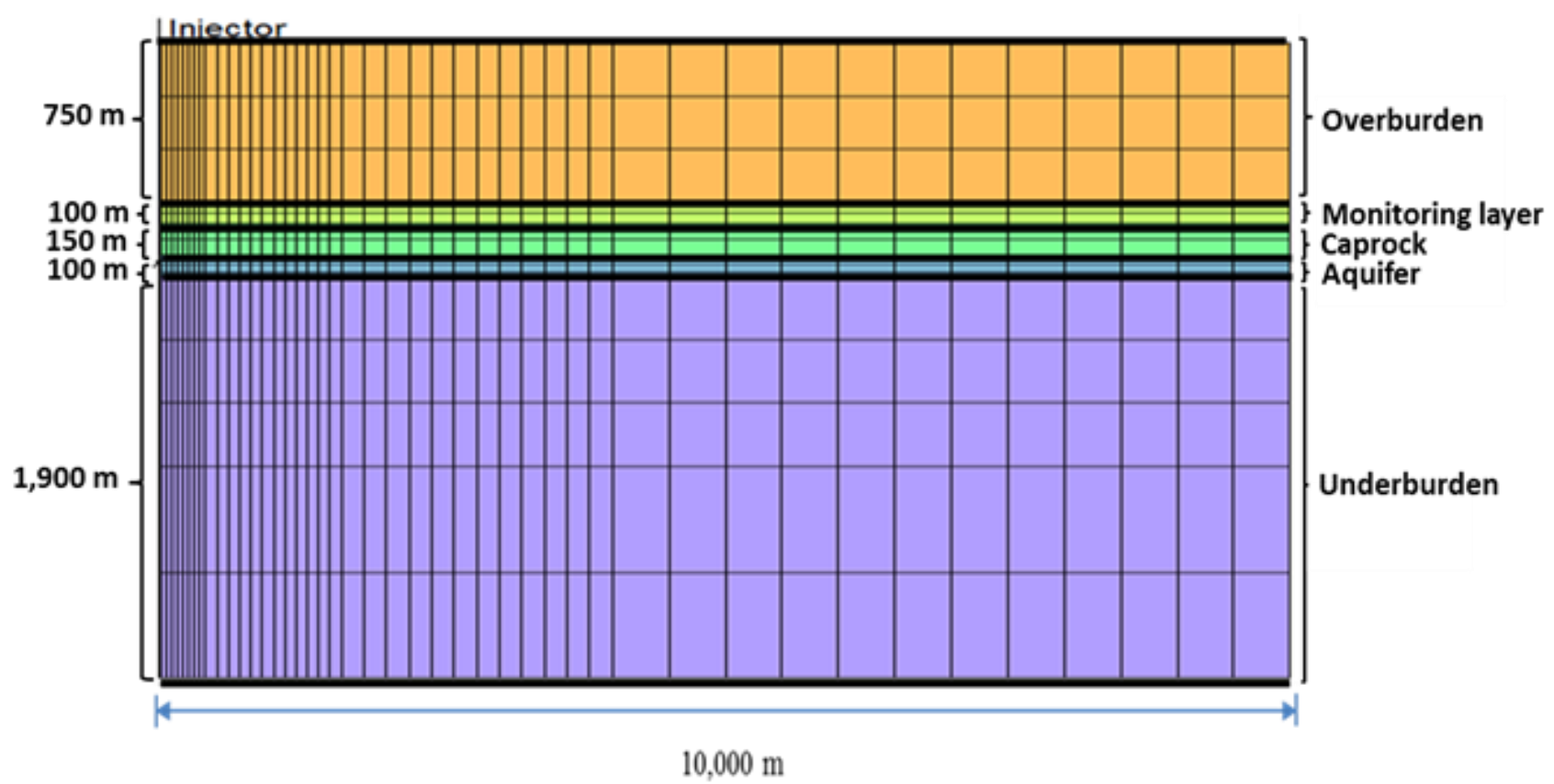

(a) Two - dimensional view

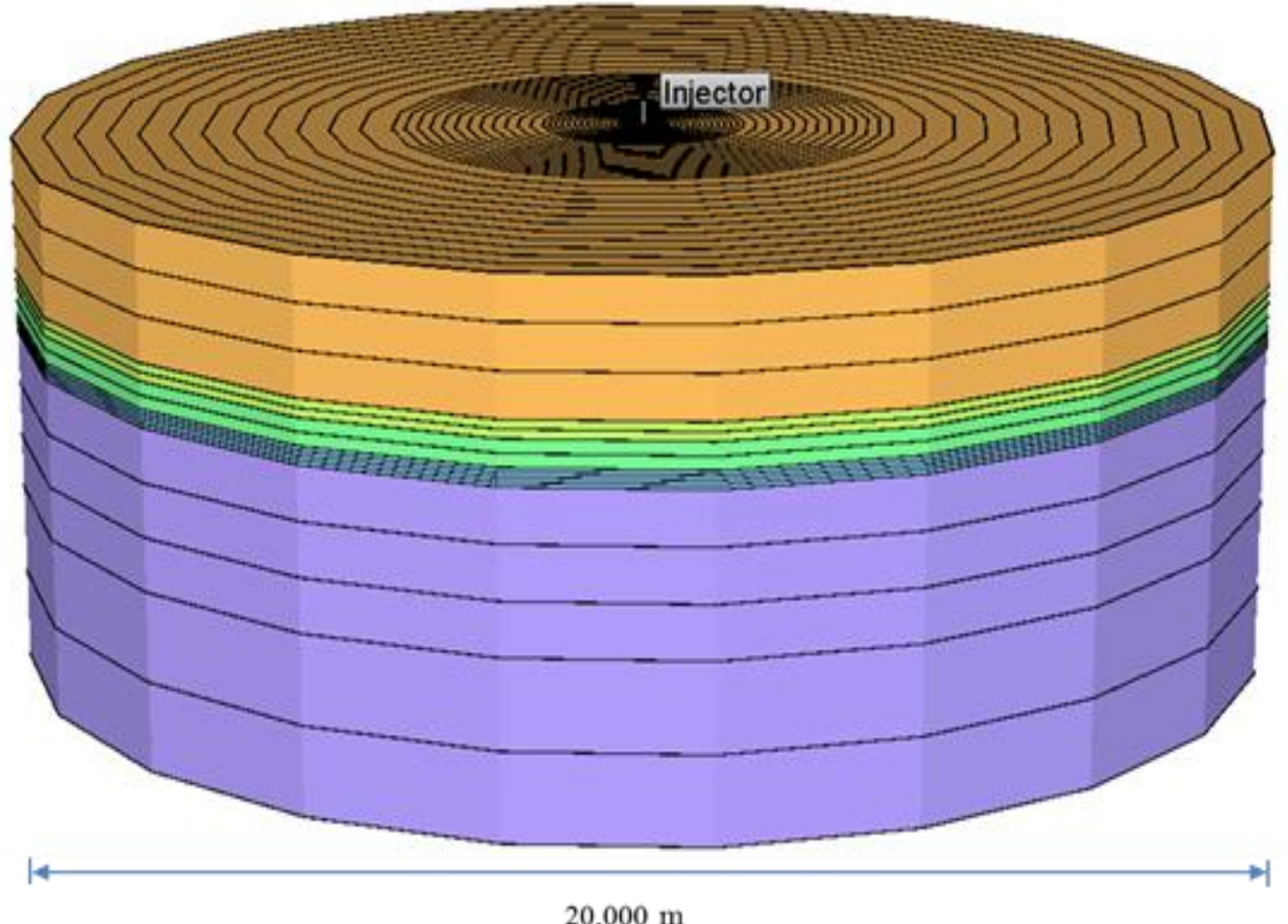

(b) Three - dimensional view

Figure 4.13: Geometry of axisymmetric, coupled multi-phase fluid flow and geomechanical model 


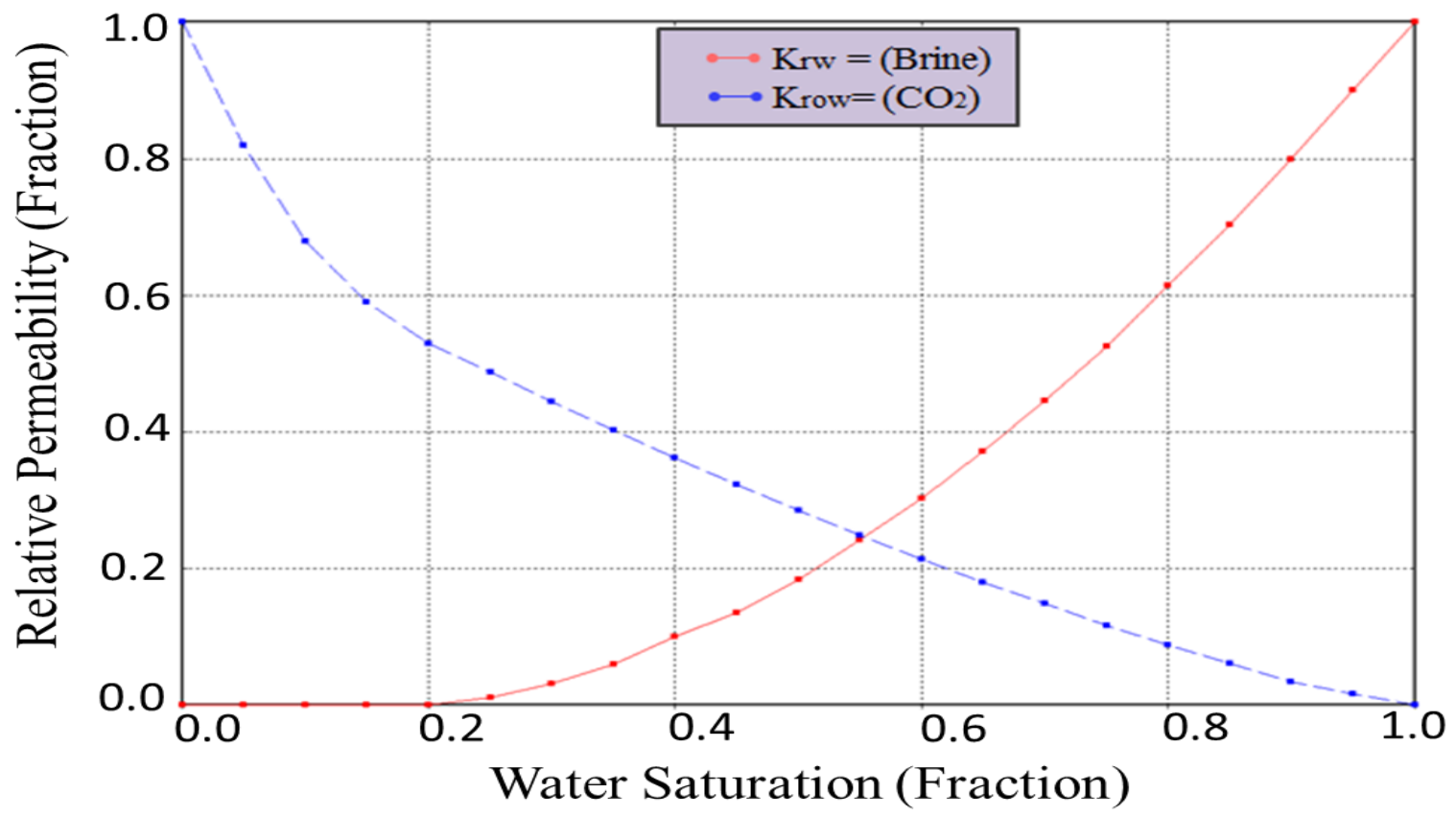

Note: Obtained from published literature (Bennion and Bachu, 2005; Siriwardane et al., 2013)

Figure 4.14: Relative permeability curves used in the study

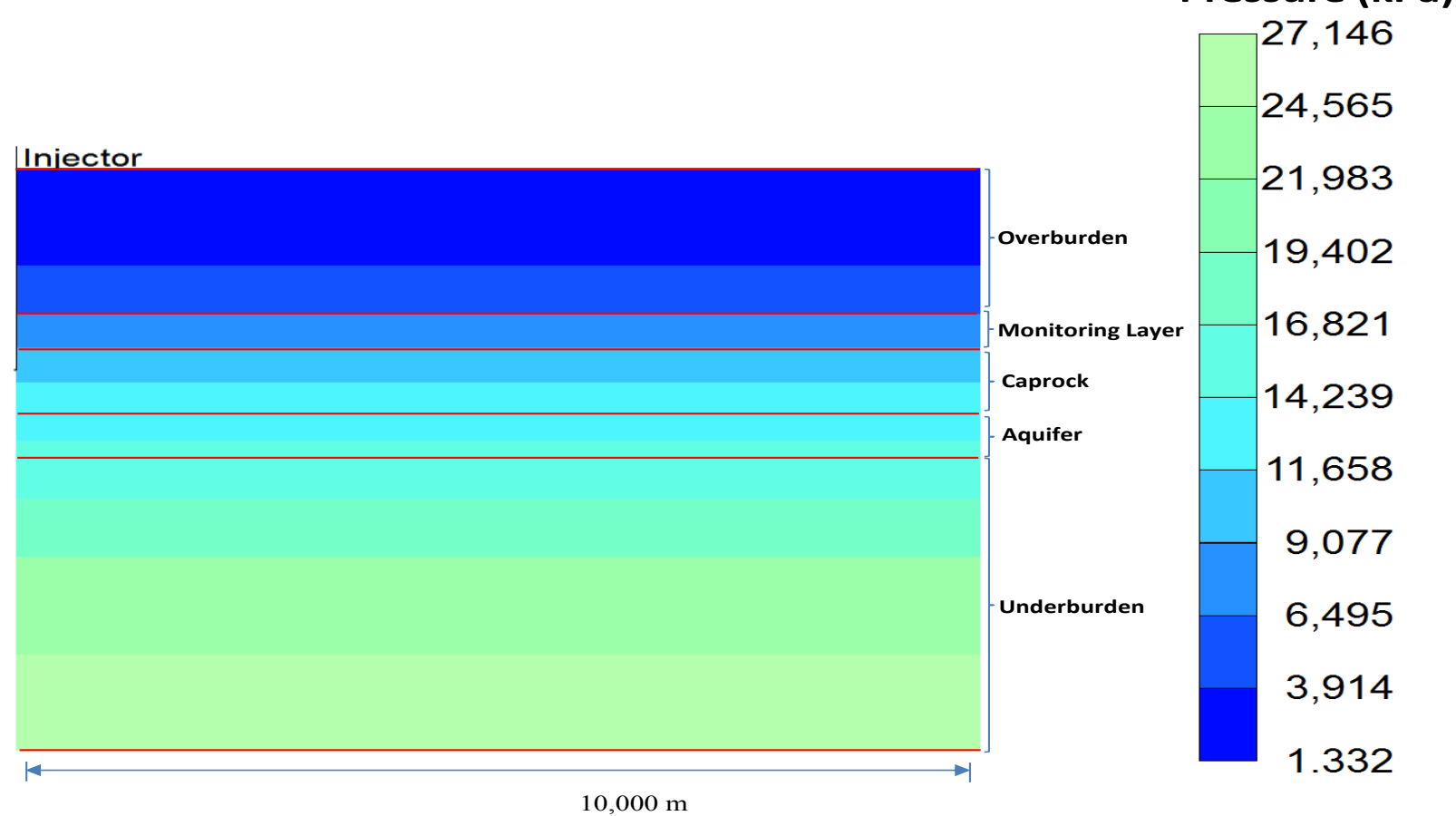

Pressure ( $\mathrm{kPa})$

Figure 4.15: Initial fluid pressure distribution $(\mathrm{kPa})$ by using an axisymmetric, coupled multiphase fluid flow and geomechanical model 


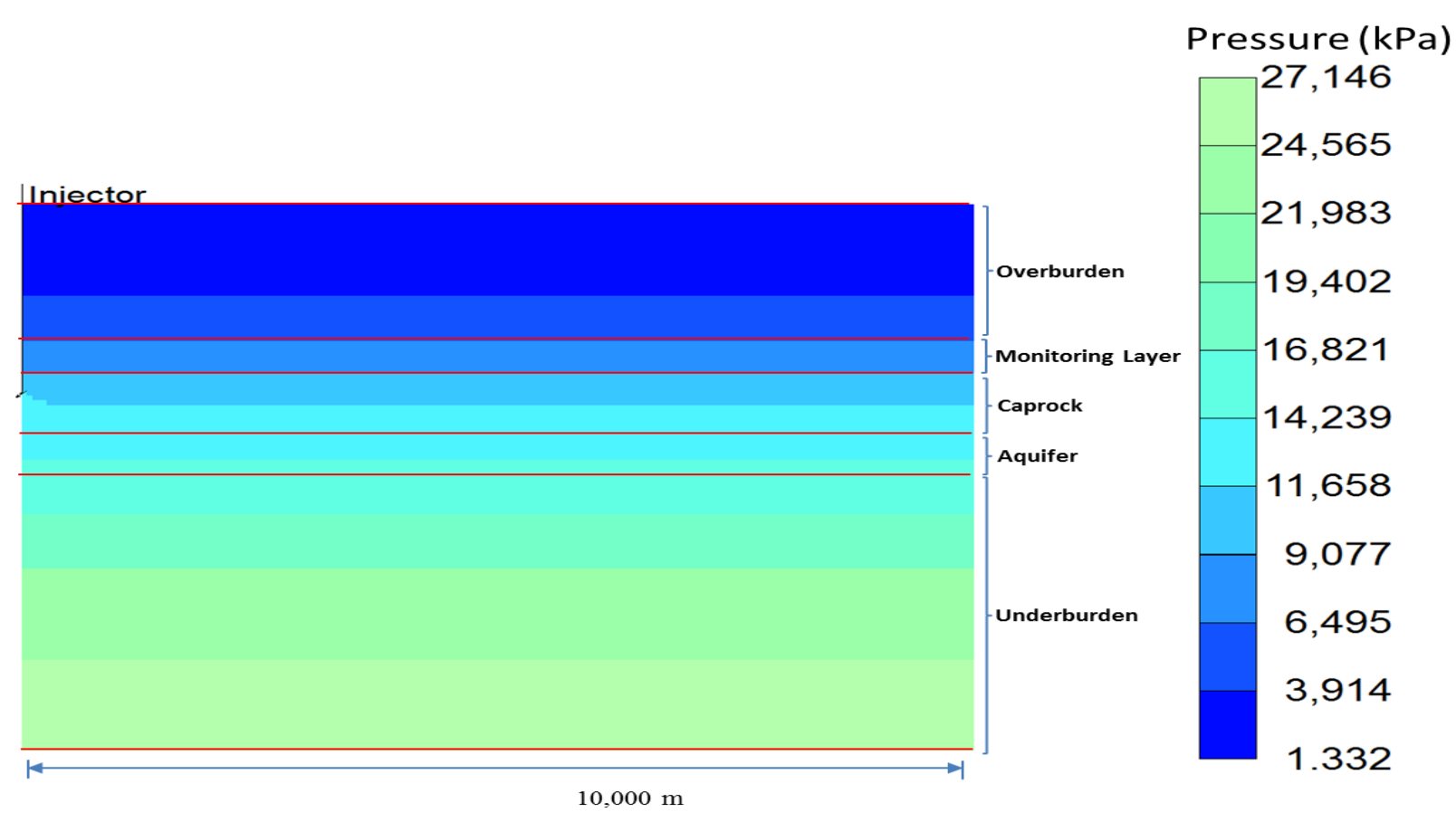

Figure 4.16: Computed fluid pressure distribution $(\mathrm{kPa})$ at the end of 5-year $\mathrm{CO}_{2}$ injection period by using an axisymmetric multi-phase flow and geomechanical model

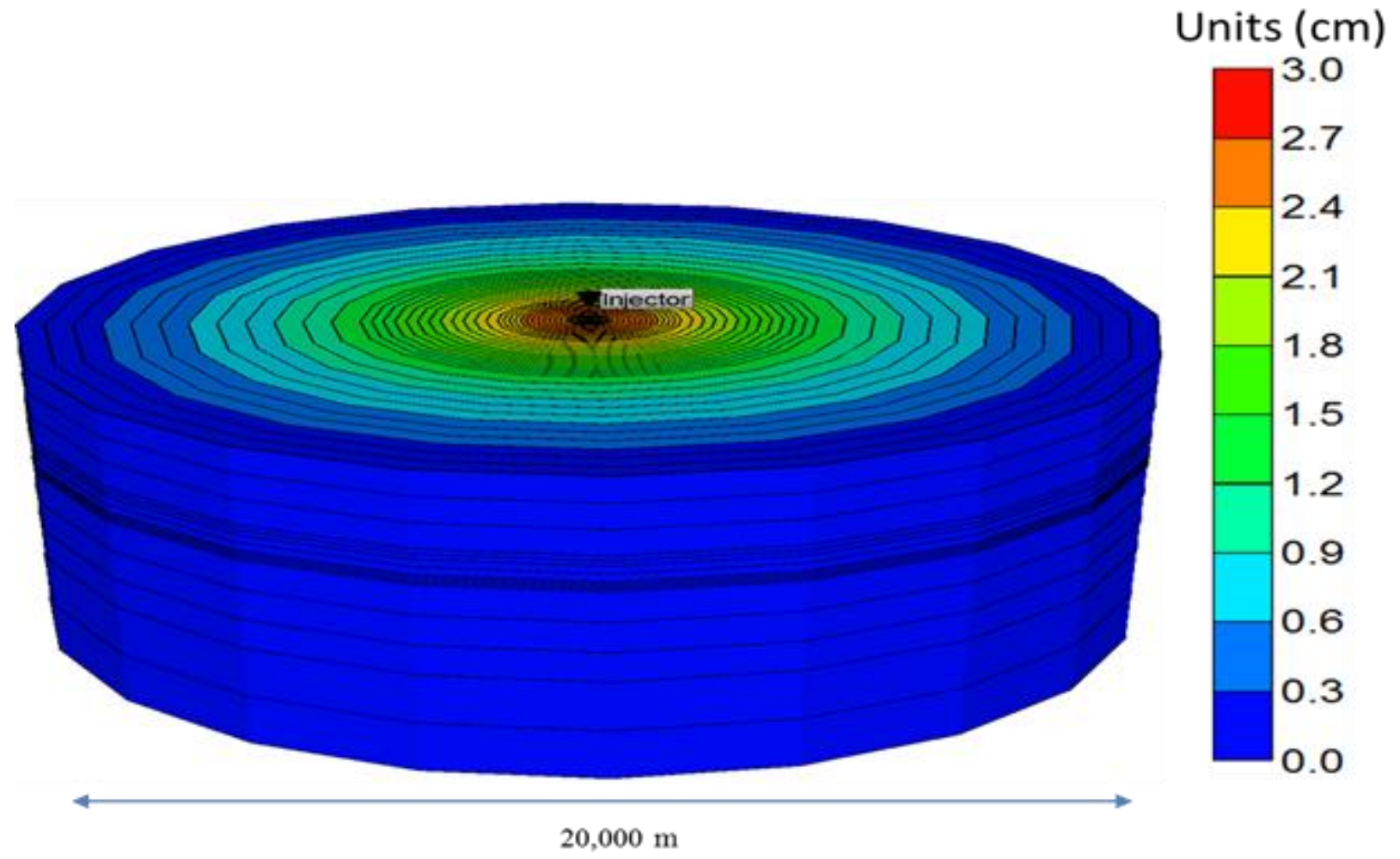

Figure 4.17: Computed vertical displacements $(\mathrm{cm})$ by using an axisymmetric multi-phase flow and geomechanical model 


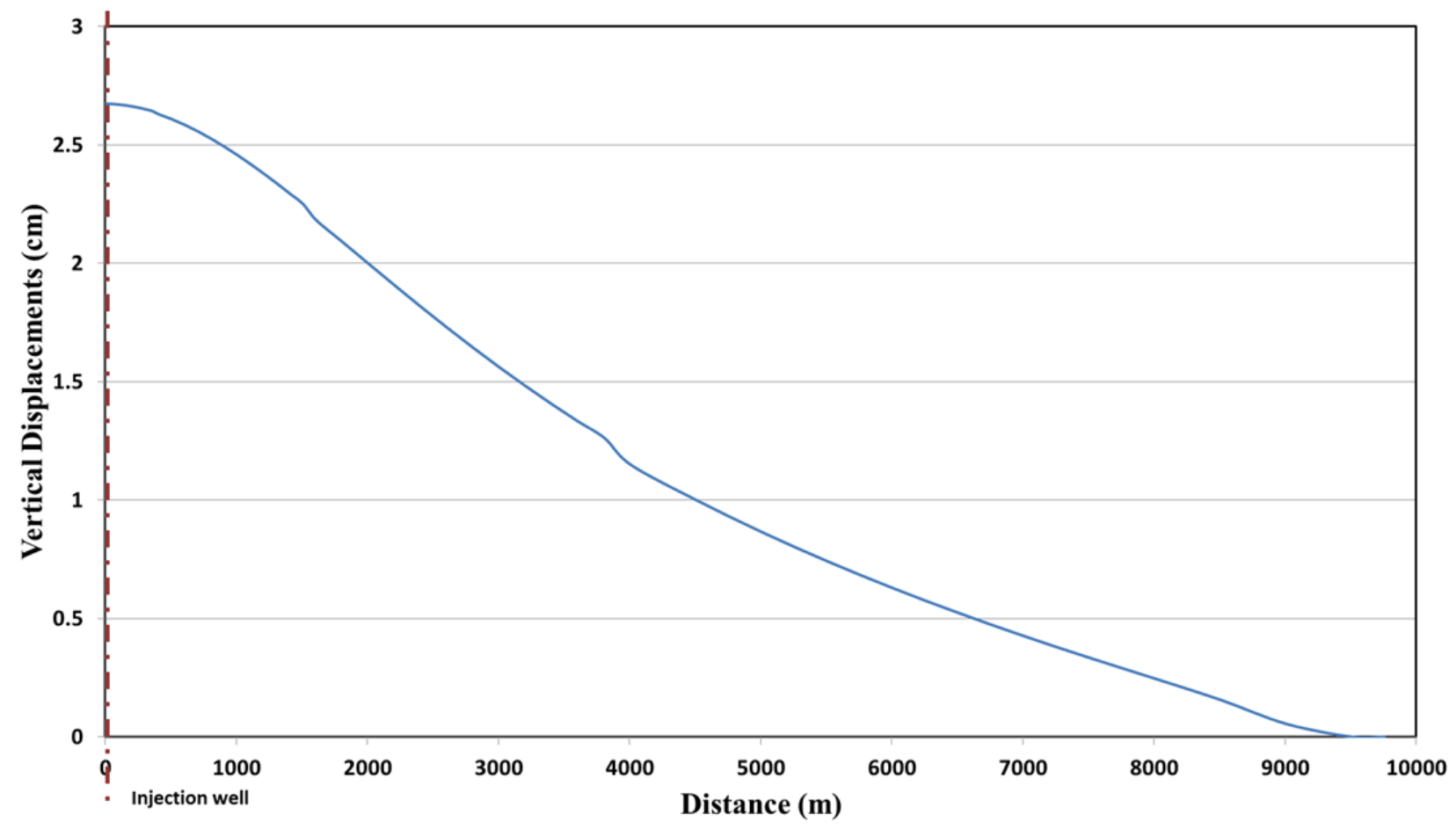

Figure 4.18: Computed vertical displacements by using an axisymmetric multi-phase flow and geomechanical model

\subsubsection{Three-dimensional modeling}

A three-dimensional model (with $89 \times 89 \times 16$ grid blocks) was constructed to perform multi-phase fluid flow and deformation analyses. The model was used to investigate the fluid pressure changes and overburden deformation behavior during large-scale $\mathrm{CO}_{2}$ injection. Similar to axisymmetric model, a refined grid block configuration was assumed near the injection zone. Figure 4.19 shows the model geometry. Table 4.1 shows the assumed material properties of the geologic layers. The boundary elements in the monitoring layer, caprock and reservoir layer were modified with large volume multipliers to model infinitely large extent of the reservoir. The $\mathrm{CO}_{2}$ injection was carried out at a depth of $1,050 \mathrm{~m}$ with a flow rate of 100,000 tonnes/year.

Figure 4.20 shows the initial fluid pressure distribution with an assumed fluid pressure gradient of $9.81 \mathrm{kPa} / \mathrm{m}(0.43 \mathrm{psi} / \mathrm{ft})$. Figure 4.21 show the changes in the fluid pressure at the end of 5-year $\mathrm{CO}_{2}$ injection period. Results show an increase in the fluid pressure near the injection region and surrounding geologic media. Figure 4.22 shows the vertical displacements caused due to $\mathrm{CO}_{2}$ injection. Figure 4.23 shows the vertical displacements plotted with lateral distance. The computed maximum vertical displacement was $2.62 \mathrm{~cm}$ after a 5 -year $\mathrm{CO}_{2}$ injection period. 


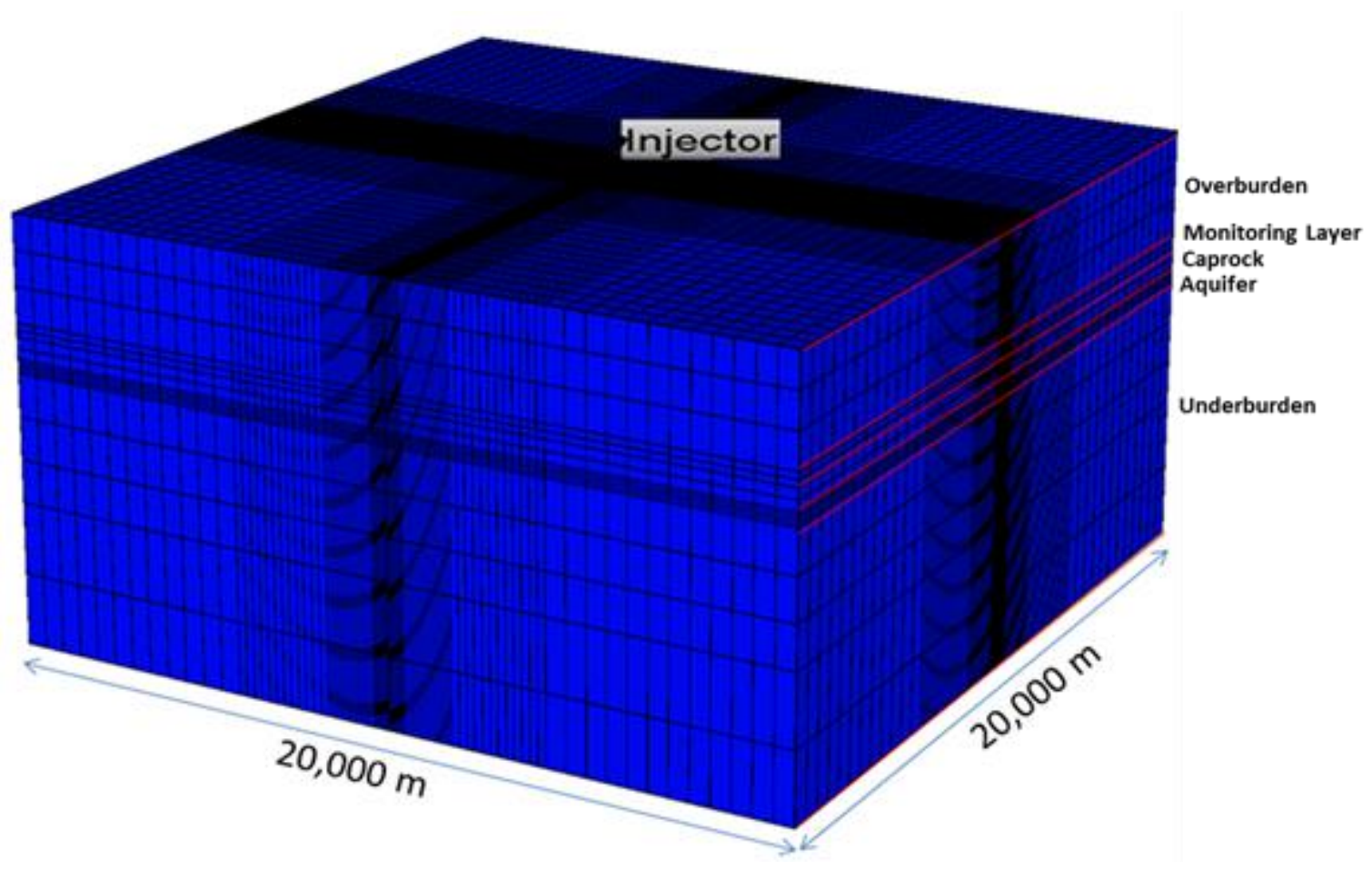

Figure 4.19: Three-dimensional fluid flow for multi-phase flow and geomechanical model

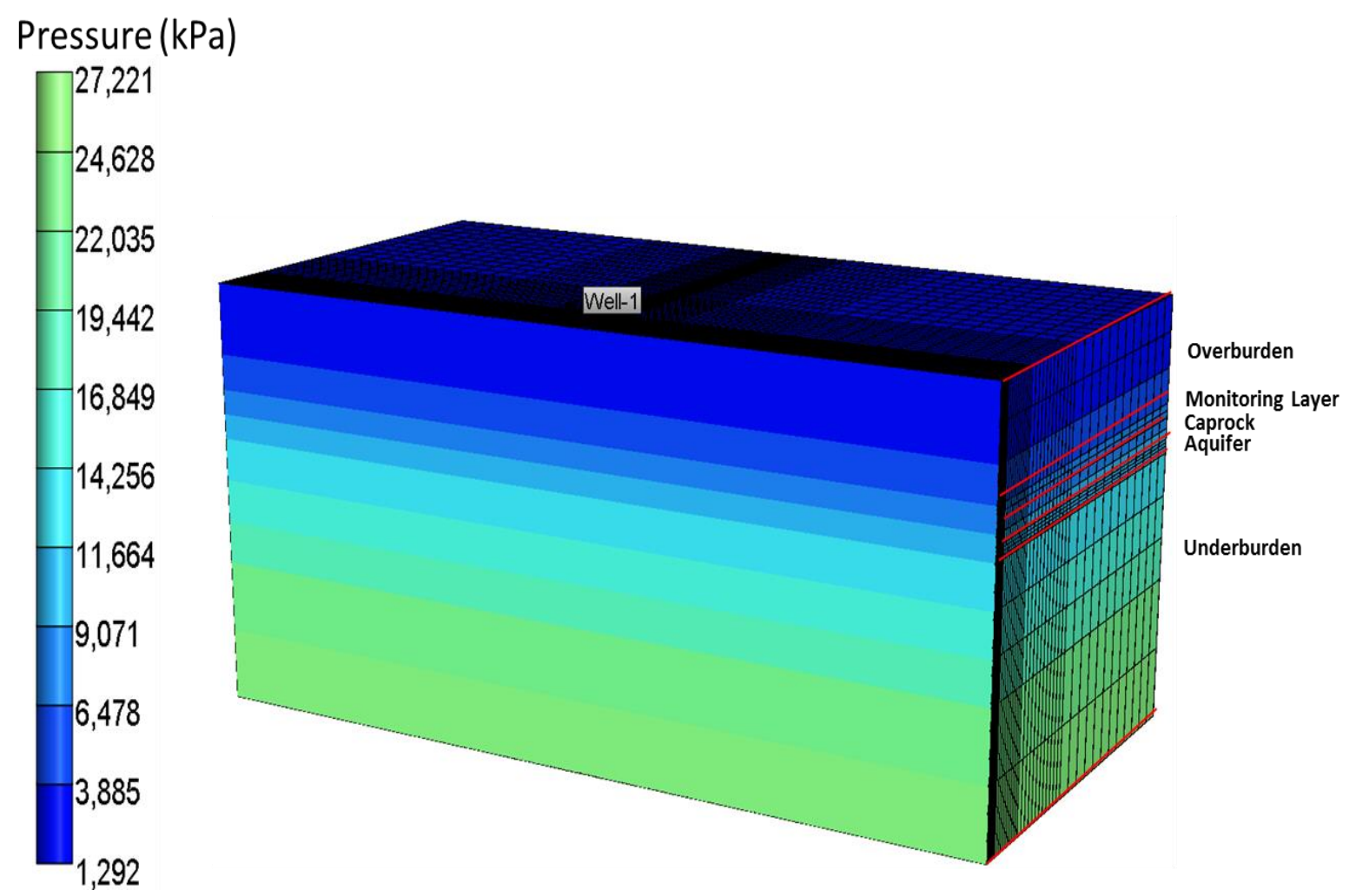

Figure 4.20: Initial fluid pressure distribution (kPa) by using a 3-D multi-phase flow and geomechanical model 


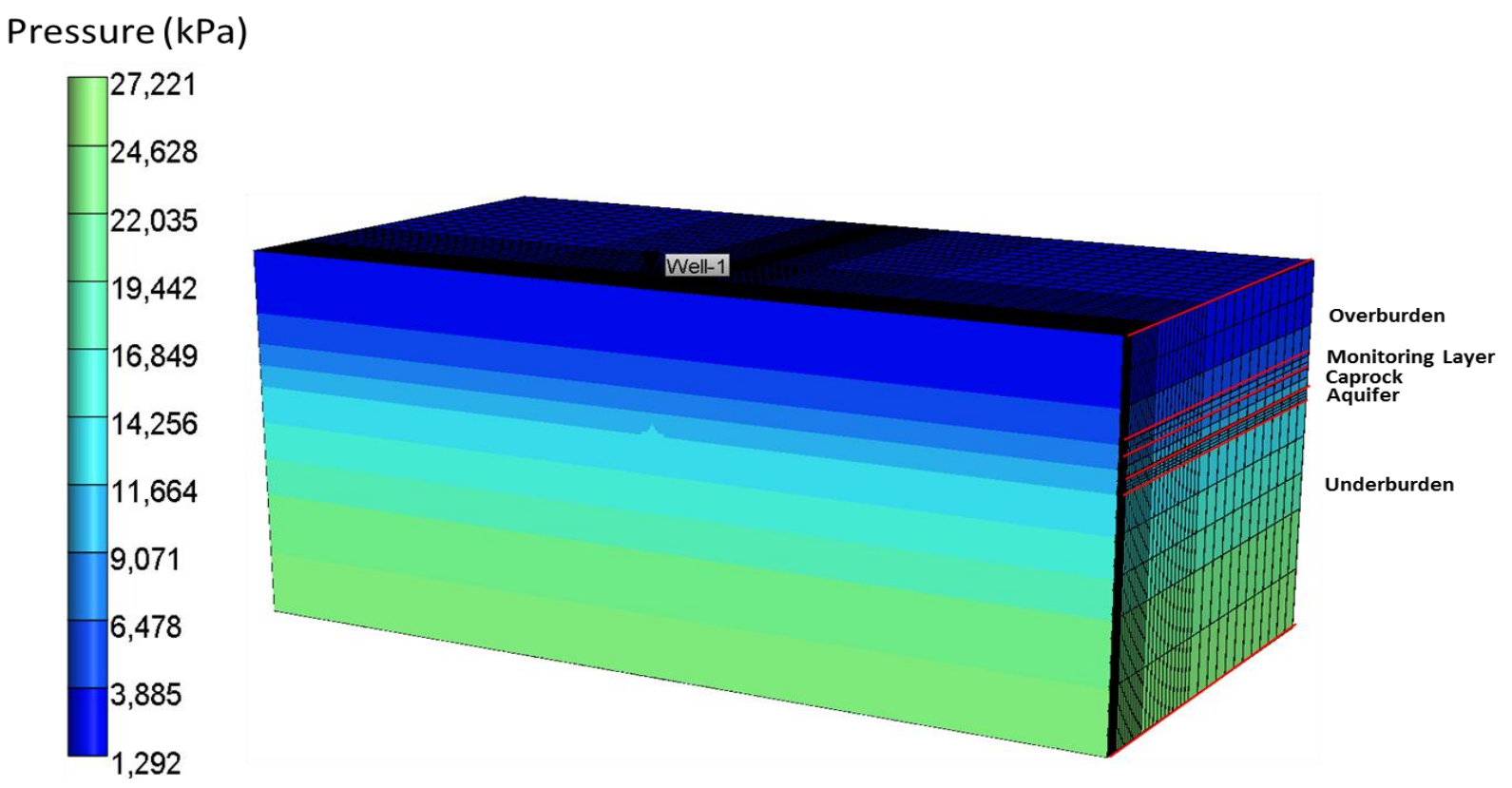

Figure 4.21: Computed fluid pressure distribution $(\mathrm{kPa})$ at the end of 5 years by using a 3-D multi-phase flow and geomechanical model

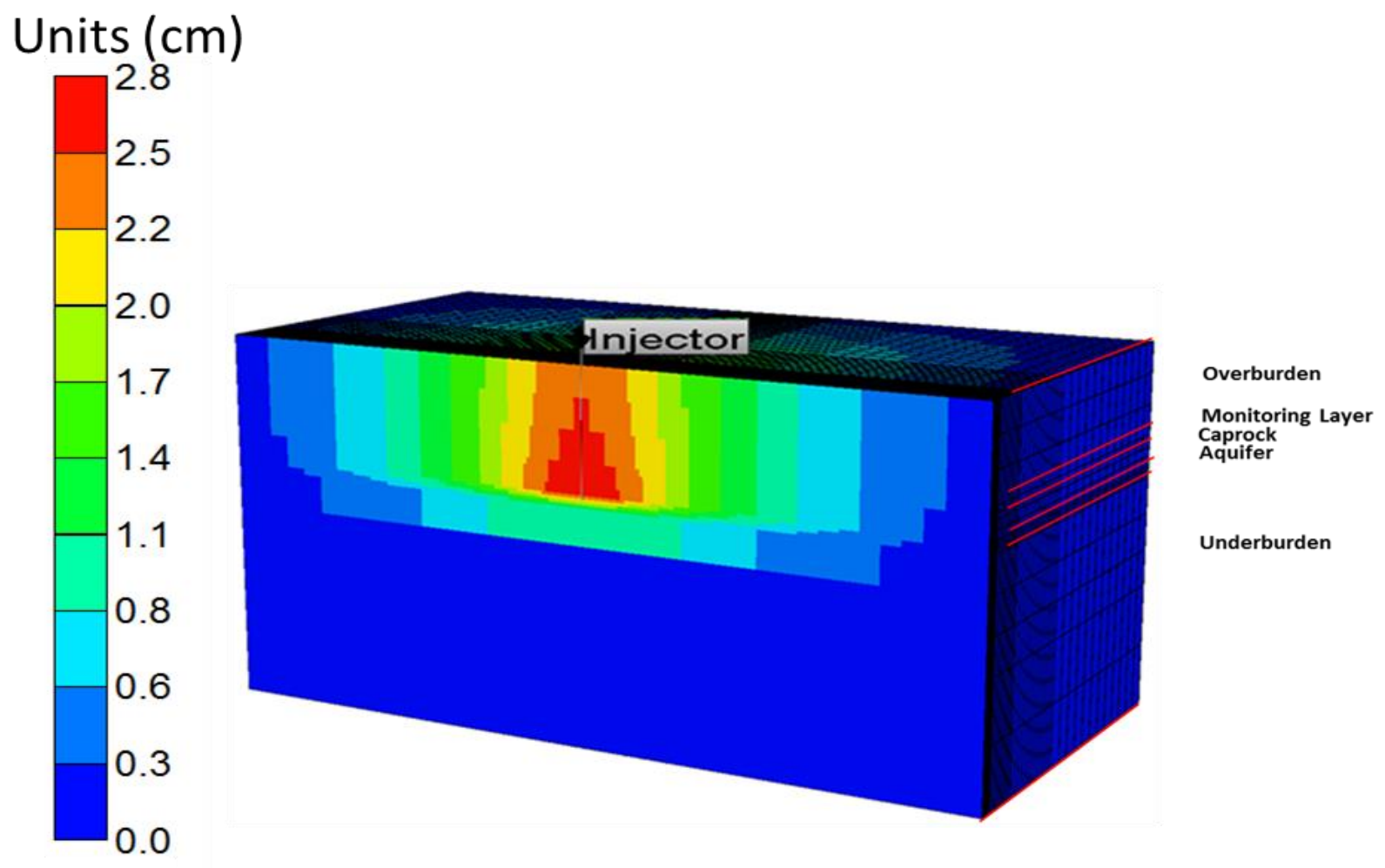

Figure 4.22: Computed vertical displacements $(\mathrm{cm})$ by using a 3-D multiphase flow and geomechanical model 


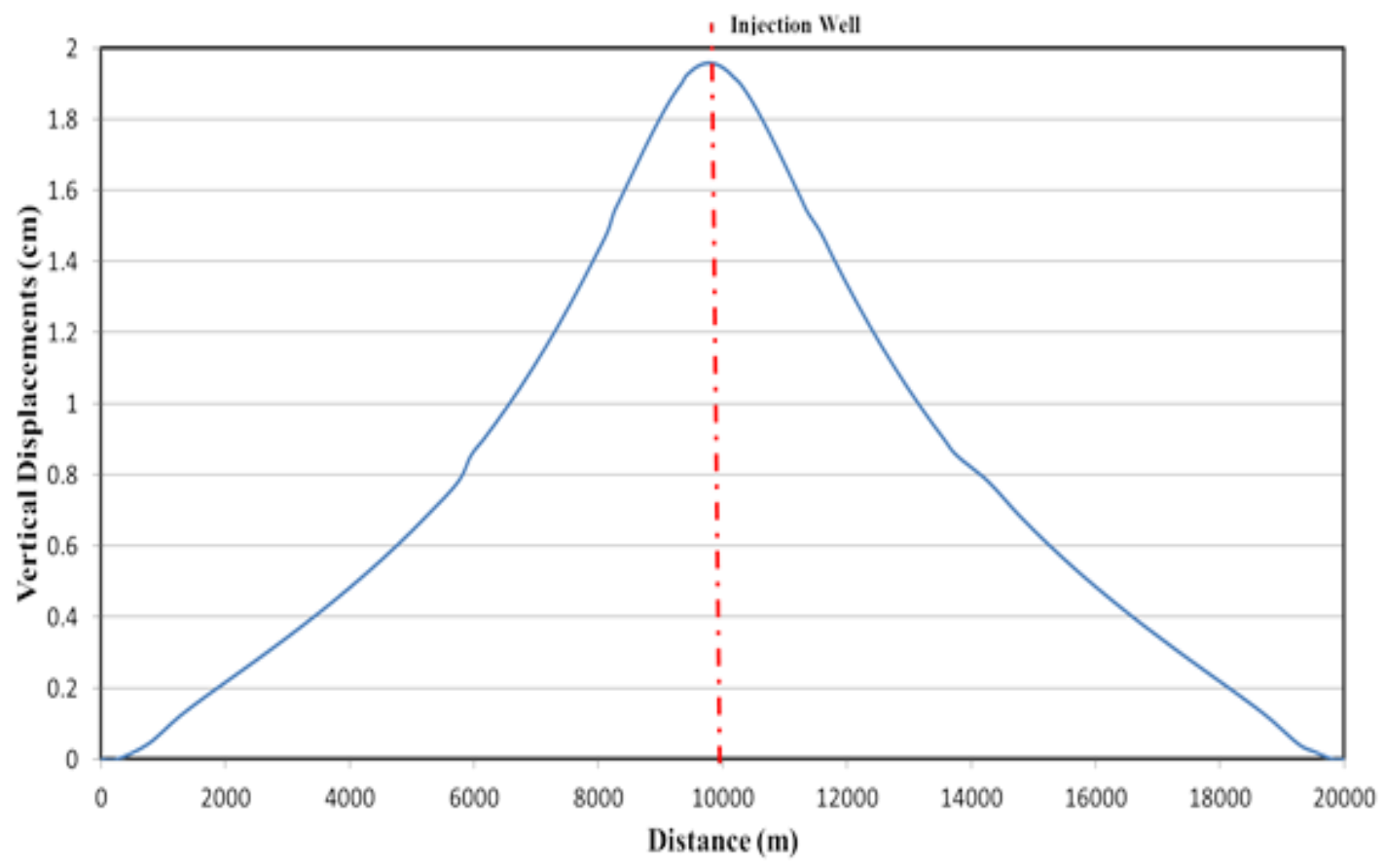

Figure 4.23: Computed vertical displacements by using a 3-D multiphase flow and geomechanical model

\subsection{Comparison of single-phase and multi-phase fluid flow models coupled with geomechanics}

. The maximum computed uplift was about $2.62 \mathrm{~cm}$ for the multi-phase fluid flow model (for both, axisymmetric and 3-D model) and $1.9 \mathrm{~cm}$ for the single-phase fluid flow (for both axisymmetric and 3-D model. In the single-phase fluid flow model, the amount of fluid injected was low because of the high viscosity of water compared to $\mathrm{CO}_{2}$ (Siriwardane et al., 2013). In the case of multi-phase fluid flow, the volume of $\mathrm{CO}_{2}$ is significantly larger (approximately 5 times more) because of the low viscosity of $\mathrm{CO}_{2}$ (Siriwardane et al., 2013). Therefore, displacements are higher in multi-phase compared to single- phase models. Table 4.2 shows a comparison of computed ground displacements $(\mathrm{cm})$ for the axisymmetric and the threedimensional models for single-phase and multi-phase fluid flow coupled with geomechanics. Modeling results show same magnitudes of ground displacements in the case of axisymmetric and three-dimensional models considered in this study. 
Table 4.2: Comparison of ground displacements

\begin{tabular}{|c|c|c|}
\hline & Axisymmetric Model & Three-Dimensional Model \\
\hline Flow rate (tonnes/year) & 100,000 & 100,000 \\
\hline $\begin{array}{c}\text { Ground displacements- } \\
\text { Coupled multi-phase fluid } \\
\text { flow and geomechanical } \\
\text { model (cm) }\end{array}$ & 2.62 & 2.62 \\
\hline $\begin{array}{c}\text { Ground displacements- } \\
\text { Coupled single-phase fluid } \\
\text { flow and geomechanical } \\
\text { model (cm) }\end{array}$ & 1.9 & 1.9 \\
\hline
\end{tabular}

\subsection{Geomechanical modeling of rock failure caused due to $\mathrm{CO}_{2}$ injection}

Computer Modeling Group's GEM simulator (CMG, 2012) was used in the study presented in this section. A three-dimensional and an axisymmetric model were constructed to investigate the rock failure due to $\mathrm{CO}_{2}$ injection. A Mohr-Coulomb failure criterion was used in this study to determine the extent of rock failure. The $\mathrm{CO}_{2}$ injection was carried out at a depth of $1,050 \mathrm{~m}$ with a pressure constraint of $10.3 \mathrm{MPa}(1,500 \mathrm{psi})$. The properties considered for these models are shown in the given Table 4.3. Figure 4.24 shows the plastic strains developed in 3-D model and Figure 4.25 shows the cumulative $\mathrm{CO}_{2}$ injection volume. Figure 4.26 shows the plastic strains developed in axisymmetric model and Figure 4.27 cumulative $\mathrm{CO}_{2}$ injection volume. From the results it shows that the magnitudes of plastic strains in 3-D model are less compared to the axisymmetric model. 
Table 4.3: Geomechanical properties used in this section

\begin{tabular}{|c|c|c|c|c|c|}
\hline Material/Property & Overburden & $\begin{array}{c}\text { Monitoring } \\
\text { Layer }\end{array}$ & Caprock & Aquifer & Underburden \\
\hline $\begin{array}{c}\text { Young's modulus, E } \\
\text { (kPa) }\end{array}$ & $5.00 \mathrm{E}+06$ & $5.00 \mathrm{E}+06$ & $5.00 \mathrm{E}+06$ & $5.00 \mathrm{E}+06$ & $5.00 \mathrm{E}+06$ \\
\hline $\begin{array}{c}\text { Rock compressibility } \\
\text { (1/kPa) }\end{array}$ & $2.40 \mathrm{E}-09$ & $2.40 \mathrm{E}-09$ & $2.40 \mathrm{E}-09$ & $2.40 \mathrm{E}-09$ & $2.40 \mathrm{E}-09$ \\
\hline $\begin{array}{c}\text { Poisson's ratio, v } \\
\text { Porosity,n }\end{array}$ & 0.25 & 0.25 & 0.25 & 0.25 & 0.25 \\
\hline $\begin{array}{c}\text { Permeability, k (mD) } \\
\text { (m) }\end{array}$ & 0.0001 & 100 & $1.00 \mathrm{E}-06$ & 500 & 0.0001 \\
\hline $\begin{array}{c}\text { Cohesion, (kPa) } \\
\mathbf{c}\end{array}$ & $5.00 \mathrm{E}+05$ & $5.00 \mathrm{E}+05$ & $5.00 \mathrm{E}+05$ & $5.00 \mathrm{E}+05$ & $5.00 \mathrm{E}+05$ \\
\hline $\begin{array}{c}\text { Angle of Friction, } \\
\text { (degrees) }\end{array}$ & 30 & $20-30$ & $20-30$ & $20-30$ & 30 \\
\hline
\end{tabular}




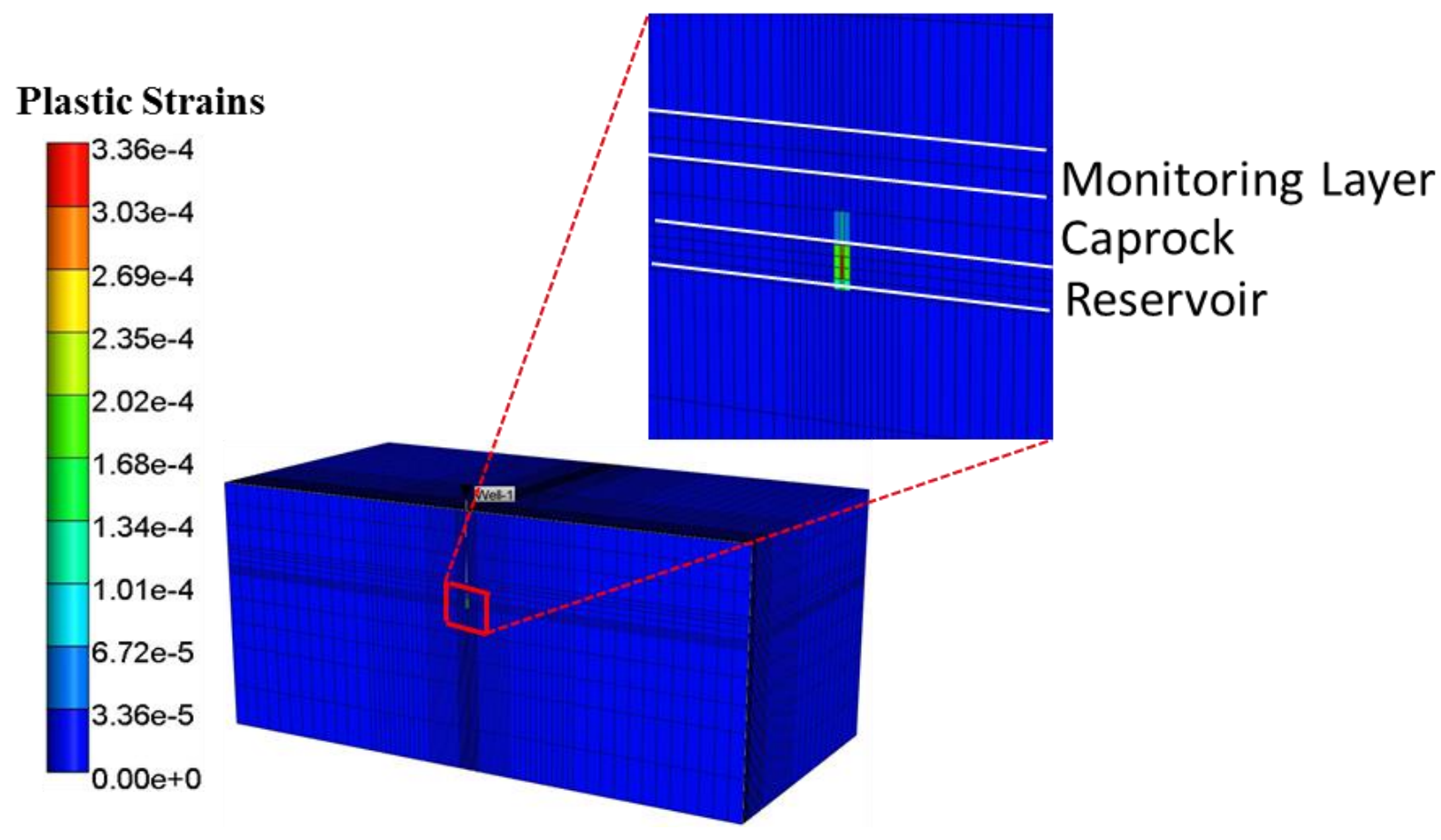

Figure 4.24: Effective plastic strains in 3-D model

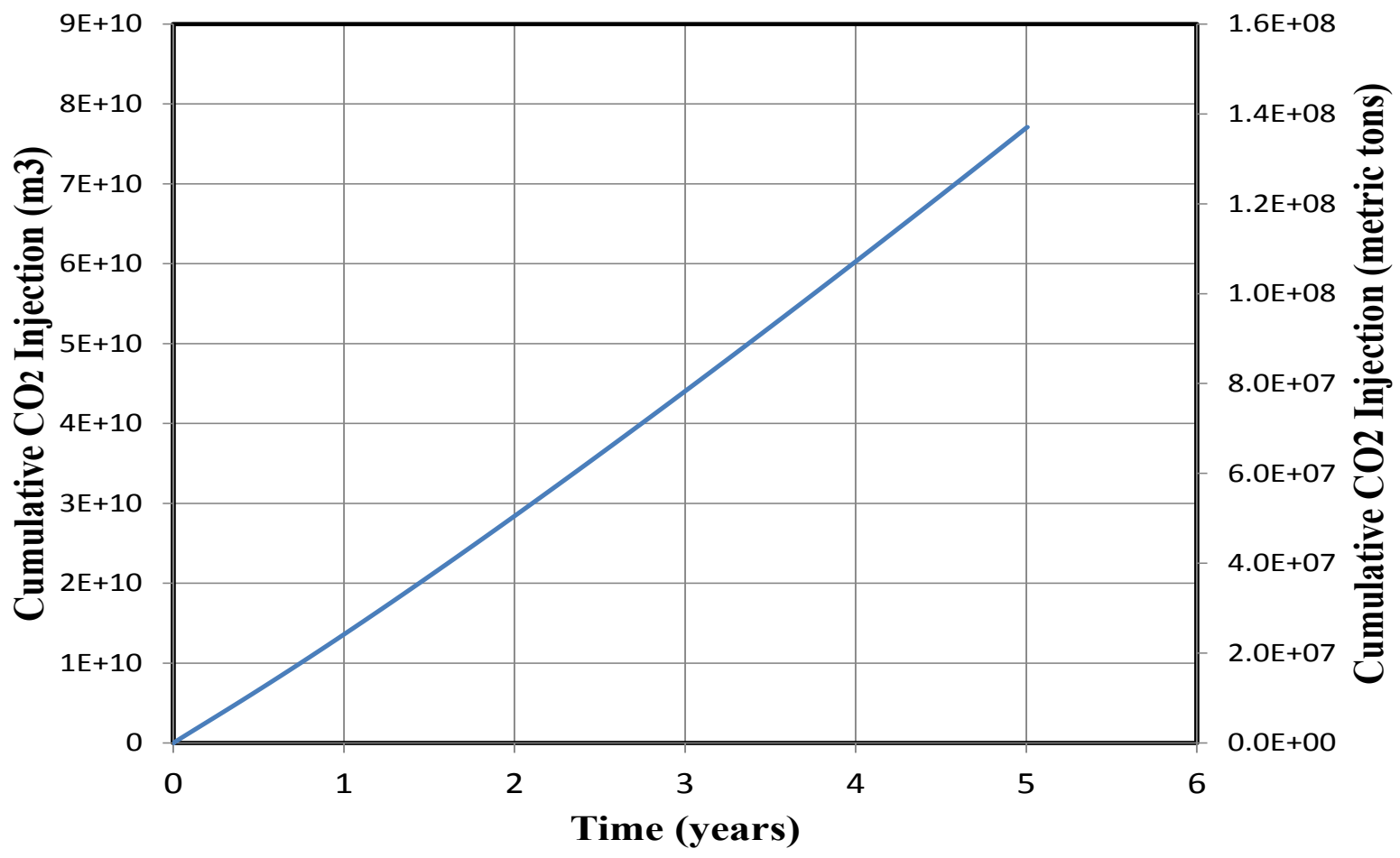

Figure 4.25 : Cumulative injection volume after 5 years of $\mathrm{CO}_{2}$ injection in 3-D model 


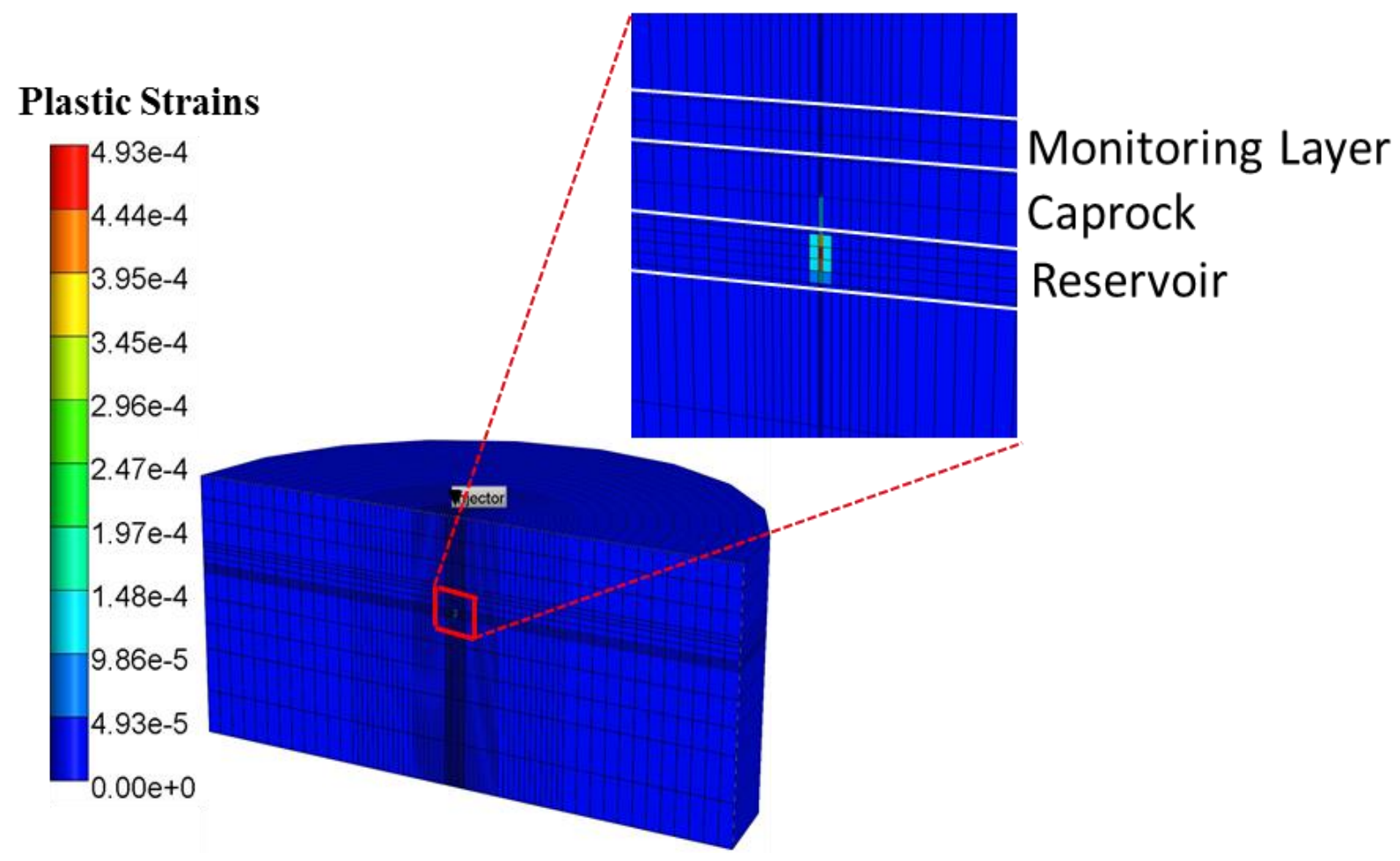

Figure 4.26: Effective plastic strains in axisymmetric model

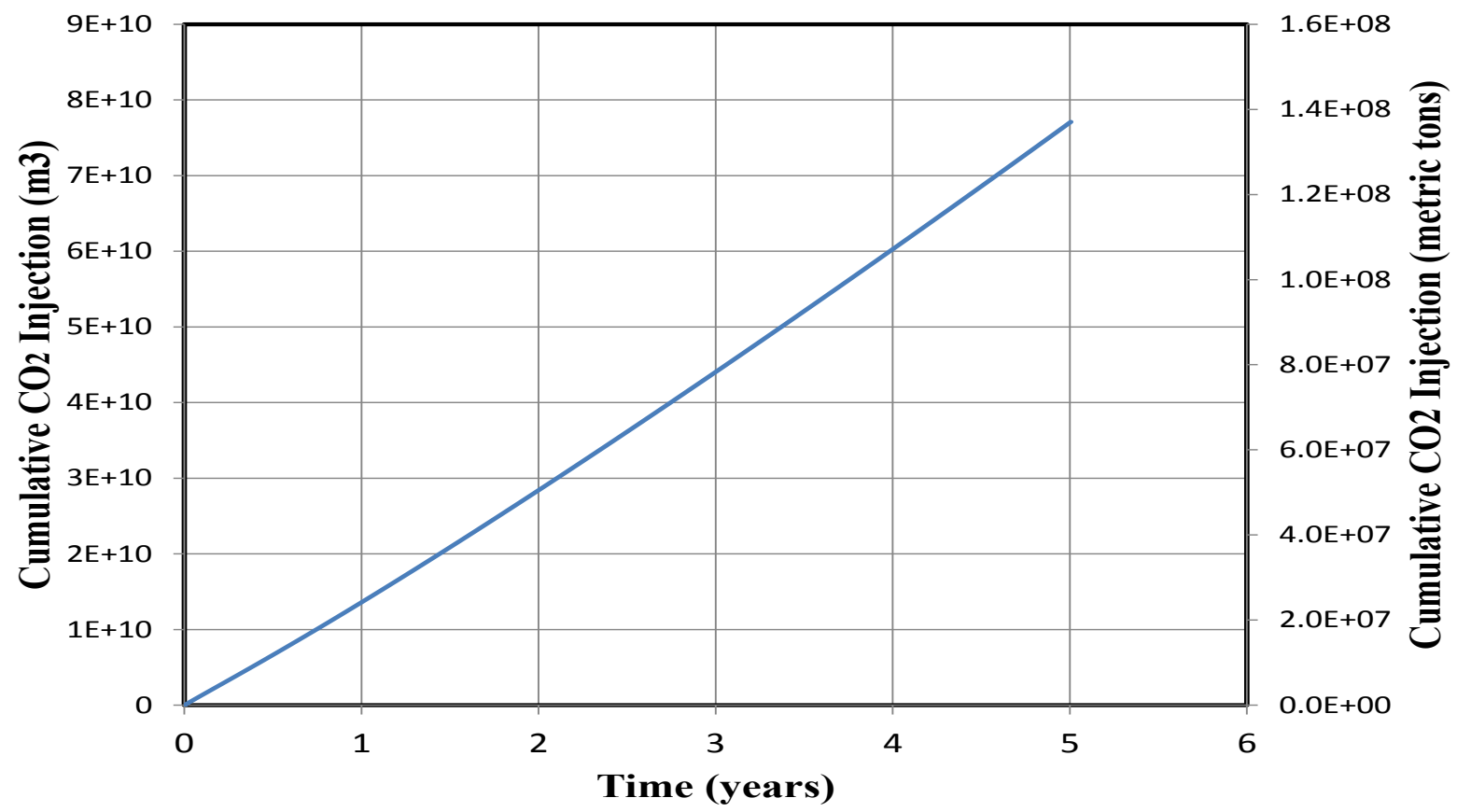

Figure 4.27: Cumulative injection volume after 5 years of $\mathrm{CO}_{2}$ injection in axisymmetric model. 


\section{CHAPTER 5 : GEOMECHANICAL MODELING OF CAPROCK SEAL FAILURE}

\subsection{Introduction}

Tight, impermeable caprock layers above the reservoir physically trap injected $\mathrm{CO}_{2}$ and allow it to store in the geologic formation for long-periods of time. However, mechanical seal failure of caprock layer due to $\mathrm{CO}_{2}$ injection may lead to geomechanical instability, lose caprock integrity and storage risks. A caprock fracture or activation of a dormant existing fault due to $\mathrm{CO}_{2}$ injection could result in potential $\mathrm{CO}_{2}$ leakage and increase storage risks. Previous studies have indicated that the presence of faults or fracture could lead to dissipation of injected fluid or gases, and influence the overburden properties such as rock porosity and permeability (Cappa and Rutqvist, 2011; Medina et al., 2011; Martinez et al., 2013; Streit and Hillis, 2004; Tran et al., 2009). When a fluid is injected, the reservoir pressure increases and fluid migrates through the permeable reservoir geologic medium. If the injection pressure or injection rate exceeds allowable fracture pressure of the overburden material, conditions such as activation of a caprock fracture or reactivation of previous existing faults may result in mechanical failure of the overburden material and leads to reduction of effectiveness of the caprock.

\subsection{Mohr-Coulomb Failure Criteria}

The Mohr-Coulomb failure criterion is a set of linear equations in principal stress space describing the conditions for which an isotropic material will fail, with any effect from the intermediate principal stress being neglected (ABAQUS, 2012; Desai and Siriwardane, 1984; Helwany, 2007). In the Mohr-Coulomb failure criterion, it is assumed that yield occurs when the

shear stresses exceed the shear strength of the material. Figure 5.1 shows a representation for Mohr-Coulomb yield model (ABAQUS, 2012). The Mohr circle does not touch the failure envelope if the shear stresses do not exceed the shear strength of the material. 


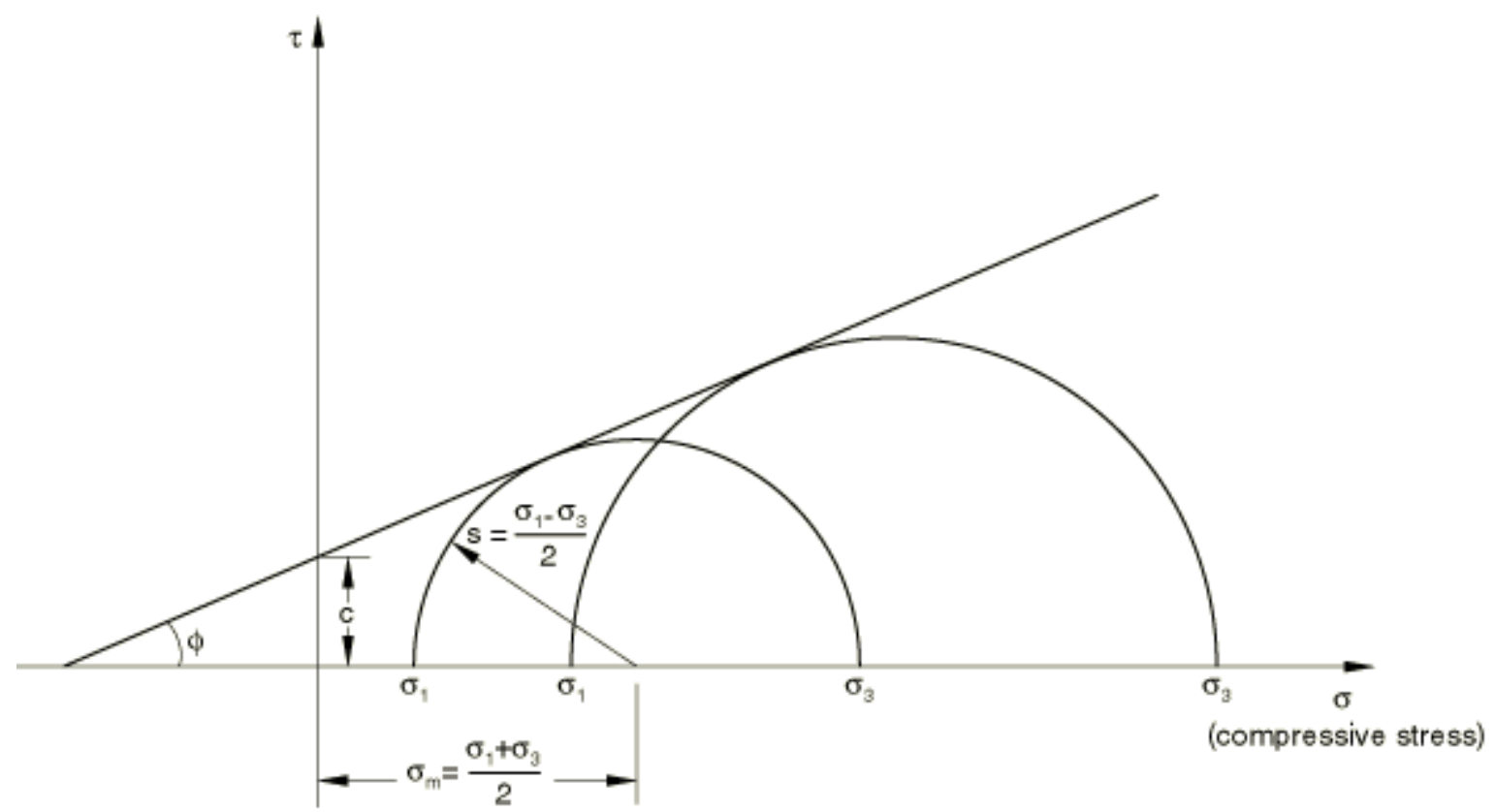

Note: This figure was obtained from the published literature: (ABAQUS, 2012)

Figure 5.1: Mohr-Coulomb yield model

According to the Mohr-Coulomb criterion, the shear strength $(\tau)$ increases with increasing normal stress $\left(\sigma_{n}\right)$ on the failure plane (Desai and Siriwardane, 1984; Helwany, 2007):

$$
\tau=c-\sigma_{n} \tan \phi
$$

In Equation 5.1, ' $\mathrm{c}$ ' is equal to the intercept on $\tau$-axis and $\phi$ is the angle which the envelope makes with $\sigma$-axis. The component, c of the shear strength is known as cohesion. Cohesion holds the particles of the soil together and is independent of the normal stress $\left(\sigma_{n}\right)$. The angle $\phi$ is called the angle of internal friction. It represents the frictional resistance between the particles, which is directly proportional to the normal stress, respectively (ABAQUS, 2012).

From Mohr's circle,

$$
\begin{gathered}
\tau=s \cos \phi \\
\sigma=\sigma_{m}+s \sin \phi
\end{gathered}
$$


Substituting for $\tau$ and $\sigma$, multiplying both sides by $\cos \phi$, and reducing, the Mohr-Coulomb model can be written as (ABAQUS, 2012; Desai and Siriwardane, 1984):

$$
\begin{gathered}
s+\sigma_{m} \sin \phi-c \cos \phi=0 \\
s=\frac{1}{2}\left(\sigma_{1}-\sigma_{3}\right)
\end{gathered}
$$

where $\mathrm{s}$ is the radius of the Mohr's circle and can be expressed as the half of the difference between the maximum principal stress, $\sigma_{1}$, and the minimum principal stress, $\sigma_{3}$ (and is, therefore, the maximum shear stress). Mean stress $\left(\sigma_{\mathrm{m}}\right)$ can be defined as the average of the maximum and minimum principal stresses as shown in Equation 5.6 (ABAQUS, 2012; Helwany, 2007; Desai and Siriwardane, 1984):

$$
\sigma_{m}=\frac{1}{2}\left(\sigma_{1}+\sigma_{3}\right)
$$

\subsection{Modeling Details to Investigate Caprock Seal Failure}

A two-dimensional coupled multi-phase flow and deformation model was constructed with grid block configuration of $65 \times 1 \times 22$ grid blocks as shown in Figure 5.2 using CMG simulator (CMG, 2012). A refined grid network was used near the injection zone and is also capable of modeling a fractured zone located 500m away from injection source. Coupled multiphase flow and geomechanical modeling was performed by injecting carbon dioxide $\left(\mathrm{CO}_{2}\right)$ into a water saturated reservoir by considering a hypothetical injection site (as shown in Figure 4.1). The lateral boundaries of the reservoir, caprock and monitoring layer were modified by using volume modifiers to model infinitely large extent of these layers. The $\mathrm{CO}_{2}$ injection was carried out with a vertical injection well at the center of target reservoir and with a differential pressure of $6.89 \mathrm{MPa}(1,000 \mathrm{psi})$ for five years. The material properties of the five layers used in the modeling study presented in this section are shown in Table 5.1. Geomechanical properties were assumed based on those reported in the published literature (Rutqvist et al., 2008; Siriwardane et al., 2013). This table is same as Table 4.1. Fluid pressure changes caused due to $\mathrm{CO}_{2}$ injection can be seen in Figure 5.3. Stress changes $(\mathrm{kPa})$ due to the injection were shown in Figure 5.4. 
Table 5.1: Reservoir and geomechanical properties used in this chapter

\begin{tabular}{|c|c|c|c|c|c|}
\hline Material Property & $\begin{array}{c}\text { Overburden } \\
\text { Layer }\end{array}$ & $\begin{array}{c}\text { Monitoring } \\
\text { Layer }\end{array}$ & $\begin{array}{c}\text { Caprock } \\
\text { Seal }\end{array}$ & Aquifer & $\begin{array}{c}\text { Underburden } \\
\text { Layer }\end{array}$ \\
\hline Layer Thickness (m) & 750 & 100 & 150 & 100 & 1900 \\
\hline Grid Top (m) & 0 & 750 & 850 & 1000 & 1100 \\
\hline Stress gradient (kPa/m) & 22.62 & 22.62 & 22.62 & 22.62 & 22.62 \\
\hline Elastic Modulus (kPa) & $5 \mathrm{E}+06$ & $5 \mathrm{E}+06$ & $5 \mathrm{E}+06$ & $5 \mathrm{E}+06$ & $5 \mathrm{E}+06$ \\
\hline $\begin{array}{c}\text { Poisson's Ratio } \\
\text { Permeability (mD) }\end{array}$ & 0.25 & 0.25 & 0.25 & 0.25 & 0.25 \\
\hline $\begin{array}{c}\text { Porosity (fraction) } \\
\text { Cohesion } \\
\mathbf{c}(\mathbf{k P a})\end{array}$ & 0.02 & 0.1 & 0.005 & 0.1 & 0.02 \\
\hline $\begin{array}{c}\text { Friction Angle } \\
\phi(d e g r e e s)\end{array}$ & 30 & 30 & 30 & 30 & 30 \\
\hline
\end{tabular}


Mohr's coulomb failure criterion was used to investigate rock failure during fluid injection. A parametric study was performed to determine the influence of cohesion value and angle of internal friction for development of plastic strains in the caprock. Figure 5.5 shows the plastic strains developed ( $\mathrm{c}=200 \mathrm{kPa}$ and $\phi=21.5^{\circ}$ in reservoir, caprock and monitoring layer) after 5 years of continuous $\mathrm{CO}_{2}$ injection. The lateral extent of the damage due to fluid injection in the reservoir was limited to the region around the injection well. Figure 5.6 shows the plastic strains developed $\left(\mathrm{c}=200 \mathrm{kPa}\right.$ and $\phi=21.5^{\circ}$ in caprock, monitoring layer and $\mathrm{c}=5000 \mathrm{kPa}$ and $\phi=21.5^{\circ}$ in reservoir) after 5 years of continuous $\mathrm{CO}_{2}$ injection. Results show that, as the compressive strength i.e., cohesion is higher in the reservoir compared to caprock, the reservoir withstands the changes in pore fluid pressure and whereas plastic strains were developed in caprock layer due to its smaller cohesion value.

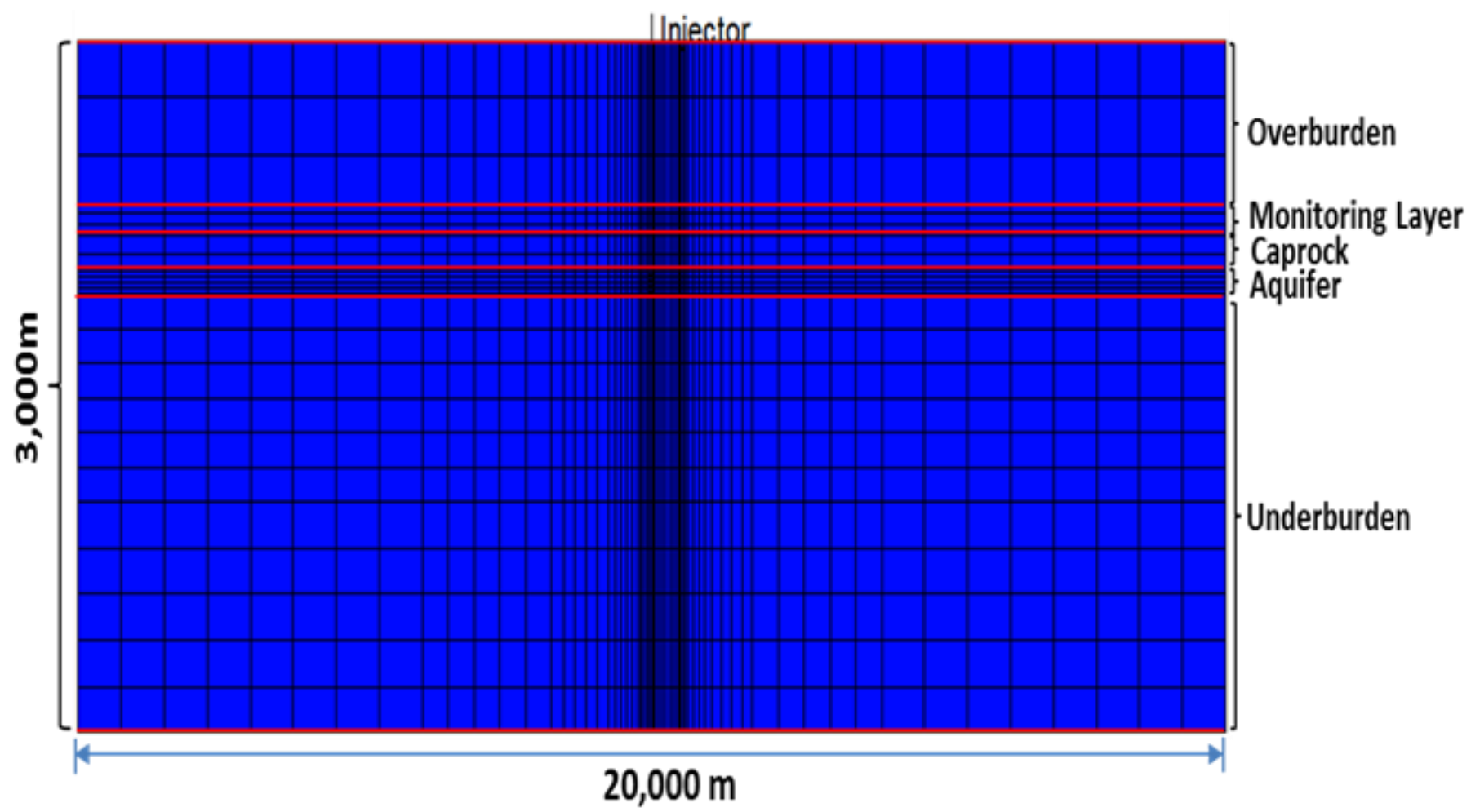

Figure 5.2: Model Geometry 
Pressure (kPa)

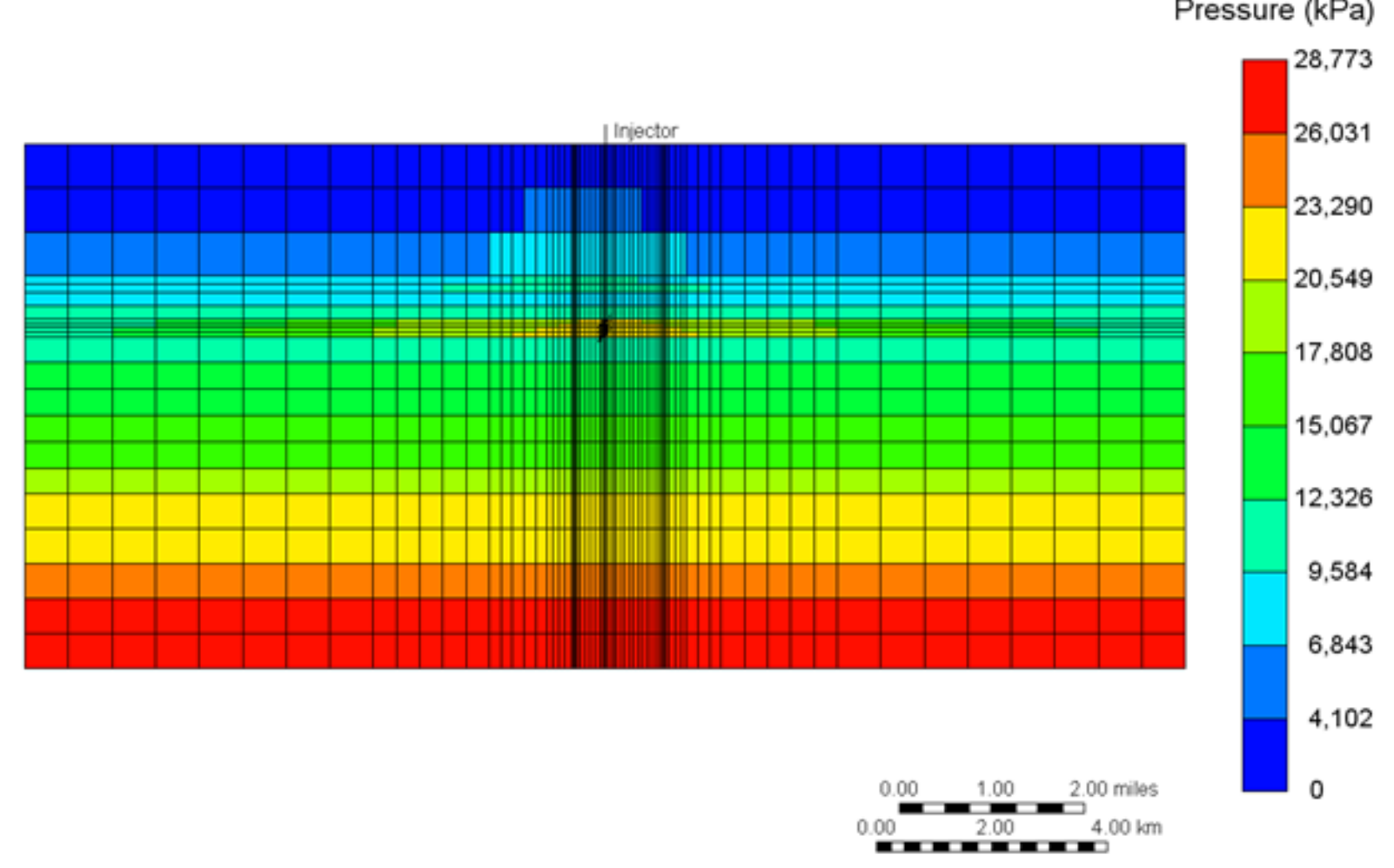

Figure 5.3: Fluid pressure distribution $(\mathrm{kPa})$ at the end of $\mathrm{CO}_{2}$ injection

Vertical Effective stress (kPa)

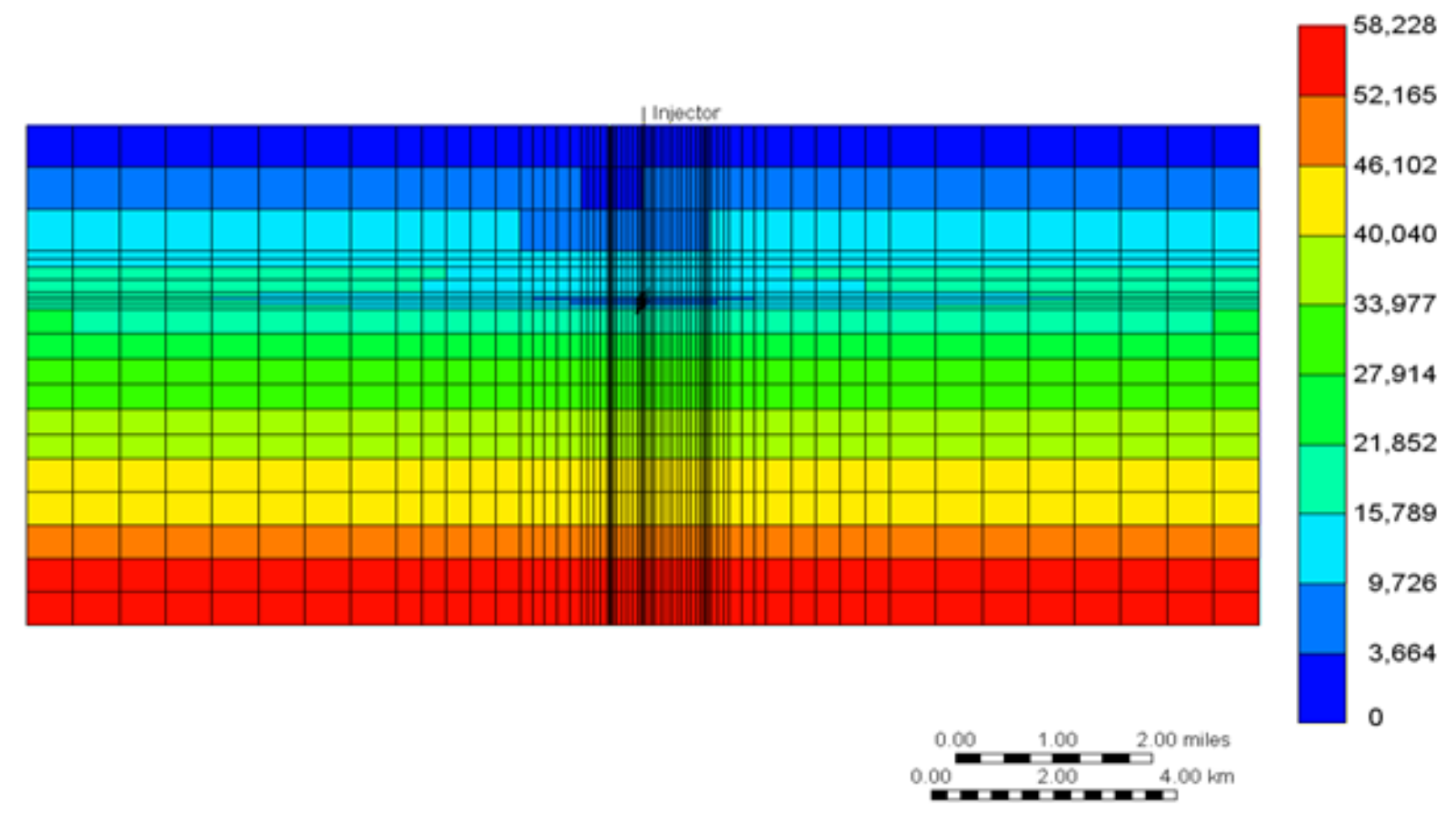

Figure 5.4: Vertical effective stress distribution $(\mathrm{kPa})$ at the end of $\mathrm{CO}_{2}$ injection 


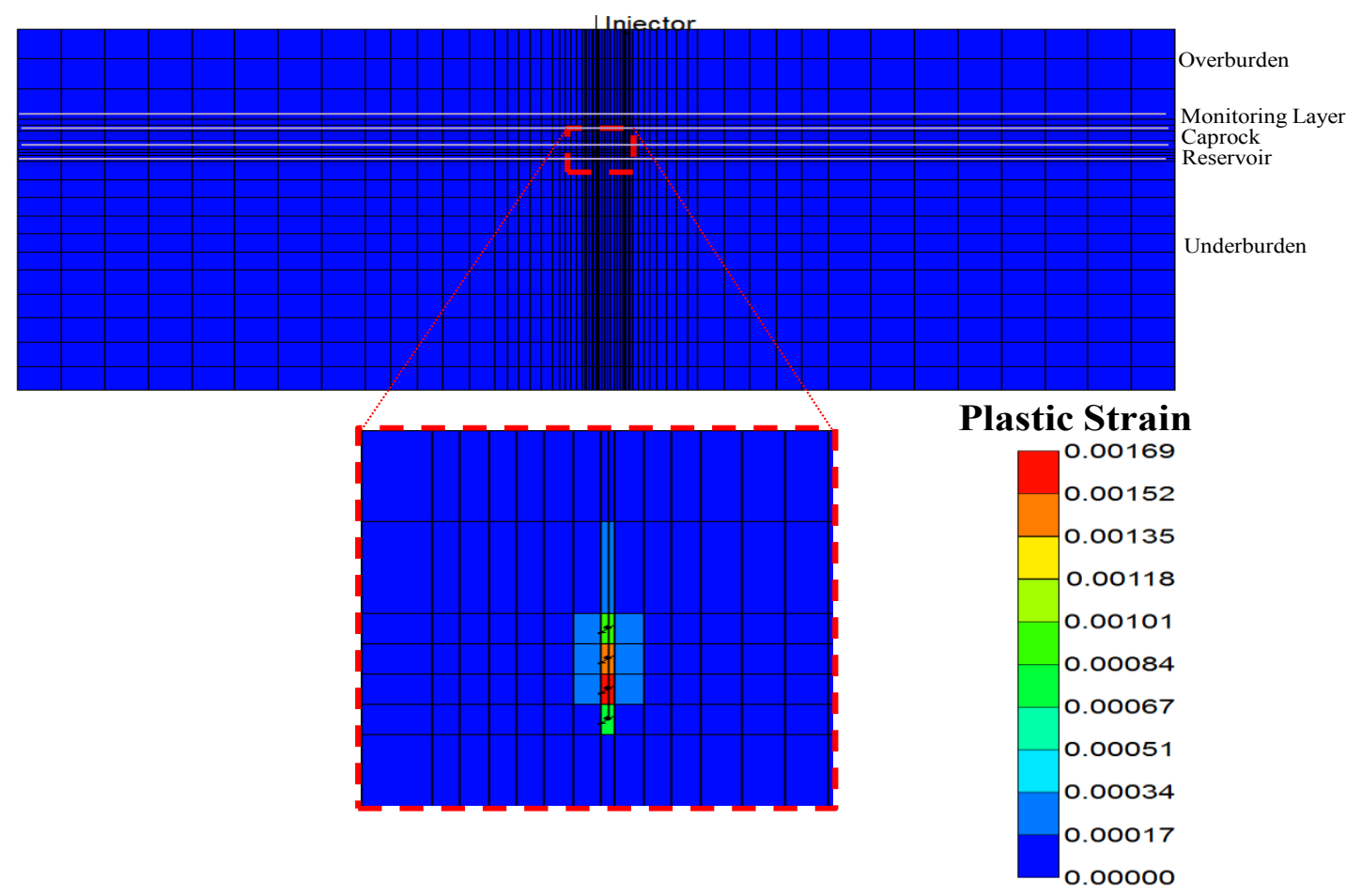

Figure 5.5: Plastic strains developed after 5 years of $\mathrm{CO}_{2}$ injection when $\mathrm{c}=200 \mathrm{kPa}$ in the reservoir

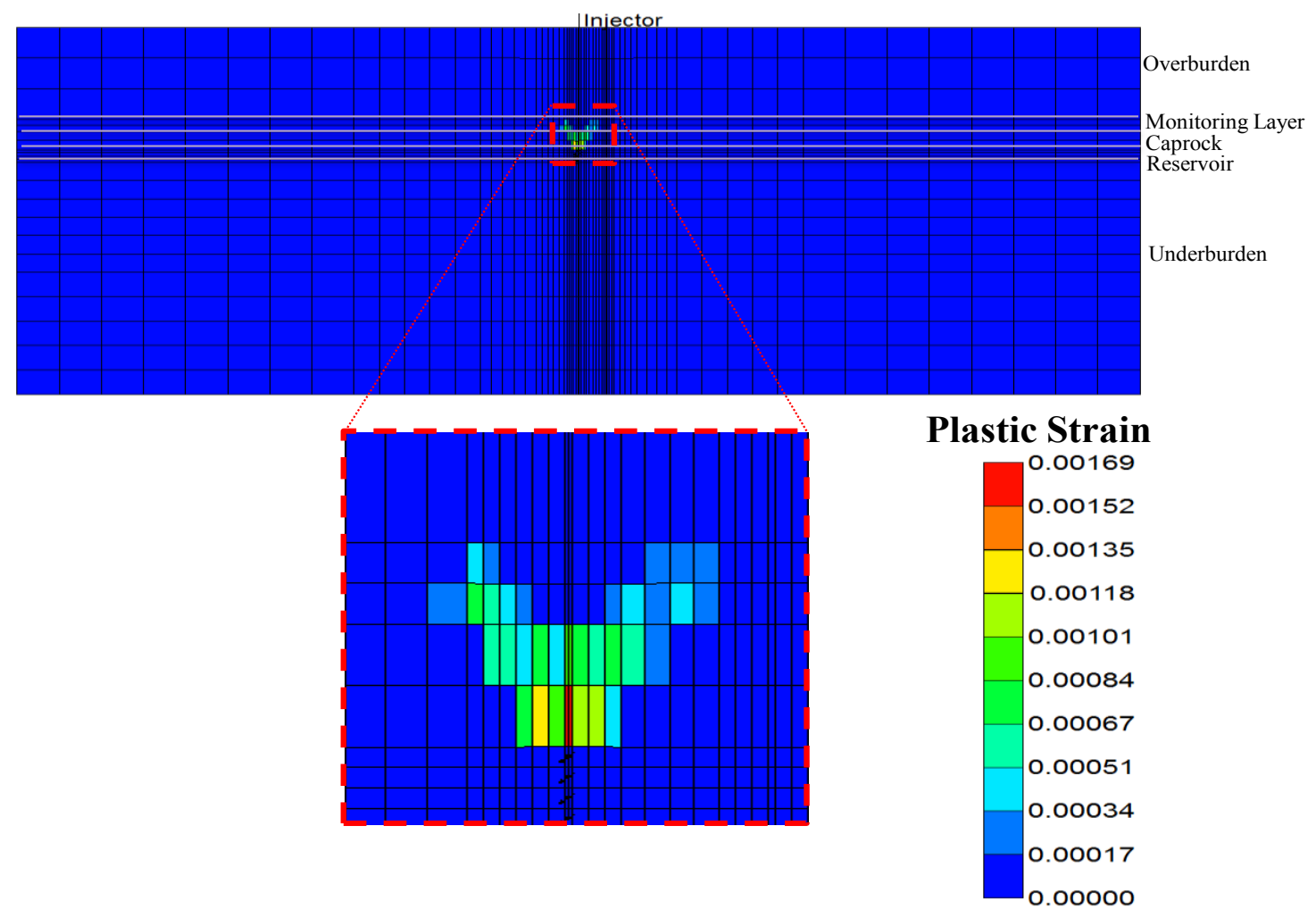

Figure 5.6: Plastic strains developed after 5 years of $\mathrm{CO}_{2}$ injection when $\mathrm{c}=5,000 \mathrm{kPa}$ in the reservoir 


\subsection{Parametric analysis of geomechanical properties}

Computer Modeling Group's GEM simulator (CMG, 2012) was used in the study presented in this section. Results from the parametric studies were analyzed and a range of geomechanical properties that cause shear failure in the overburden caprock were determined. Mohr-Coulomb failure criterion was considered to simulate overburden shear failure. Table 5.1 shows a summary of parametric study. In order to investigate the influence of each parameter (cohesion, angle of friction, and permeability), several case scenarios have been presented to demonstrate shear failure in the caprock as shown in Table 5.2. A range of geomechanical properties (cohesion, angle of friction, permeability, Elastic Modulus, Poisson's Ratio, Compressibility) used in the parametric study is shown Table 5.2. Figure 5.7 to Figure 5.11 show the plastic strains for case 1, where cohesion was varied while angle of friction and permeability remained same. Figure 5.12 to Figure 5.16 show the plastic strains for case 2, where angle of friction was varied while cohesion and permeability remained constant. Figure 5.17 to Figure 5.21 show the plastic strains for case 3, where permeability was varied while angle of friction and cohesion remained constant. A summary of cases considered in section is given below.

Table 5.2: A summary of parametric study

\begin{tabular}{|c|l|}
\hline Case 1 & Influence of cohesion on shear failure \\
\hline Case 2 & Influence of angle of friction on shear failure \\
\hline Case 3 & Influence of permeability on shear failure \\
\hline
\end{tabular}


Table 5.3: Geomechanical properties

\begin{tabular}{|c|c|c|c|c|}
\hline \multicolumn{2}{|c|}{ CASE } & $\begin{array}{c}\text { Angle of } \\
\text { friction } \mathbf{\Phi} \\
\text { (degrees) }\end{array}$ & $\begin{array}{c}\text { Permeability k } \\
\text { (mD) }\end{array}$ & Cohesion c \\
(kPa)
\end{tabular}




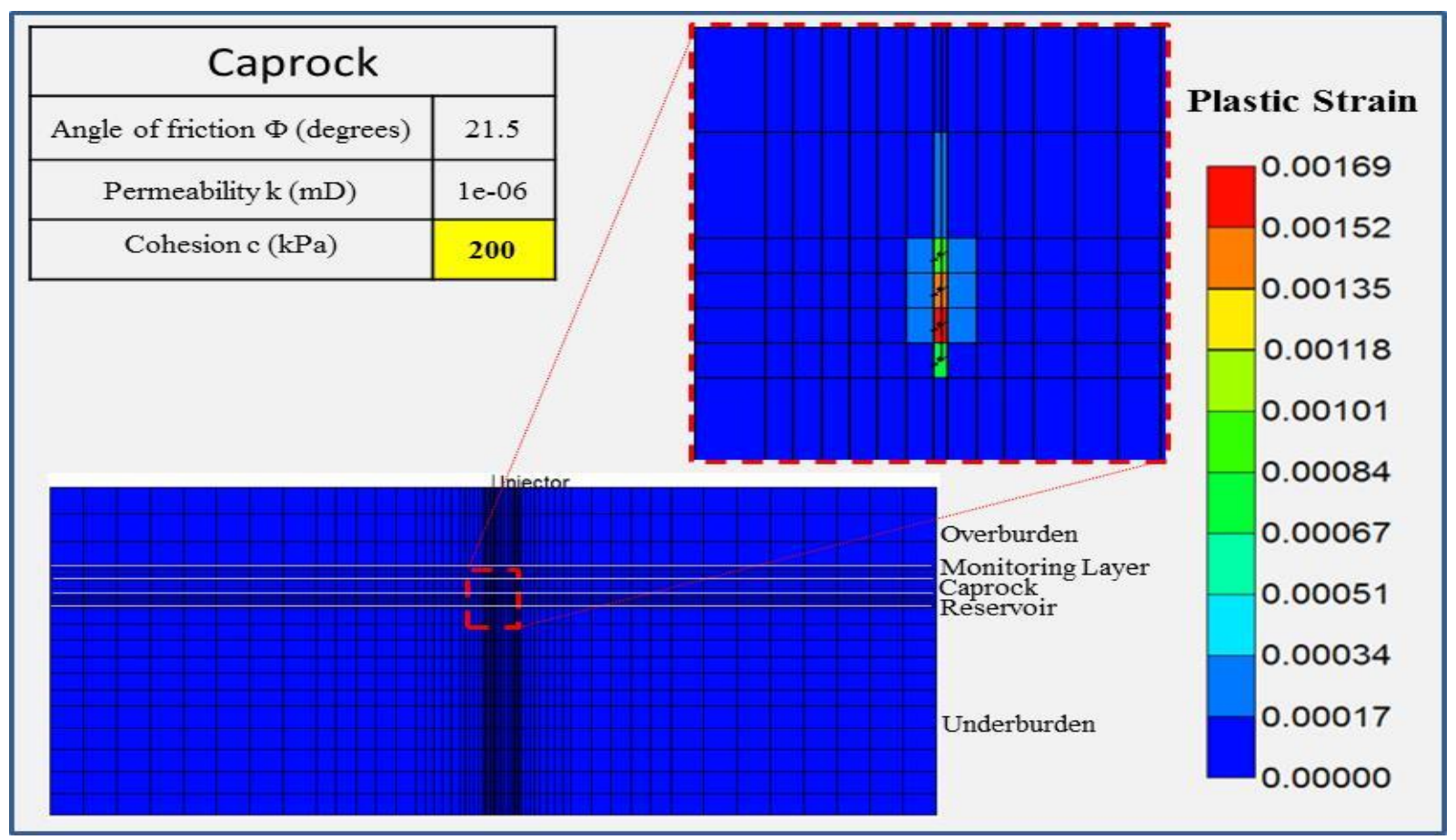

Figure 5.7: Plastic strains for Case 1(a)

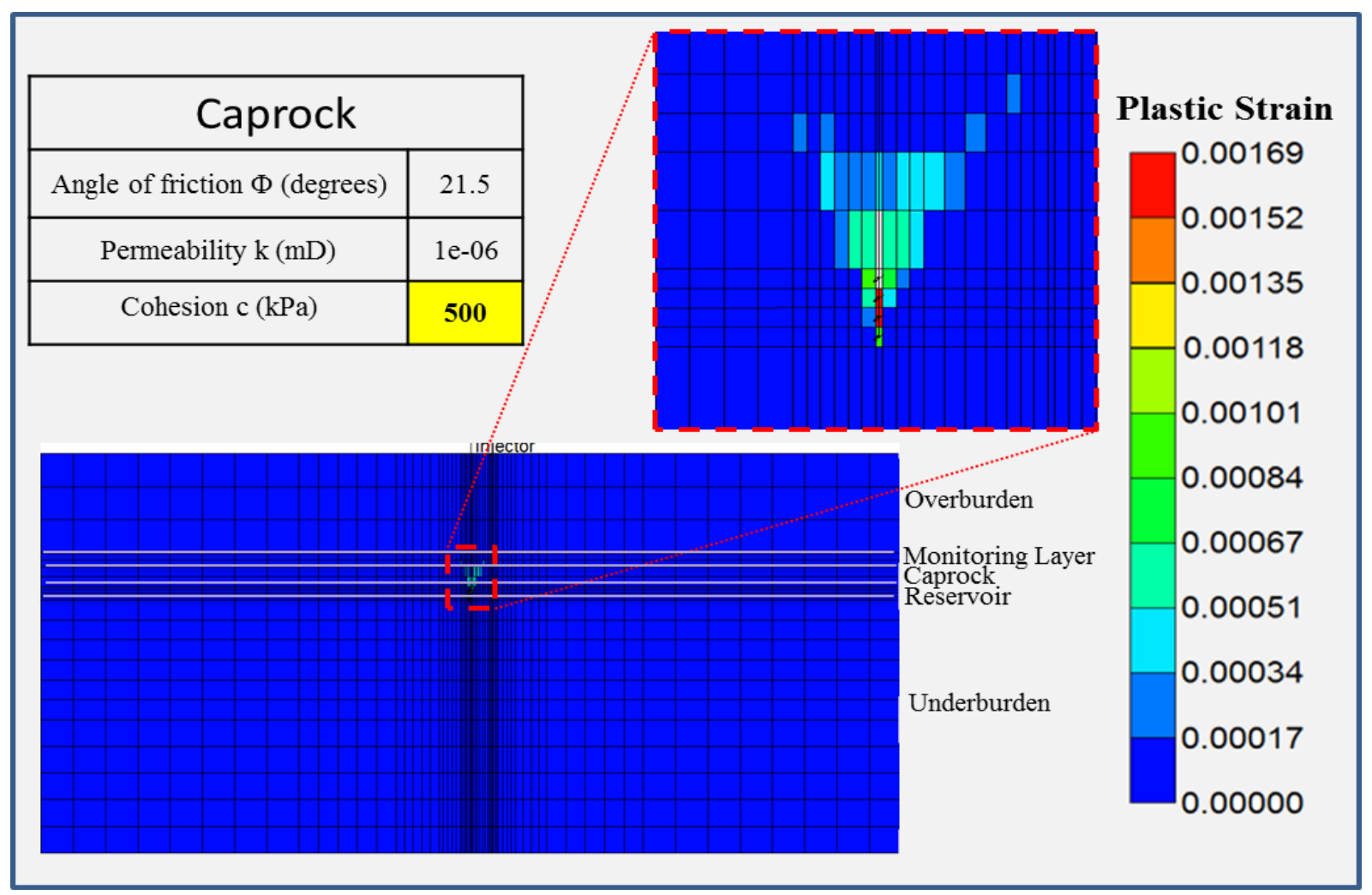

Figure 5.8: Plastic strains for Case 1(b) 


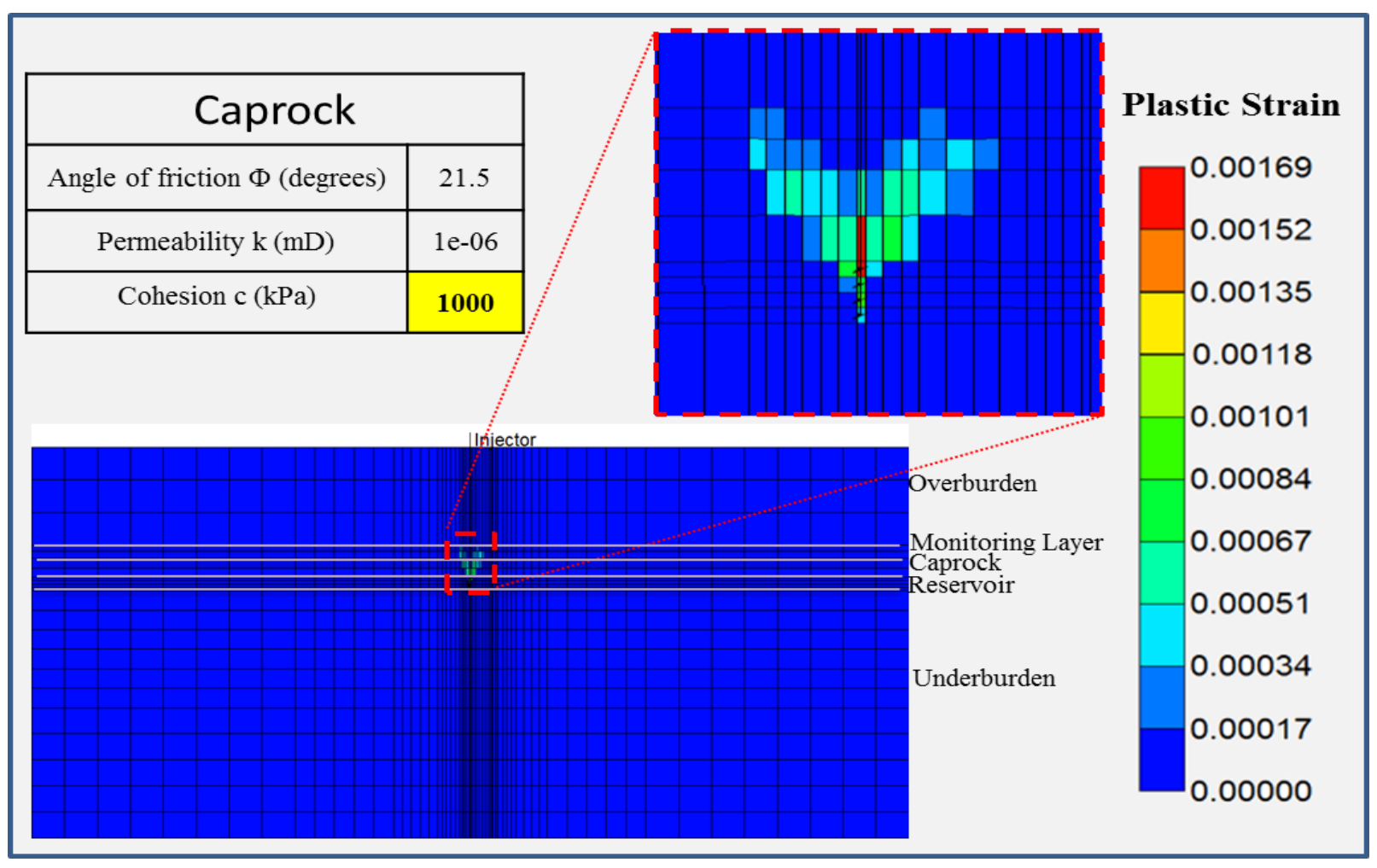

Figure 5.9: Plastic strains for Case 1(c)

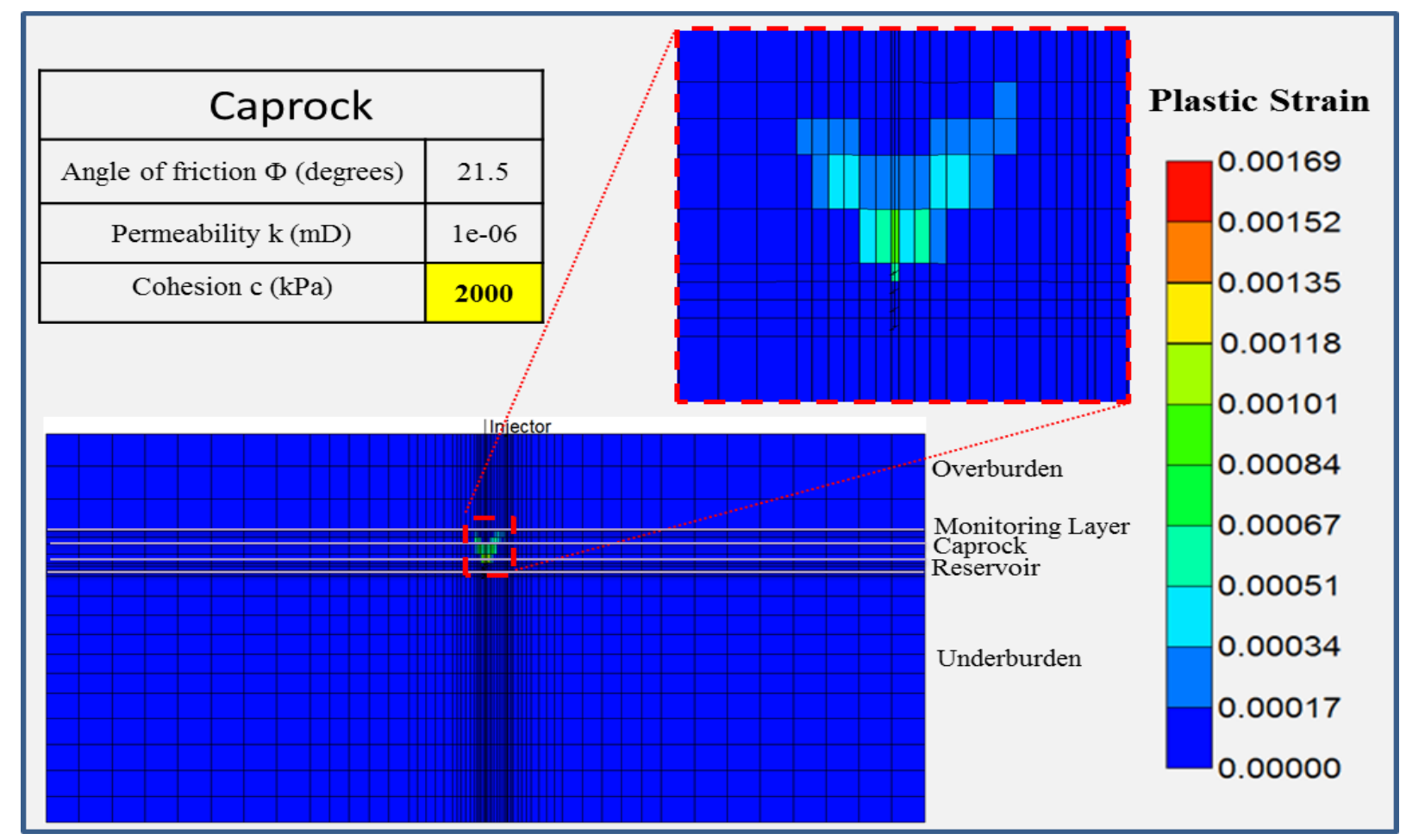

Figure 5.10: Plastic strains for Case 1(d) 


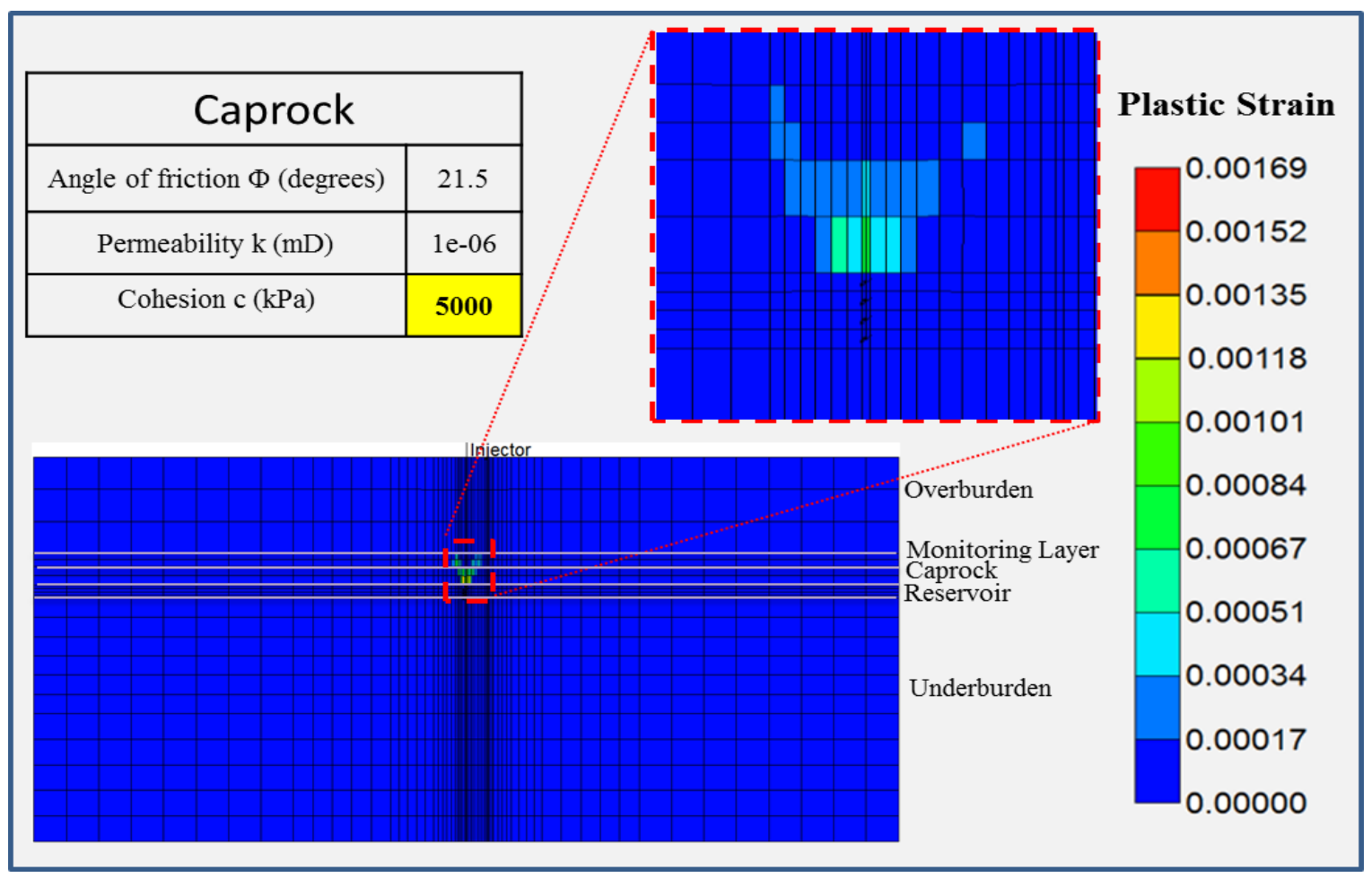

Figure 5.11: Plastic strains for Case 1(e)

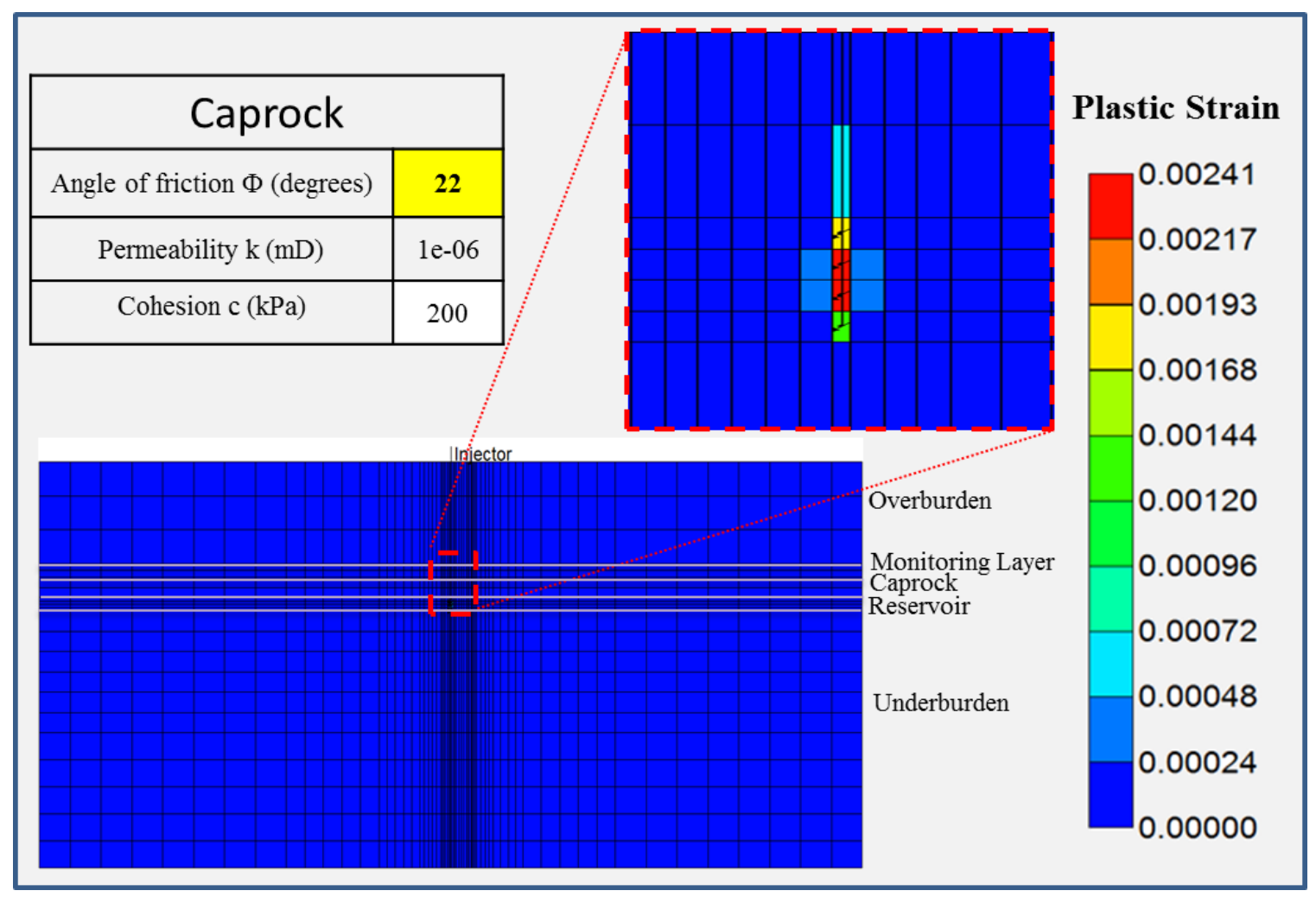

Figure 5.12: Plastic strains for Case 2(a) 


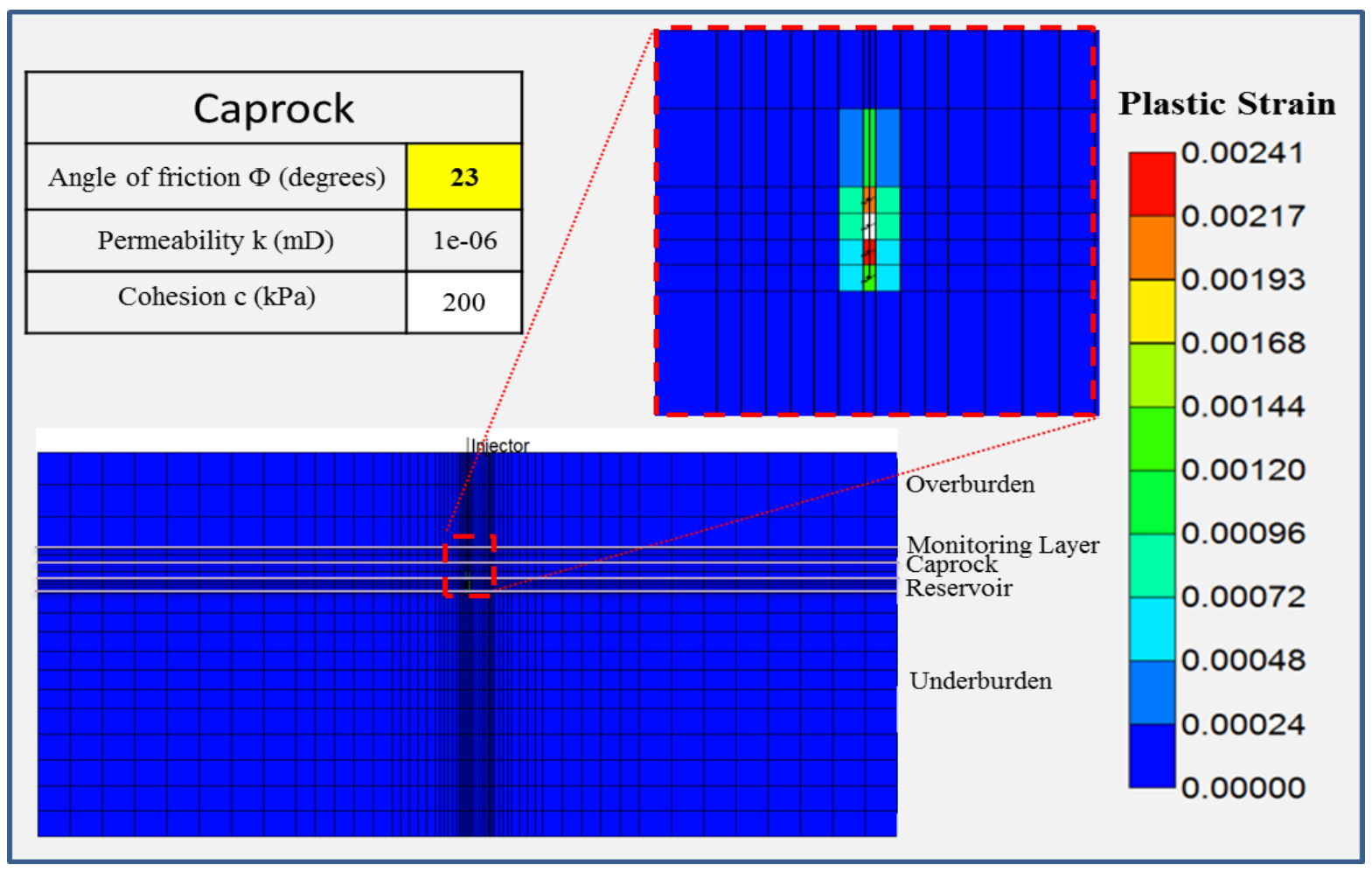

Figure 5.13: Plastic strains for Case 2(b)

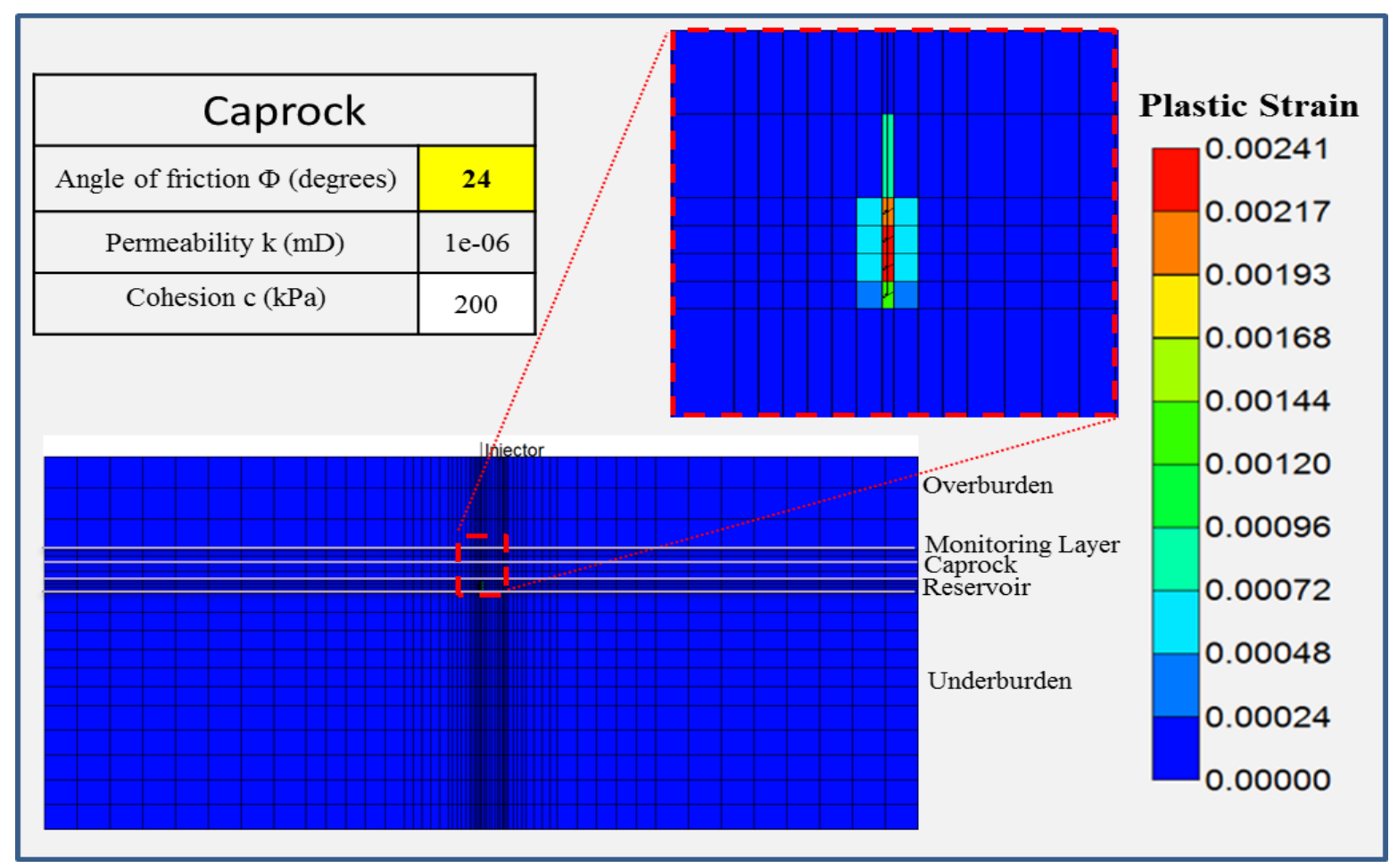

Figure 5.14: Plastic strains for Case 2(c) 


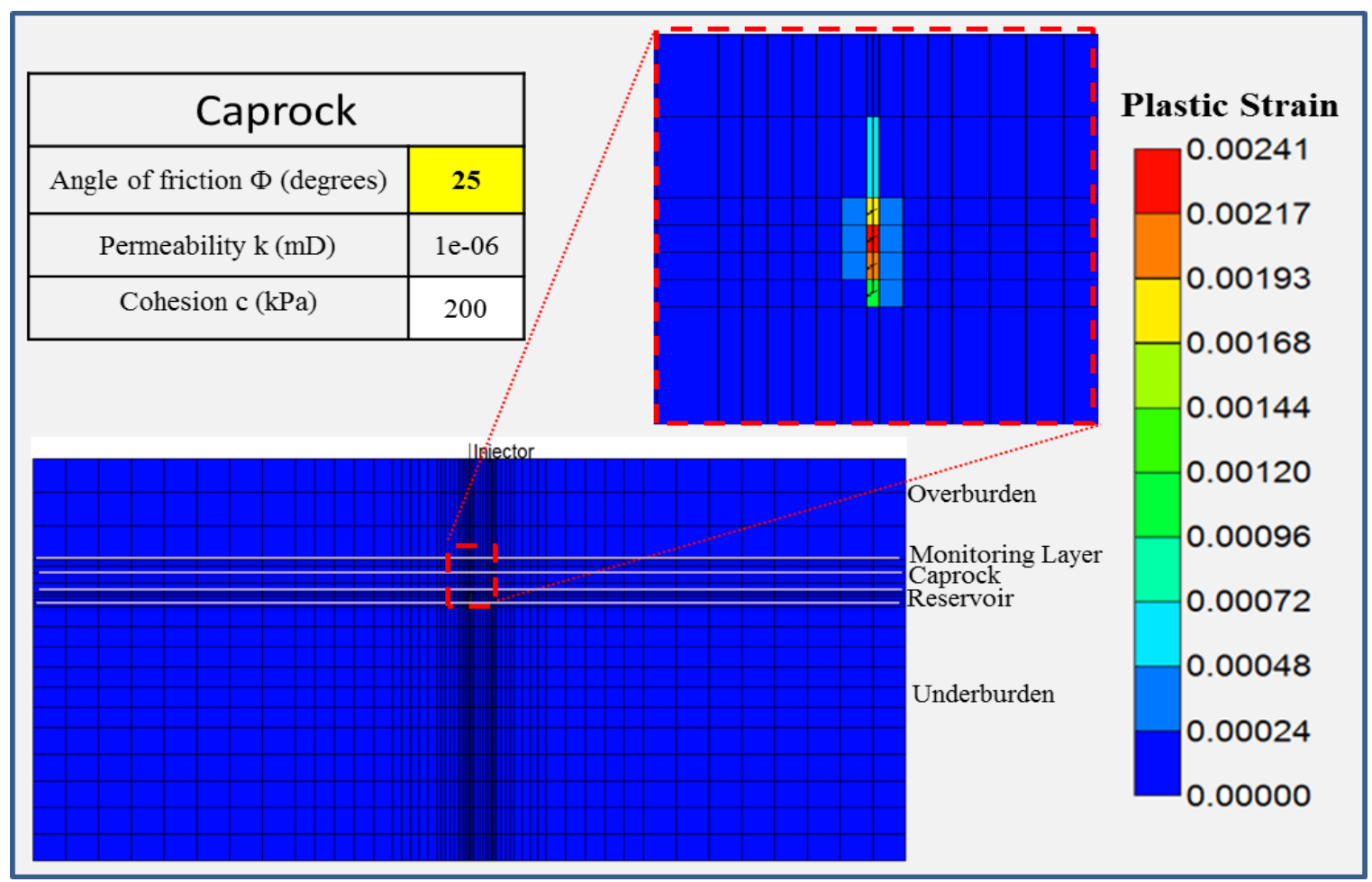

Figure 5.15: Plastic strains for Case 2(d)

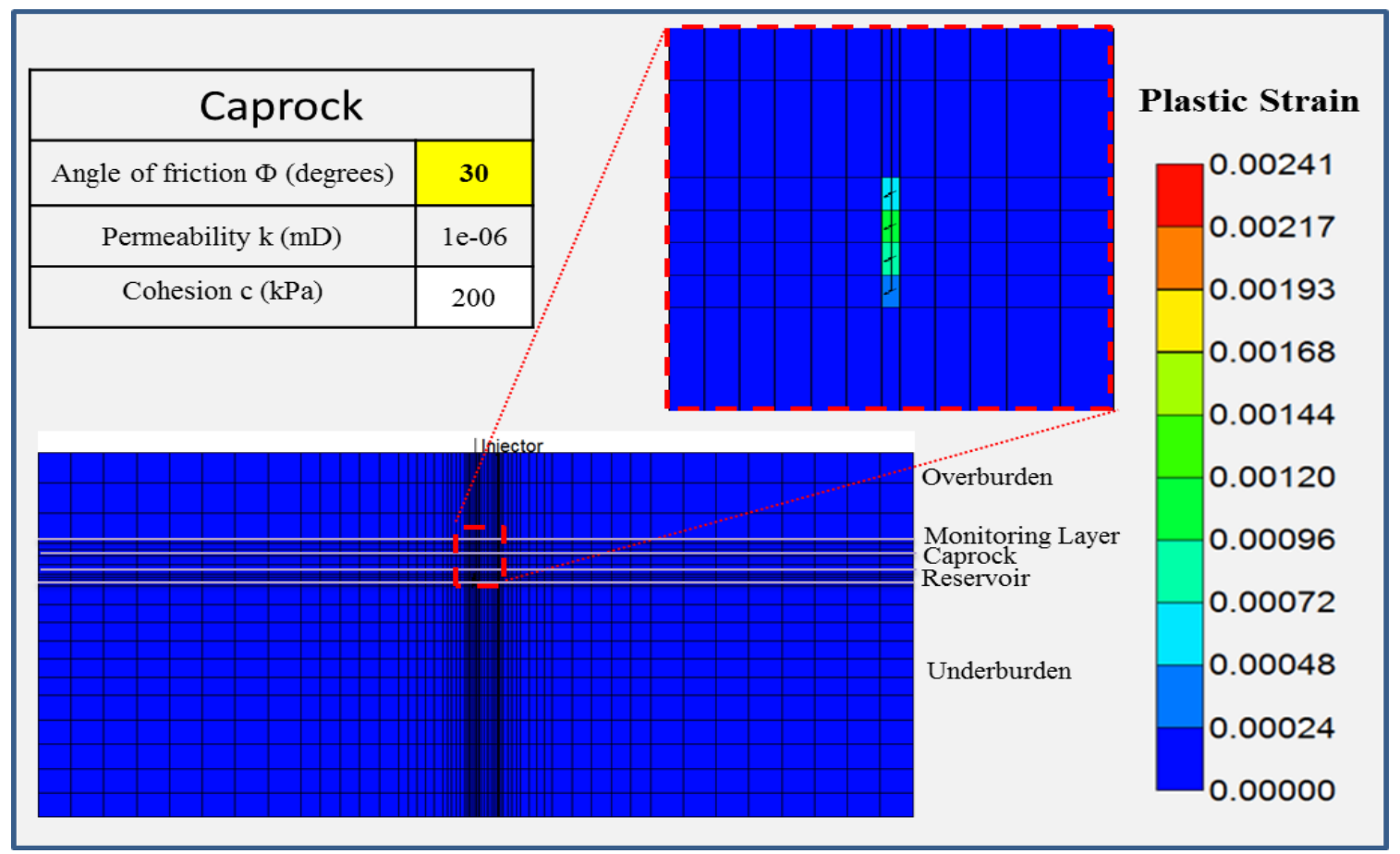

Figure 5.16: Plastic strains for Case 2(e) 


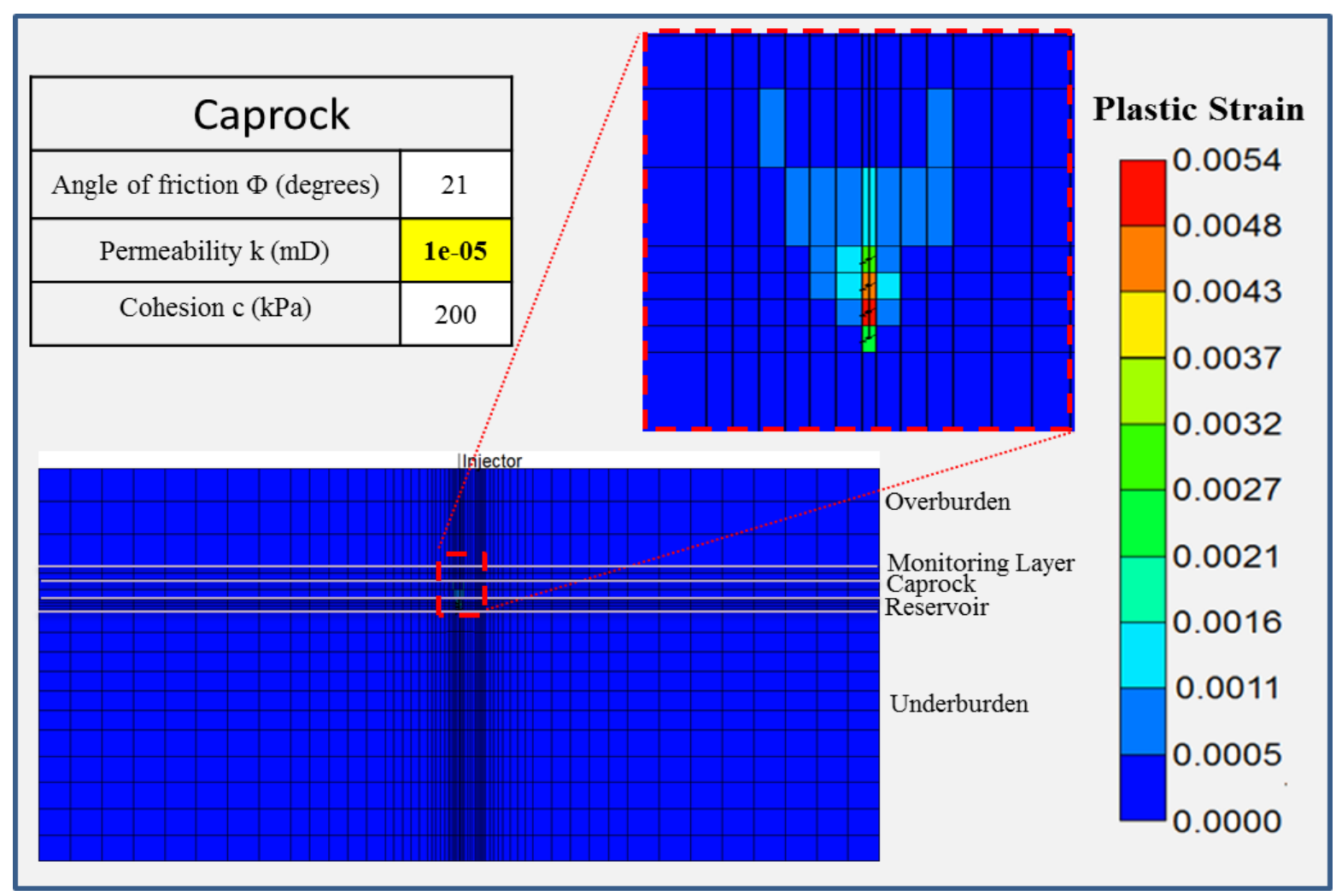

Figure 5.17: Plastic strains for Case 3(a)

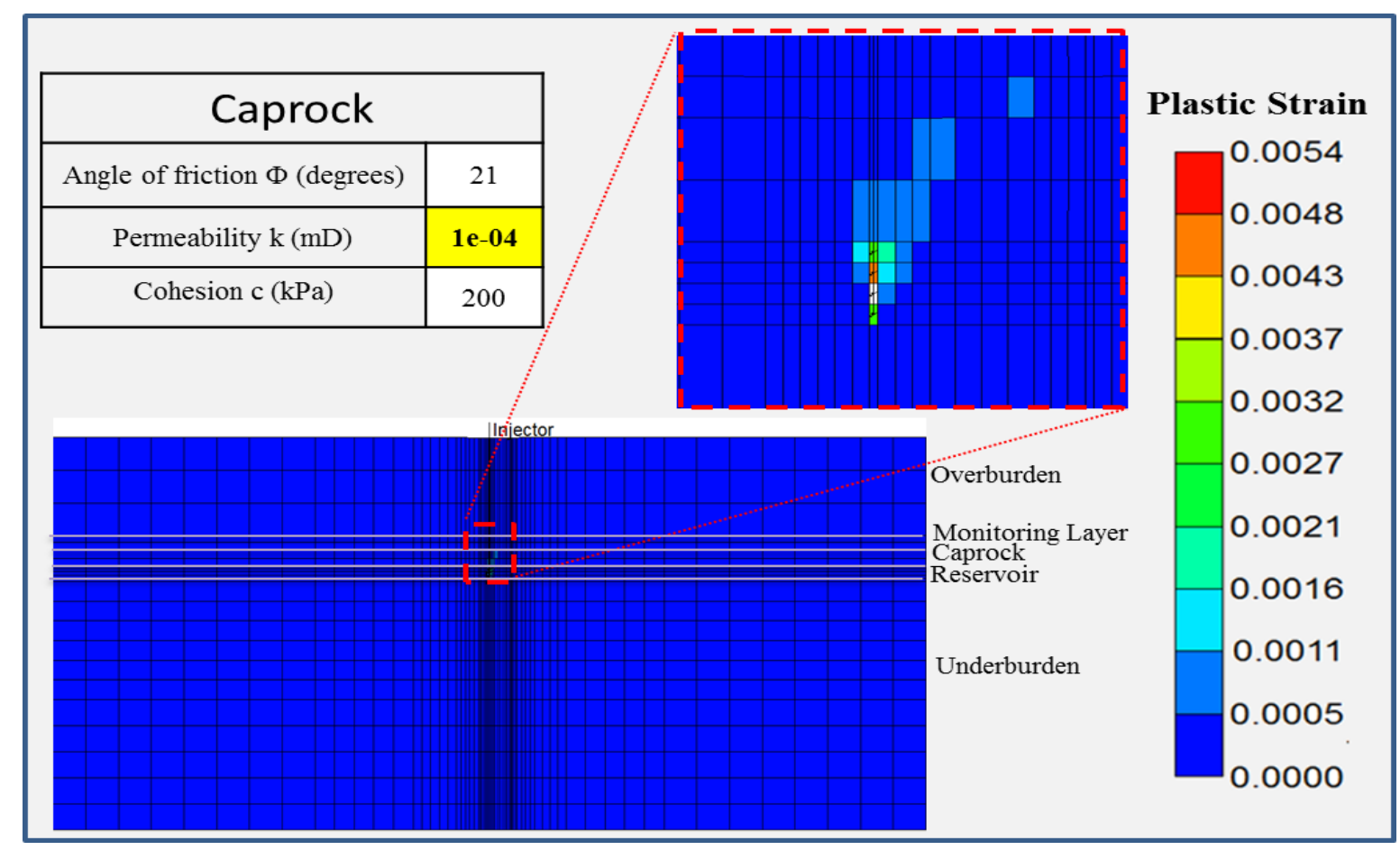

Figure 5.18: Plastic strains for Case 3(b) 


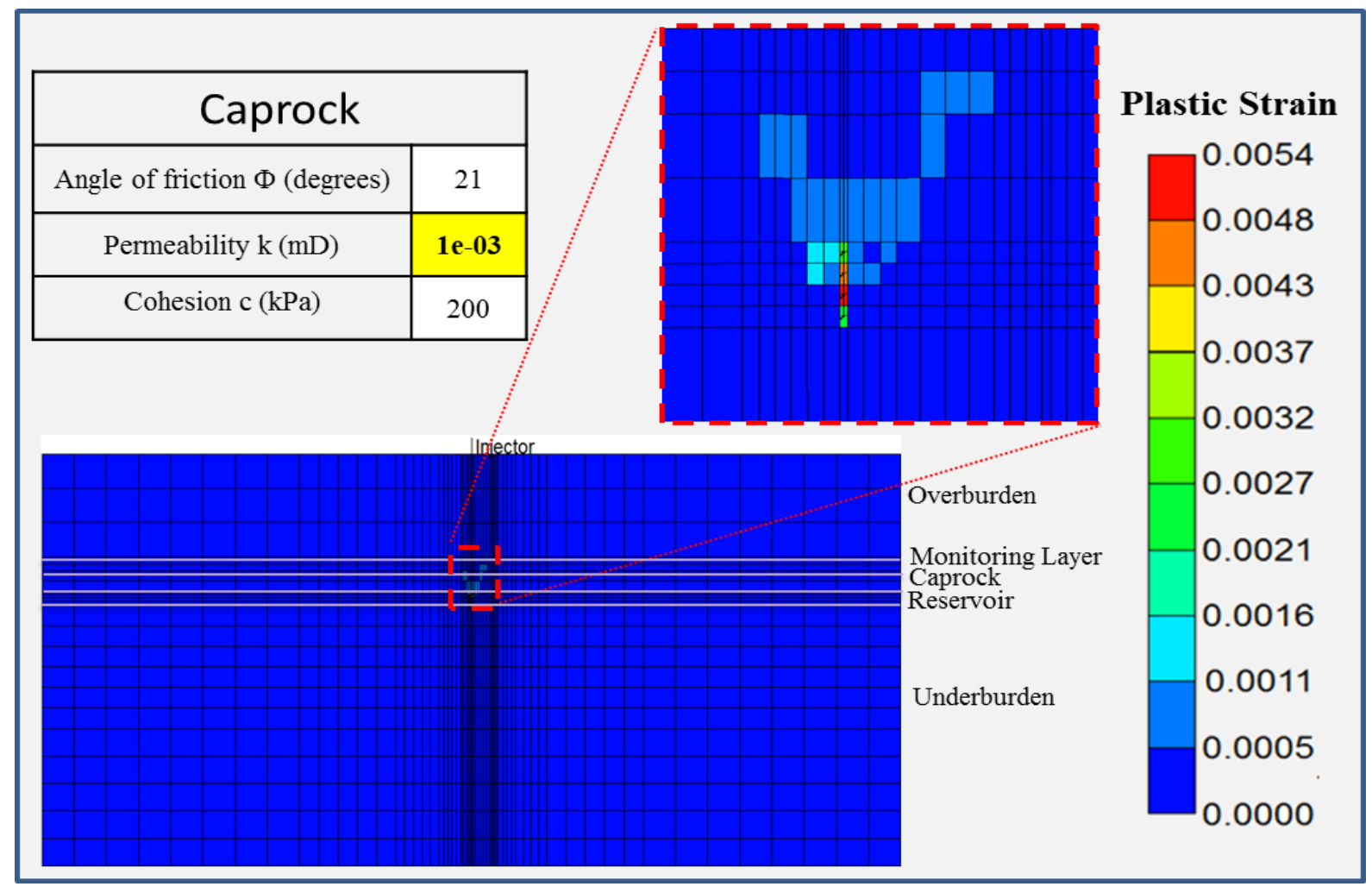

Figure 5.19: Plastic strains for Case 3(c)

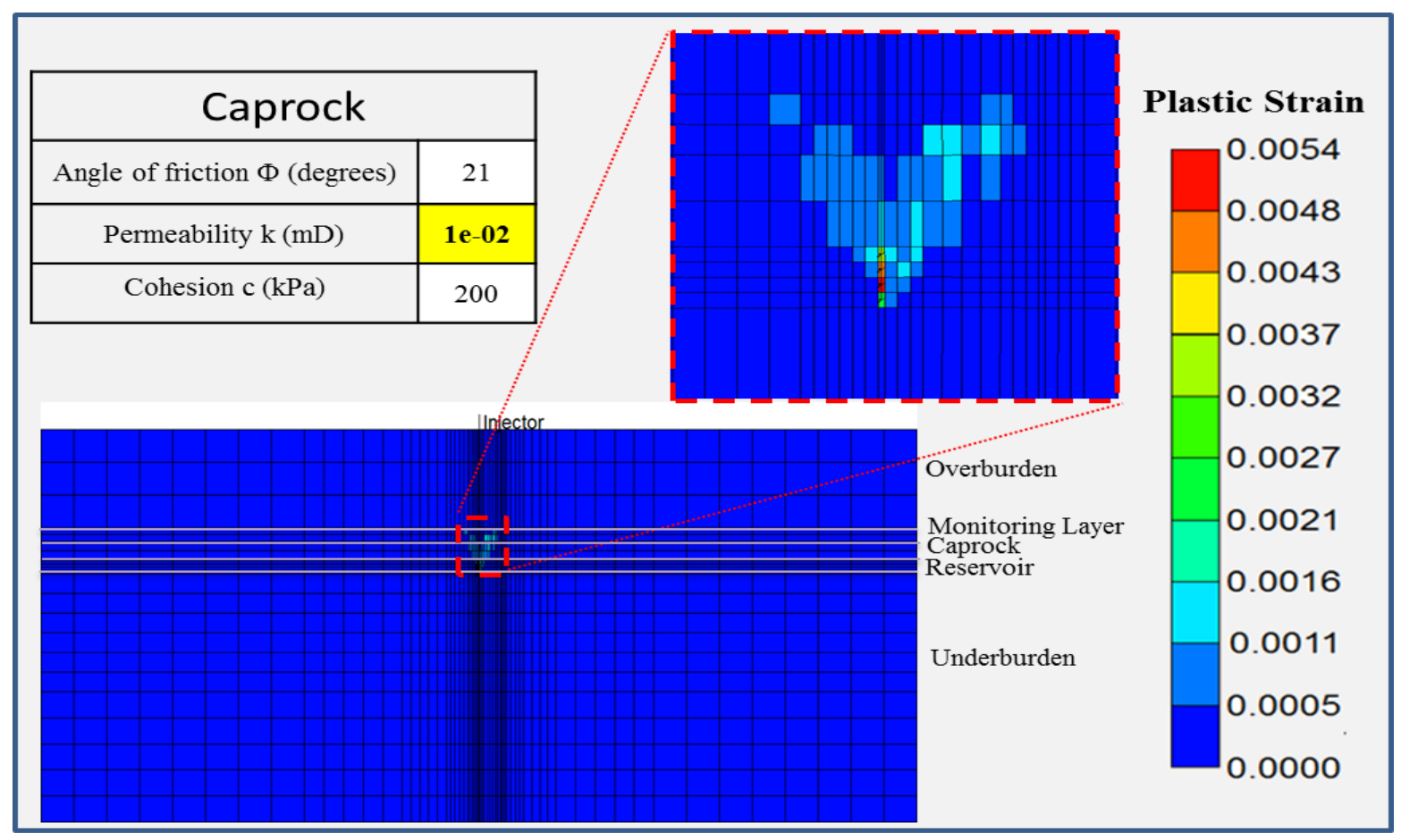

Figure 5.20: Plastic strains for Case 3(d) 


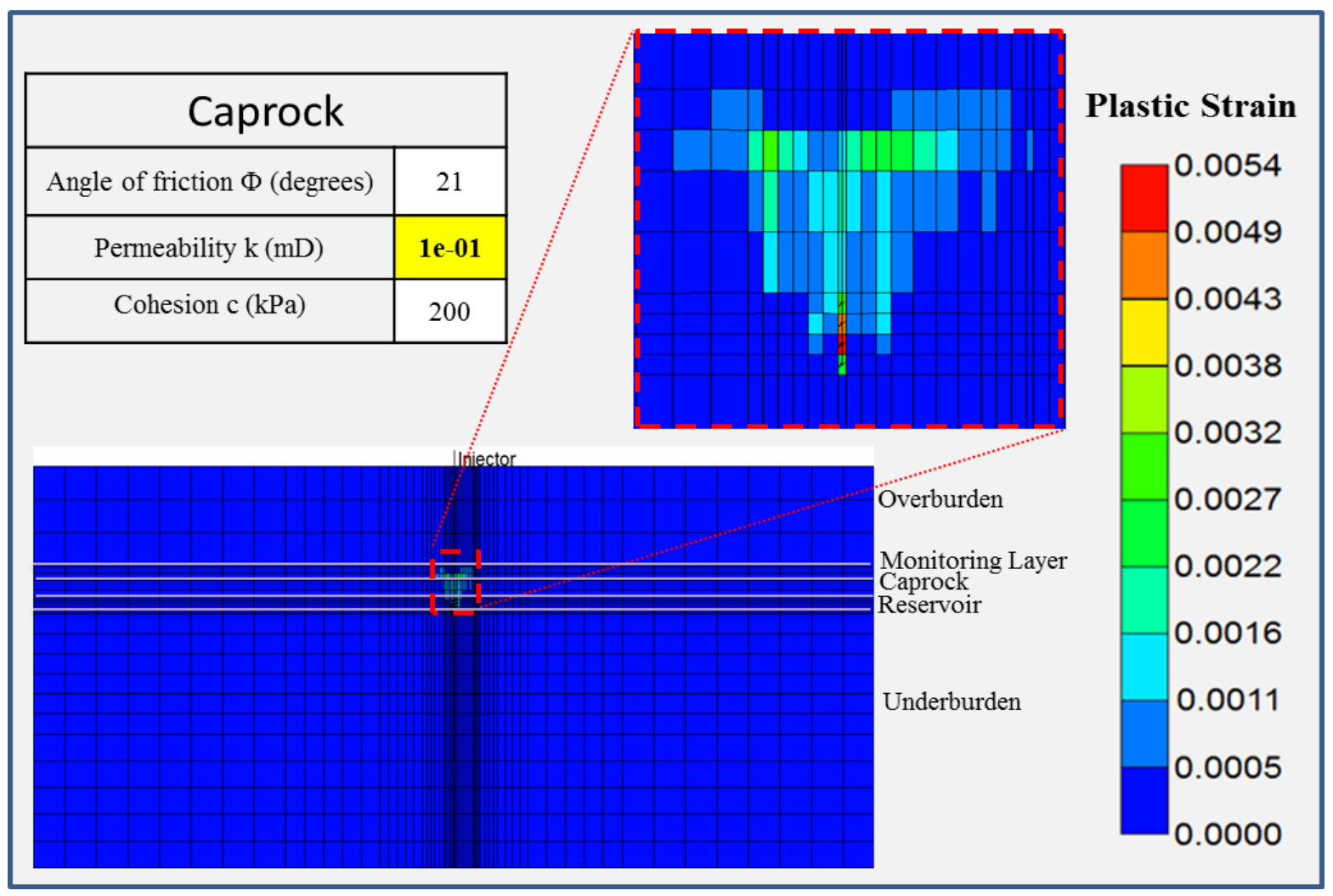

Figure 5.21: Plastic strains for Case 3(e)

The magnitude of equivalent plastic strains during a shear failure in the caprock layer can act as a proxy in identifying the extent of damage zone. From case 1, modeling results show that magnitudes of computed plastic strains are higher when cohesion value is $200 \mathrm{kPa}$. Case 2 shows that magnitudes of computed plastic strains are higher when friction angle is $22^{\circ}$ and Case 3 shows that the extent of damage zone (i.e., zone of plastic strains) near the injection well is greater when the caprock permeability is higher. If the permeability of caprock layer is higher, the injected $\mathrm{CO}_{2}$ rises to the top of the reservoir and flows into the caprock region. The fluid flow in the caprock layer increases the fluid pressure causing changes in effective stresses and resulting in caprock damage. 


\section{CHAPTER 6 : INCLINED FAULT ANALYSIS}

\subsection{Introduction}

Faults and fractures may result from ancient tectonic processes, natural earthquakes or induced seismic activities resulting from overpressurisation of a reservoir during fluid injection (Cappa and Rutqvist, 2011; Morris et al., 2011b; Shapiro and Dinske, 2009). Storage of $\mathrm{CO}_{2}$ in deep saline formations requires estimates of sustainable fluid pressures that will not induce fracturing or create fault permeability that could lead to $\mathrm{CO}_{2}$ escape. Faults and fractures form, when the intensity of stress overcomes the strength of the rock (Cappa and Rutqvist, 2011; Nacht et al., 2010; Rutqvist et al., 2007; Streit and Hillis, 2004). Numerical Modeling have shown that increasing pore fluid pressure in rocks and faults reduces their strength and can induce brittle failure (Cappa and Rutqvist, 2011; Morris et al., 2011b; Nacht et al., 2010; Rutqvist et al., 2007; Streit and Hillis, 2004). This results in increasing pore fluid pressure and low effective stresses. Shear stress(s), $\tau$ acting parallel to fault induce sliding along the fault surface and positive effective normal stresses $\left(\sigma_{n}^{\prime}\right)$ help fault blocks come together as shown in Figure 6.1. (Cappa and Rutqvist, 2011; Streit and Hillis, 2004; Streit and Siggins, 2005). 


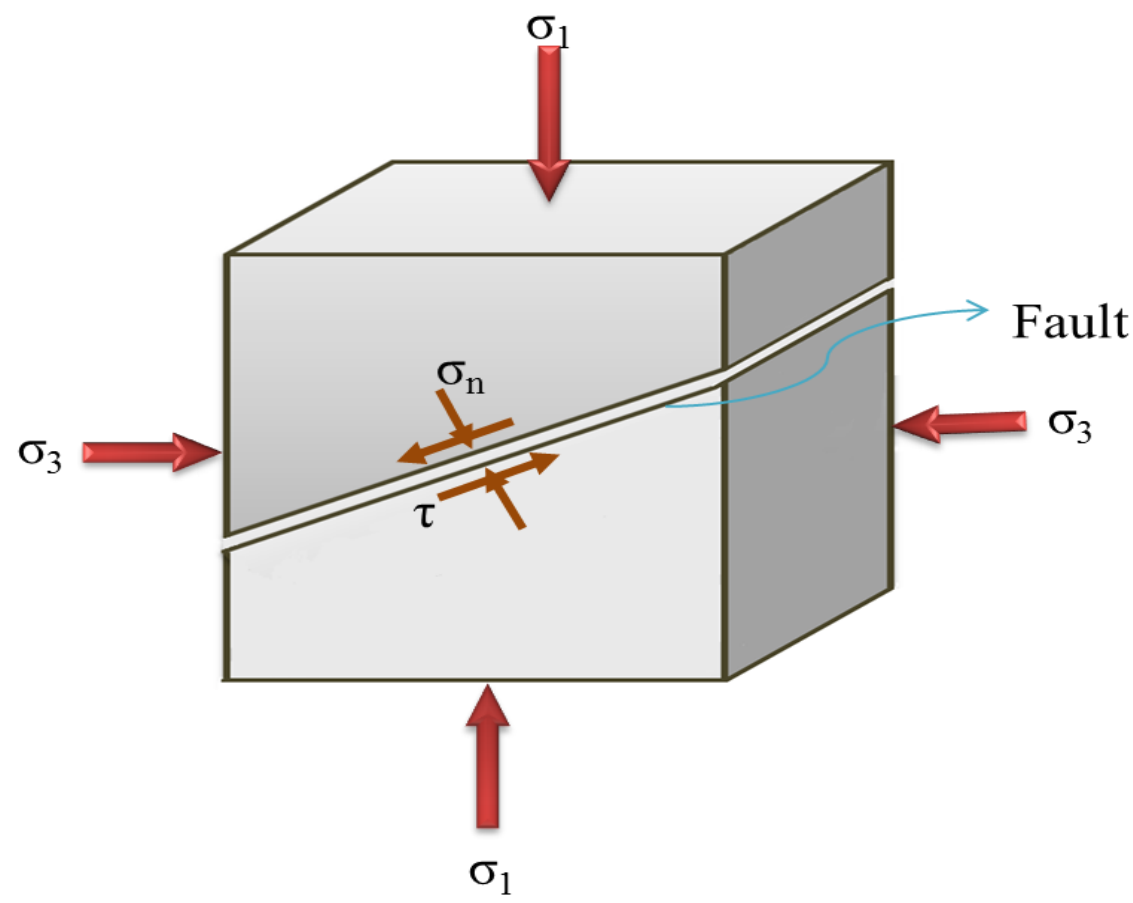

Note: Modified from published literature (Cappa and Rutqvist, 2011; Streit and Hillis, 2004; Streit and Siggins, 2005)

Figure 6.1: Normal and shear stresses on the fault

Thus, higher pore fluid pressures decrease the resistance to sliding. The Mohr diagram (Figure 6.2) explains the effects of increasing fluid pressure on fault stability (Streit and Hillis, 2004). Shear stress on the fault plane can be expressed as (Cappa and Rutqvist, 2011; Nacht et al., 2010; Rutqvist et al., 2007; Rutqvist et al., 2010; Streit and Hillis, 2004; Streit and Siggins, 2005):

$$
\tau=c+\mu\left(\sigma_{n}-p\right)
$$

where

$$
\begin{aligned}
& \mathrm{c}=\text { cohesion, } \\
& \tau=\text { shear stress, } \\
& \mathrm{p}=\text { fluid pressure, } \\
& \sigma_{\mathrm{n}}-\mathrm{p}=\text { positive effective normal stress, }
\end{aligned}
$$




$$
\begin{aligned}
& \sigma_{n}=\text { total normal stress, and } \\
& \mu=\text { coefficient of friction. }
\end{aligned}
$$

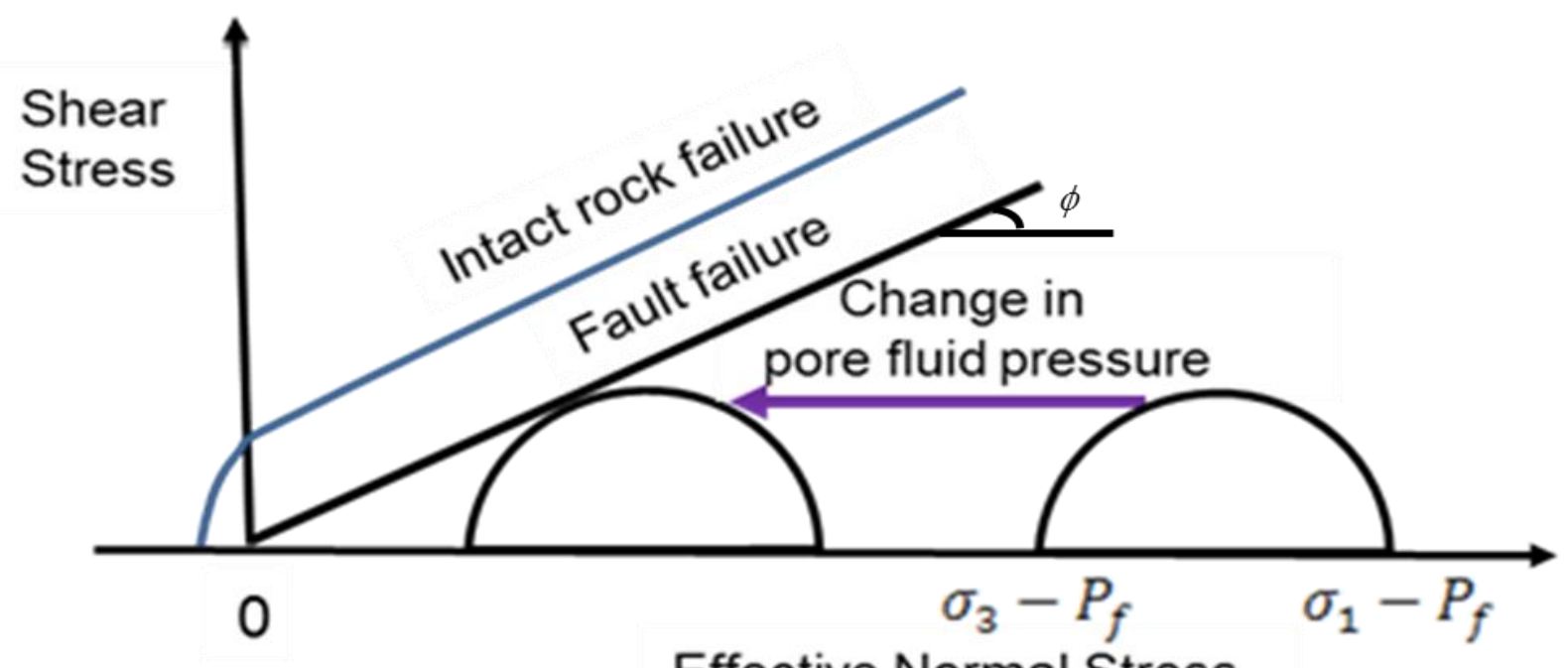

Note: This figure was obtained from the published literature (Cappa and Rutqvist, 2011; Nacht et al., 2010; Rutqvist et al., 2007; Rutqvist et al., 2010; Streit and Hillis, 2004)

Figure 6.2: Effect of increasing pore fluid pressure on fault stability

The angle of friction $(\phi)$ is equivalent to the slope of the fault failure envelope in Figure 6.2. The shear and effective normal stresses that act on a fault segment are a function of the fault orientation $(\theta)$, and are given in a two-dimensional form as (Cappa and Rutqvist, 2011; Nacht et al., 2010; Streit and Hillis, 2004):

$$
\begin{array}{r}
\tau=\frac{1}{2}\left(\sigma_{1}-\sigma_{3}\right) \sin 2 \theta \\
\sigma_{n}^{\prime}=\frac{\sigma_{1}+\sigma_{3}}{2}-\frac{\sigma_{1}-\sigma_{3}}{2} \cos 2 \theta
\end{array}
$$

where

$$
\sigma_{n}^{\prime}=\text { effective normal stress, }
$$


$\sigma_{1}=$ the major principal stress,

$\sigma_{3}=$ the minor principal stress,

$\theta=$ fault angle, and

$\tau=$ shear stress.

Frictional materials like granular soils can be modeled by using Drucker-Prager failure criterion (ABAQUS, 2012). A Drucker-Prager model explains yield behavior of granular materials or polymers that depends on the equivalent pressure stress (Abaqus 2012; Helwany, 2007). The inelastic deformation is associated with frictional mechanisms such as sliding of particles opposite each other. The yield criterion depends on the shape of the yield surface in the form of linear, hyperbolic, or exponential form (Abaqus 2012; Helwany, 2007). Figure 6.3 shows a linear Drucker-Prager failure model (ABAQUS, 2012; Helwany, 2007; Desai and Siriwardane, 1984).

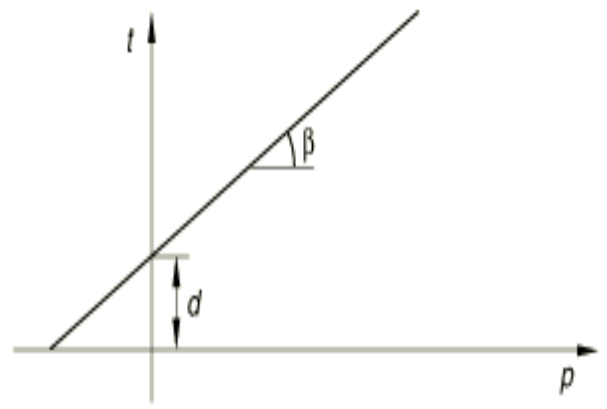

Note: This figure was obtained from the published literature (ABAQUS, 2012; Helwany, 2007) Figure 6.3: Linear Drucker-Prager model

The linear Drucker-Prager criterion is written as (Abaqus 2012; Helwany, 2007):

$$
F=t_{s}-p_{s} \tan \beta-d
$$

where

$\mathrm{t}_{\mathrm{s}}=$ deviatoric stress plane,

$\mathrm{p}_{\mathrm{s}}=$ equivalent pressure tensor,

$\mathrm{d}=$ cohesion in Drucker-Prager model, and

$\beta=$ Drucker-Prager friction angle. 
The relationship below provides a match between Mohr-Coulomb material parameters and linear Drucker-Prager material parameters in plane strain condition (Abaqus, 2012).

$$
\begin{gathered}
\tan \beta=\frac{\sqrt{3} \sin \phi}{\sqrt{1+\frac{1}{3} \sin ^{2} \phi}} \\
\frac{d}{c}=\frac{\sqrt{3} \cos \phi}{\sqrt{1+\frac{1}{3} \sin ^{2} \phi}}
\end{gathered}
$$

where

$$
\begin{aligned}
& \beta=\text { Drucker-Prager friction angle, } \\
& \phi=\text { Mohr-Coulomb friction angle }, \\
& \mathrm{d}=\text { cohesion in Drucker-Prager model, and } \\
& \mathrm{c}=\text { cohesion in Mohr-Coulomb model } .
\end{aligned}
$$

\subsection{Details of Inclined Fault Model}

Figure 6.4 shows a schematic diagram of inclined fault model $(20 \mathrm{~km} \times 3 \mathrm{~km})$. Twodimensional modeling was performed with an inclined fault and by considering hypothetical injection site. Five geologic layers - overburden strata, monitoring layer, caprock seal, aquifer and underburden layers were considered. The model consists of a storage aquifer $100 \mathrm{~m}$ in thickness, bounded by a low-permeable $150 \mathrm{~m}$ thick caprock, which, in turn, is surrounded by a monitoring layer of $100 \mathrm{~m}$ thick extended vertically $750 \mathrm{~m}$ below from ground. This multilayer system is intersected by a pre-existing normal fault with a dip angle of $80^{\circ}$ in the caprock layer and with a fault thickness of $10 \mathrm{~m}$. The permeability of fault zone in the model was idealized based on the grid block thickness. The fault zone and injection zone are spaced $500 \mathrm{~m}$ horizontally. Similar models can be found elsewhere (Cappa and Rutqvist, 2011).

In this study, finite element method was used as a simulation tool to determine the influence of fluid injection at the hypothetical site. Coupled flow and deformation finite element 
analyses (single-phase fluid flow modeling) were performed by using ABAQUS (ABAQUS, 2012) to investigate the shear slip of fault zone caused due to fluid injection. An inclined fault line in the caprock layer was considered as shown in the Figure 6.4. Table 6.1 shows the assumed reservoir and geomechanical properties for each layer. Geomechanical properties were assumed based on those reported in the published literature (Cappa and Rutqvist, 2011). These properties are different from Table 4.1 and Table 5.1. Figure 6.5 shows the finite element model constructed with an inclined fault to investigate the fault stability. Figure 6.6 shows the finite element mesh generated for the geomechanical model with an inclined fault line.

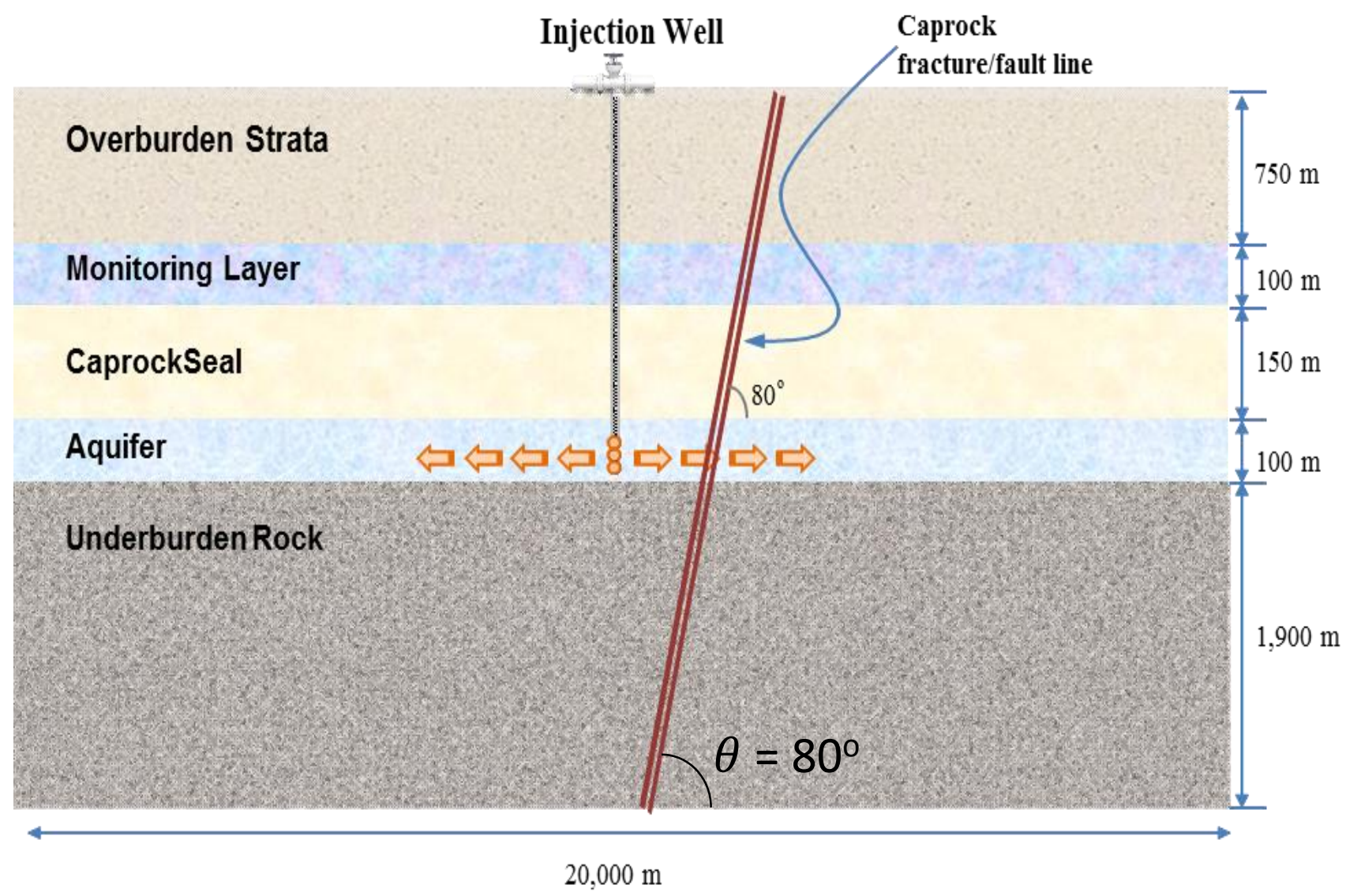

Figure 6.4: Schematic diagram of a fault located in the caprock layer $500 \mathrm{~m}$ from the injection well 
Table 6.1: Material properties used in the model with a faulted reservoir-caprock system

\begin{tabular}{|c|c|c|c|c|c|c|}
\hline $\begin{array}{l}\text { Material/ } \\
\text { Property }\end{array}$ & Overburden & $\begin{array}{c}\text { Monitoring } \\
\text { Layer }\end{array}$ & Caprock & Aquifer & Underburden & Fault \\
\hline $\begin{array}{c}\text { Young's } \\
\text { modulus, E } \\
(\mathrm{kPa})\end{array}$ & $1 \mathrm{E}+07$ & $1 \mathrm{E}+07$ & $1 \mathrm{E}+07$ & $1 \mathrm{E}+07$ & $1 \mathrm{E}+07$ & $5 \mathrm{E}+06$ \\
\hline $\begin{array}{c}\text { Porous Bulk } \\
\text { Modulus } \\
\text { (kPa) }\end{array}$ & $66.67 \mathrm{E}+07$ & $66.67 \mathrm{E}+07$ & $66.67 \mathrm{E}+07$ & $66.67 \mathrm{E}+07$ & $66.67 \mathrm{E}+07$ & $66.67 \mathrm{E}+07$ \\
\hline $\begin{array}{l}\text { Poisson's } \\
\text { ratio, } v\end{array}$ & 0.25 & 0.25 & 0.25 & 0.25 & 0.25 & 0.25 \\
\hline Porosity, n & 0.111 & 0.111 & 0.111 & 0.111 & 0.111 & 0.111 \\
\hline $\begin{array}{c}\text { Permeability } \\
\text {, k (m/day) }\end{array}$ & $1.27 \mathrm{E}-06$ & $1.27 \mathrm{E}-02$ & $1.27 \mathrm{E}-07$ & $1.27 \mathrm{E}-02$ & $1.27 \mathrm{E}-06$ & $1.27 \mathrm{E}-05$ \\
\hline $\begin{array}{c}\text { Bulk } \\
\text { modulus of } \\
\text { fluid(kPa) }\end{array}$ & $22 \mathrm{E}+05$ & $22 \mathrm{E}+05$ & $22 \mathrm{E}+05$ & $22 \mathrm{E}+05$ & $22 \mathrm{E}+05$ & $22 \mathrm{E}+05$ \\
\hline $\begin{array}{c}\text { Rock } \\
\text { Density, } \\
\text { kN/m }\end{array}$ & 21.167 & 21.167 & 21.167 & 21.167 & 21.167 & 21.167 \\
\hline $\begin{array}{c}\text { Cohesion } \\
\text { c (kPa) }\end{array}$ & 25,000 & 25,000 & 25,000 & 25,000 & 25,000 & 25,000 \\
\hline $\begin{array}{c}\text { Friction } \\
\text { Angle } \\
\phi \text { ( degrees) }\end{array}$ & 30 & 30 & 30 & 30 & 30 & 30 \\
\hline $\begin{array}{c}\text { Dilation } \\
\text { Angle } \\
\text { (degrees) }\end{array}$ & 20 & 20 & 20 & 20 & 20 & 20 \\
\hline
\end{tabular}




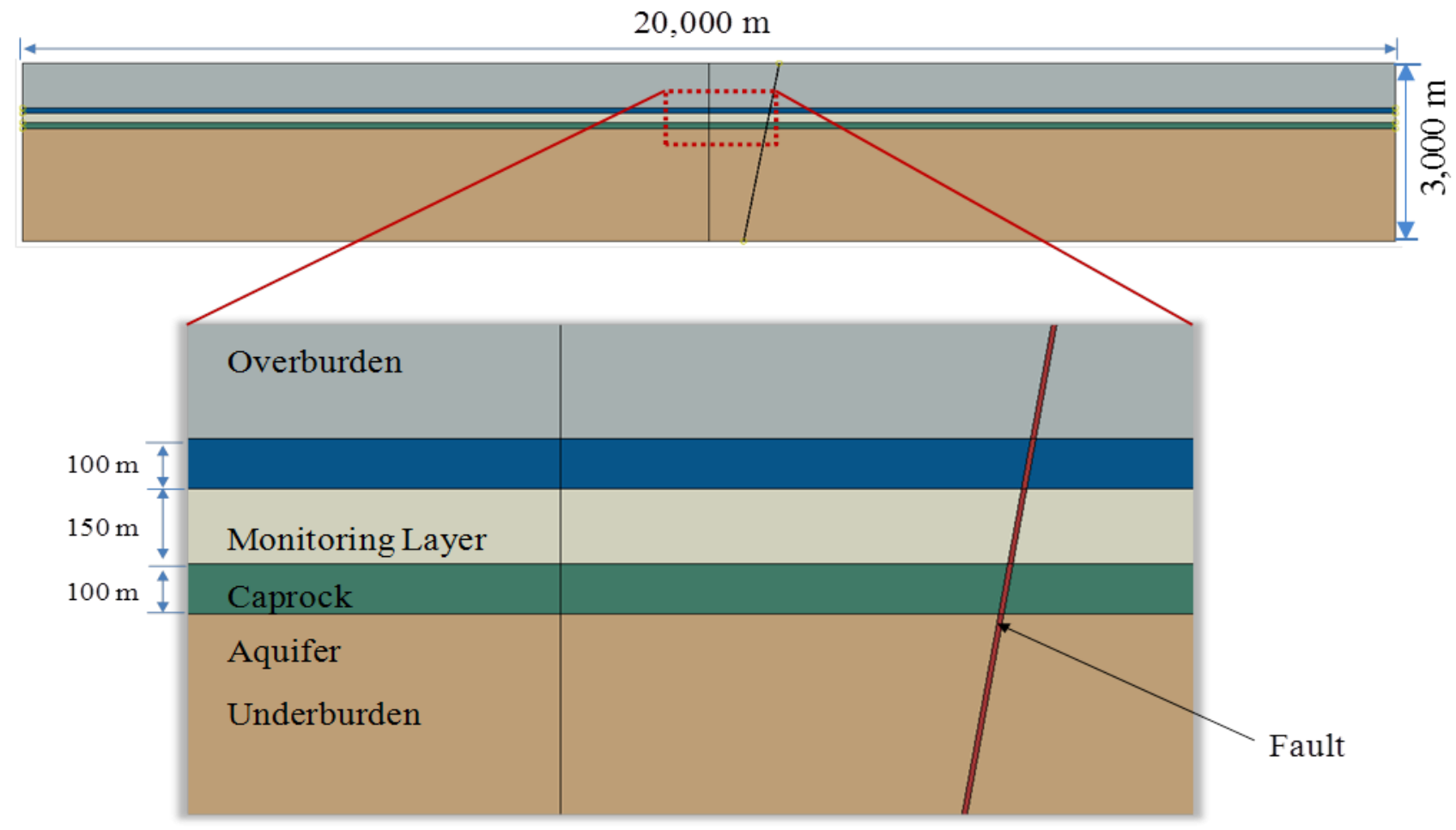

Figure 6.5: Finite element model showing the fault in the caprock layer

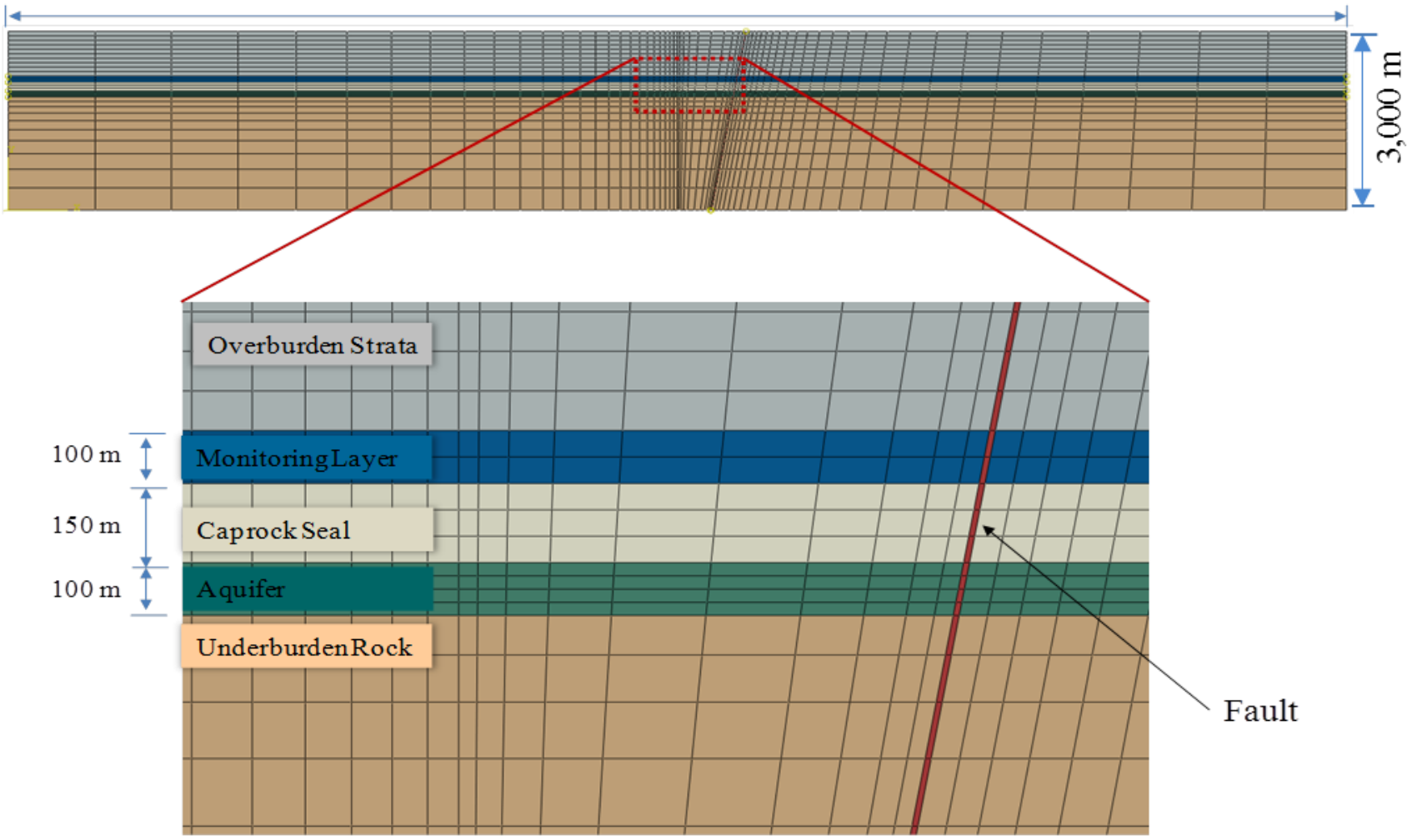

Figure 6.6: Finite element mesh 


\subsection{Prediction of damage zone due to fault movement}

\subsubsection{Mohr-Coulombs failure criterion}

In order to investigate the influence of caprock fracture/fault, an inclined fault zone was considered as shown in Figure 6.3. The fault zone was assumed to be $10 \mathrm{~m}$ thick with a dipping angle of $80^{\circ}$ located $500 \mathrm{~m}$ away from the injection source. Two-dimensional finite analyses were performed to investigate shear slip in the caprock layer due to long-term fluid injection. Five geologic layers were considered and the center of aquifer was located at 1,050 $\mathrm{m}$. The results presented in this section correspond to constant fluid injection for a period of five years with inclusion of geomechanics. A five-year fluid injection was performed at a differential pressure of 10.3 $\mathrm{MPa}$ (approximately 1,500 psi) in the target reservoir. Geostatic analysis was performed to define initial stress-state. Figure 6.7 shows the initial pore pressure distribution. Elasto-plastic material models (for Mohr-Coulomb failure criterion) were considered for the fault zone. Figure 6.8 shows the changes in fluid pressure after 5 years of fluid injection in the presence of a fault zone. 


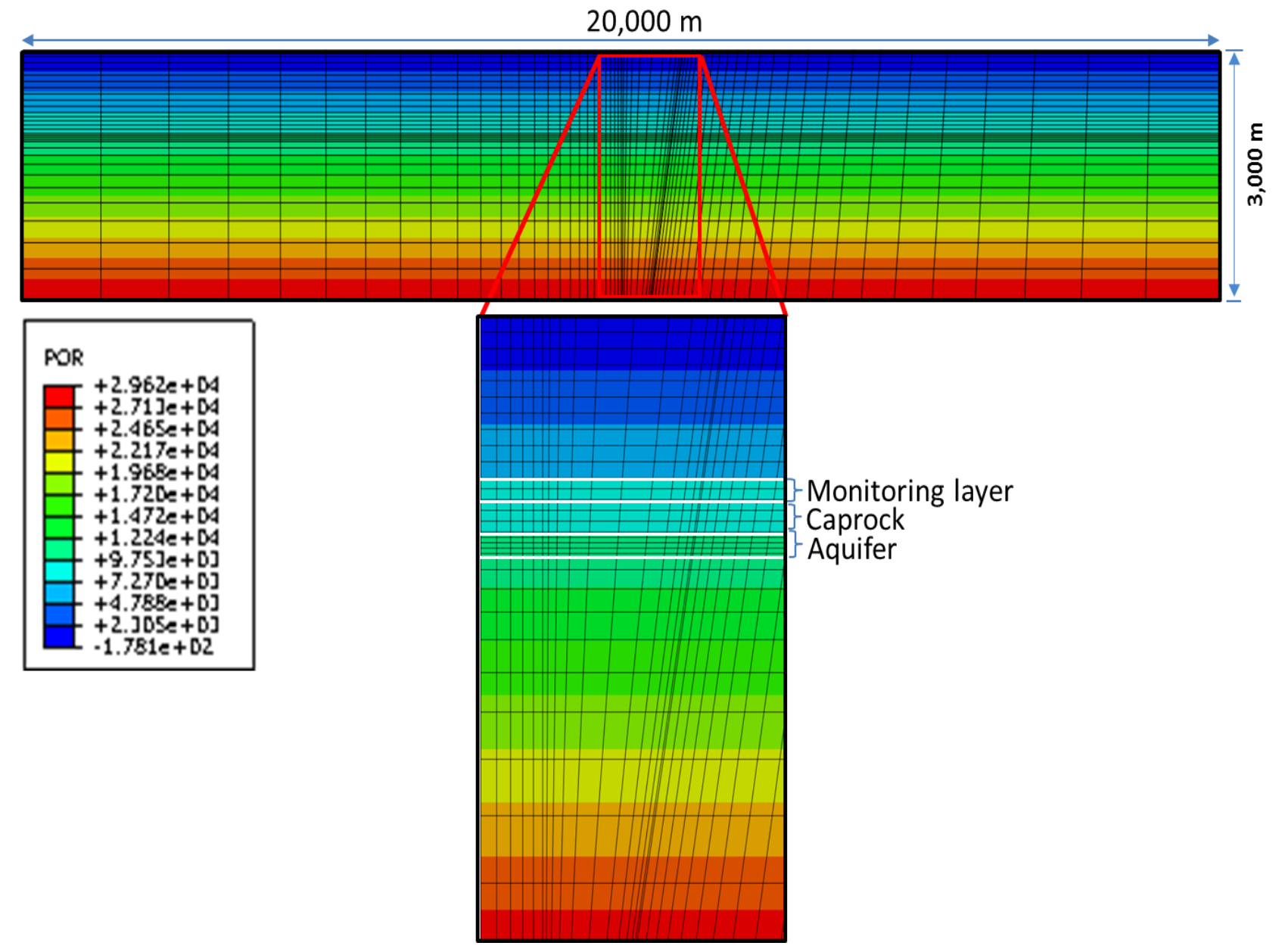

Figure 6.7: Computed initial fluid pressure distribution $(\mathrm{kPa})$ 


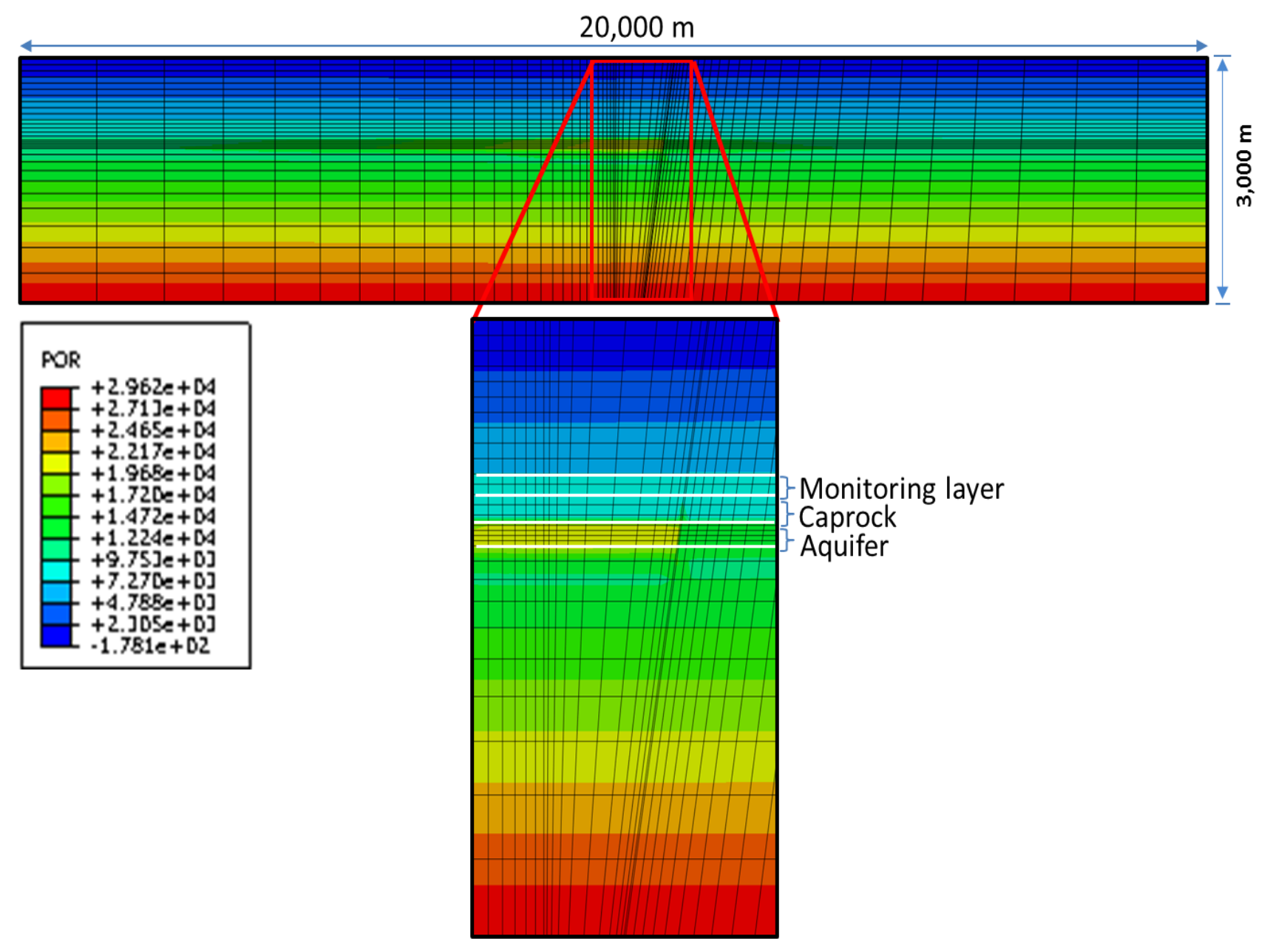

Figure 6.8: Computed pressure distribution $(\mathrm{kPa})$ after 5 years of fluid injection

Geomechanical modeling was performed to investigate the potential for shear failure along fault zone associated with underground fluid injection in a multilayered geological system. Geomechanical properties such as cohesion, angle of friction $\left(\mathrm{c}=200 \mathrm{kPa}\right.$ and $\left.\phi=25^{\circ}\right)$ were varied in fault zone to simulate shear failure due to continuous injection. Mohr-Coulomb failure criteria were considered to simulate overburden shear failure. Figure 6.9 shows the equivalent plastic strains after 5 years of fluid injection. The magnitude of plastic strains may be useful in development of geophysical methods to predict fault slip due to fluid injection. Figure 6.10 shows the variation of plastic strains near the fault line in the reservoir after 5 years of fluid injection 
Table 6.2: Geomechanical properties used in the finite element analyses

\begin{tabular}{|c|c|c|}
\hline \multirow{2}{*}{ Material/Property } & \multicolumn{2}{|c|}{ Fault Zone } \\
\cline { 2 - 3 } & Mohr-Coulomb Model & Drucker-Prager Model \\
\hline Cohesion(kPa) & 200 & 306 \\
\hline Friction Angle(degrees) & 25 & 35.2 \\
\hline Dilation Angle(degrees) & 20 & 20 \\
\hline
\end{tabular}

$20,000 \mathrm{~m}$

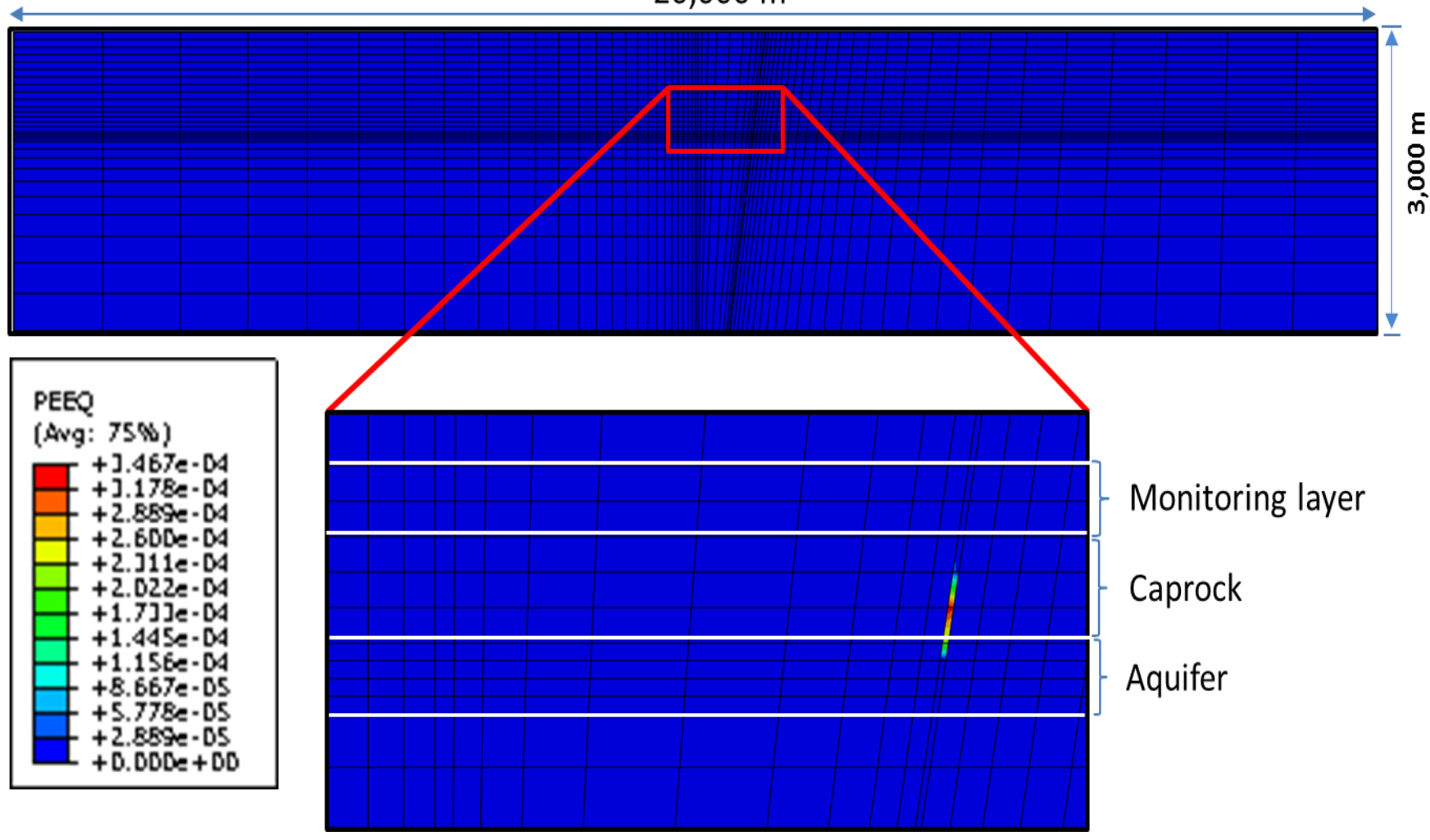

Figure 6.9: Computed equivalent plastic strains after 5 years of fluid injection by using MohrCoulombs failure criteria 


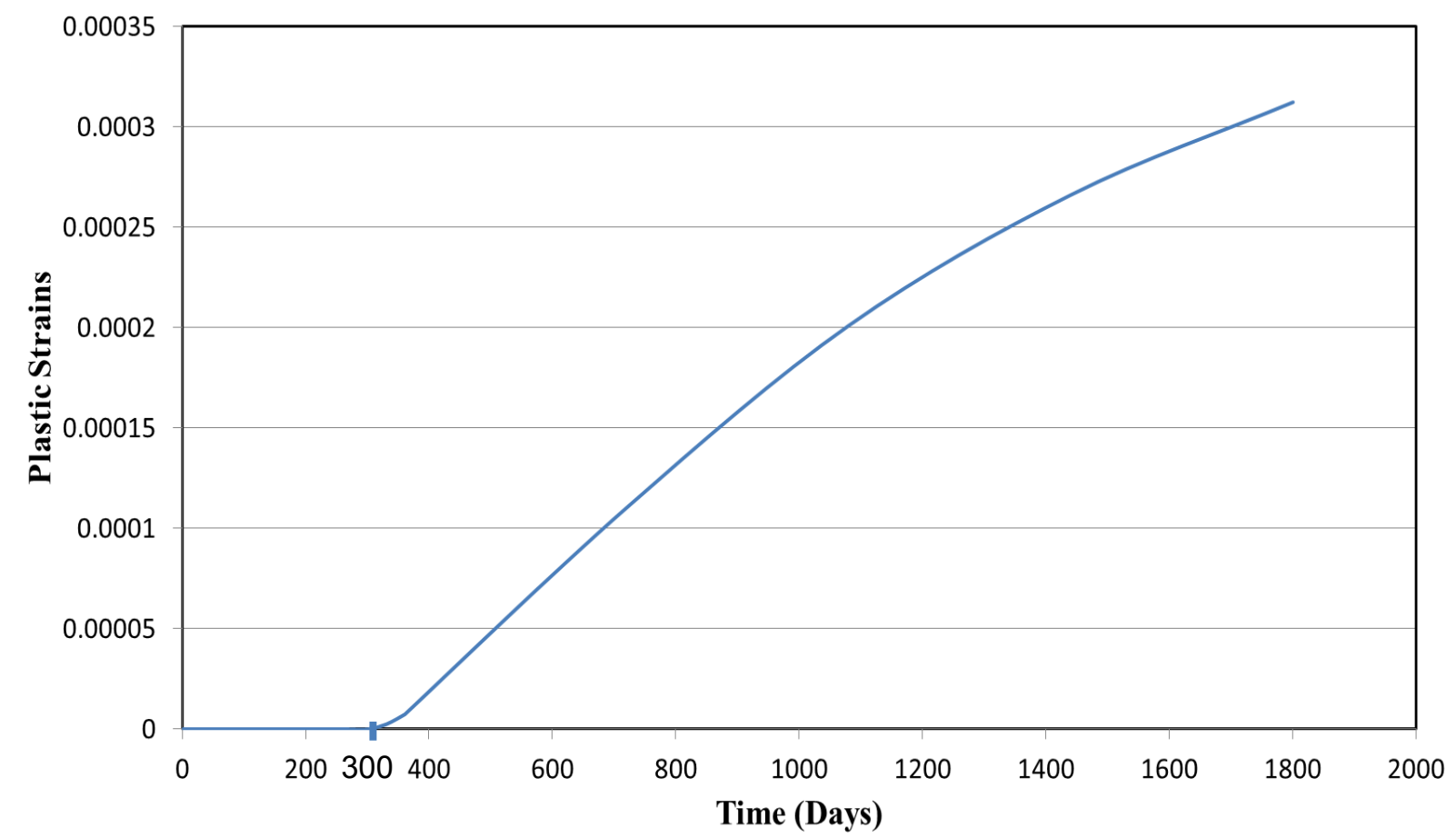

Figure 6.10: Variation of plastic strains near the fault line in the reservoir after 5 years of fluid injection by using Mohr-Coulomb criteria

\subsubsection{Drucker-Prager failure criterion}

Finite element analyses (single-phase fluid flow simulations) were performed to investigate shear failure in the caprock layer due to long-term fluid injection by using DruckerPrager failure criterion. Drucker-Prager failure criterion was used in the fault zone in this model. Drucker-Prager constant, $\mathrm{d}=306 \mathrm{kPa}$ and Druck-Prager friction angle, $\beta=35.2^{\circ}$ were varied to investigate the influence of shear failure in the caprock due to $\mathrm{CO}_{2}$ injection. A five-year fluid injection was performed at a differential pressure of $10.3 \mathrm{MPa}$ (approximately 1,500 psi) in the target reservoir at a depth of $1,050 \mathrm{~m}$. Figure 6.11 shows the effective plastic strains developed in the fault zone after 5 years of fluid injection. Figure 6.12 shows the variation of plastic strains near the fault line in the reservoir after 5 years of fluid injection. 


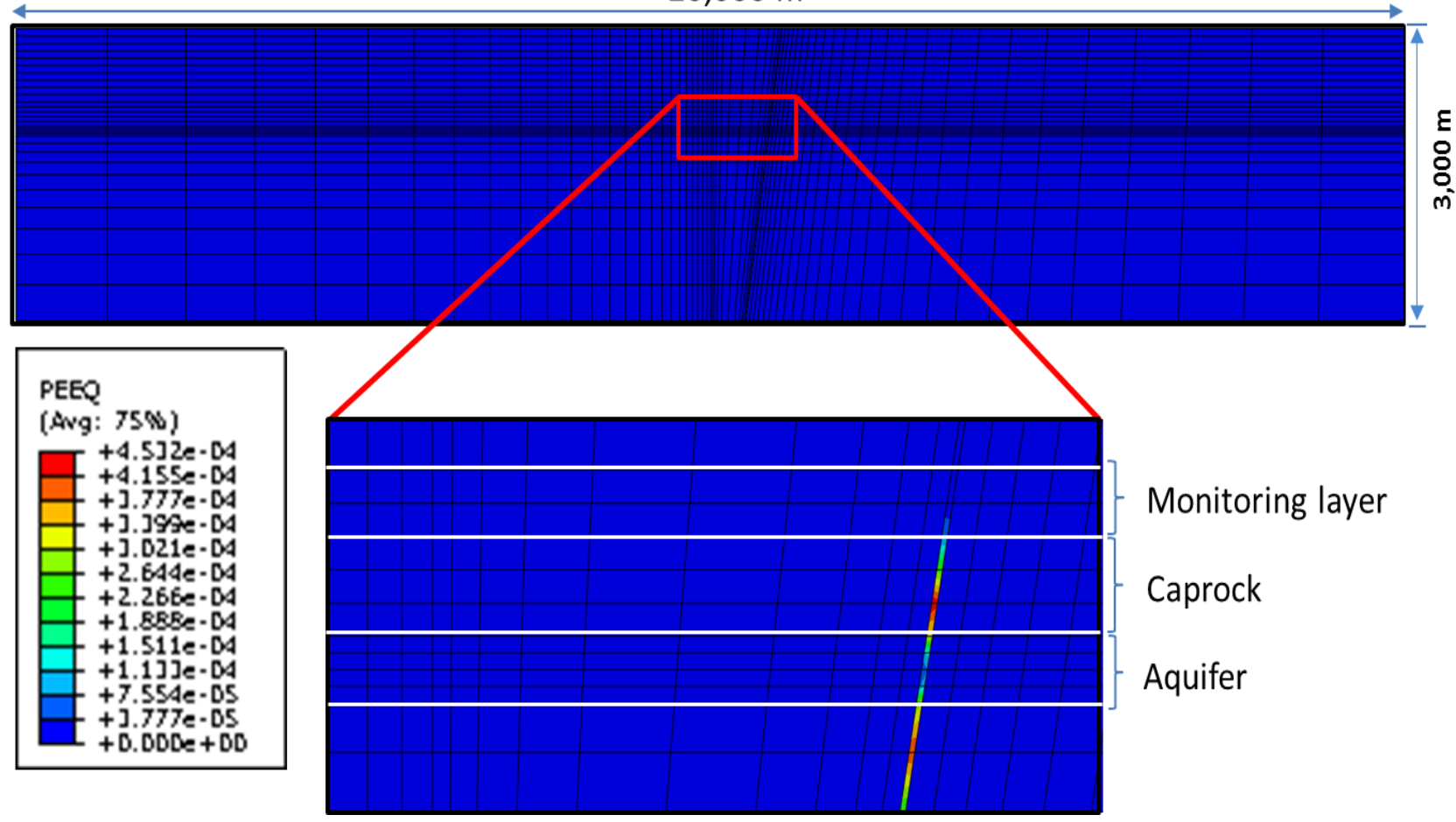

Figure 6.11: Computed equivalent plastic strains in the fault after 5 years of fluid injection by using Drucker-Prager failure criteria

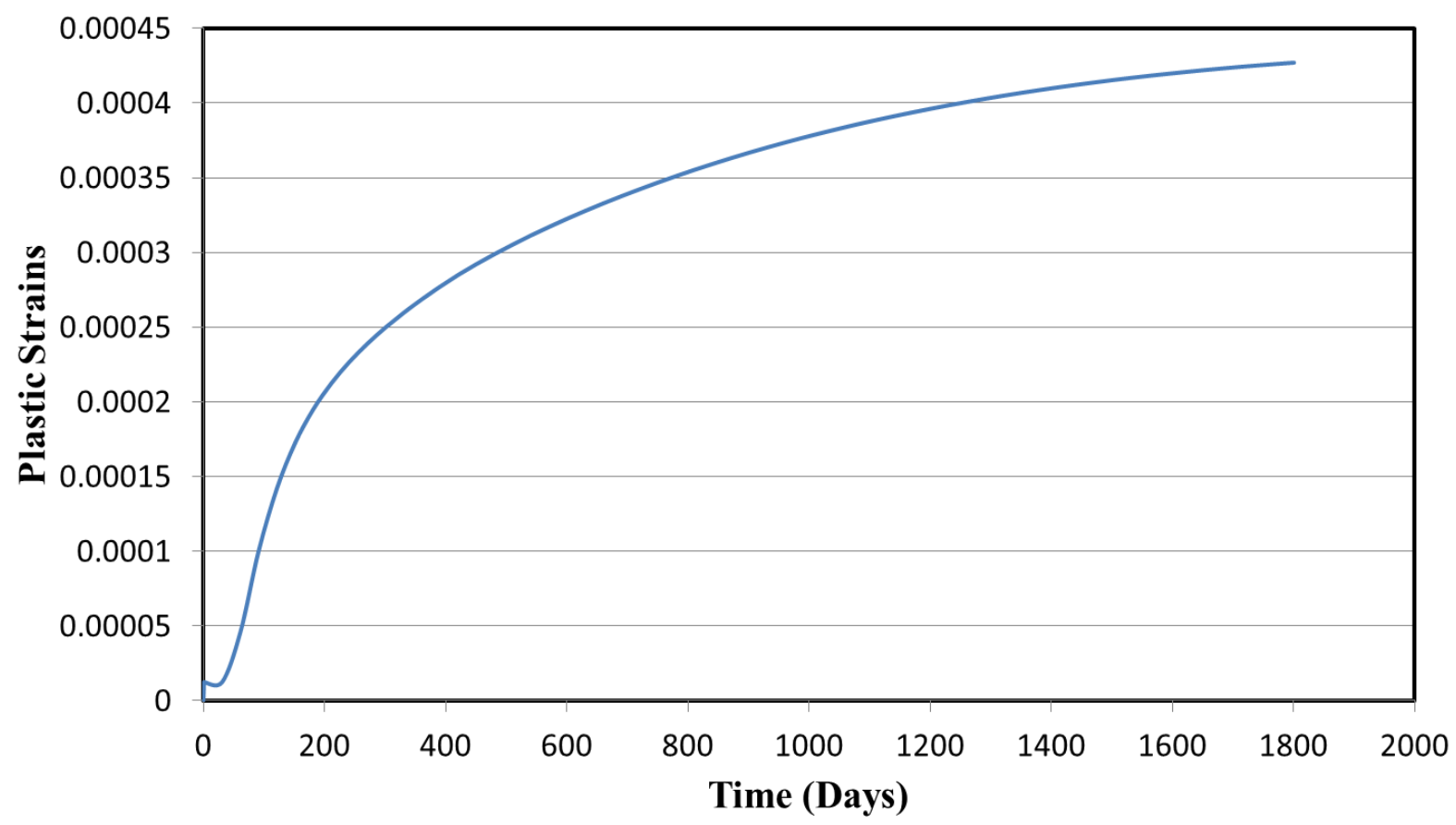

Figure 6.12: Variation of plastic strains near the fault line in the reservoir after 5 years of fluid injection by using Drucker-Prager criteria 
Modeling results show the development of plastic strains when injected fluid migrates to the fault zone. The magnitudes of equivalent plastic strains during a shear failure in the caprock layer can act as a proxy in identifying the extent of damage zone. In an inclined fault model, magnitudes of plastic strains are higher in Drucker-Prager failure criteria than MohrCoulomb failure criteria. The extent of damage zone in the inclined fault model was large for the Drucker-Prager failure model compared to Mohr-Coulomb failure model. Plastic strains can be used as a measure to investigate the extent of the damage zone. The damage zone (failure region) due to fluid injection in the inclined fault model can be first noticed with the use of Drucker-Prager failure criteria when compared to Mohr-Coulomb failure criteria. 


\section{CHAPTER 7 : SUMMARY AND CONCLUSIONS}

\subsection{Summary}

Underground reservoirs such as saline aquifers have a great potential for $\mathrm{CO}_{2}$ storage. Leakage pathways such as fractures which may exist prior to fluid injection or generated during fluid injection can make it unsuitable for $\mathrm{CO}_{2}$ storage. In the current paper, the possible communication of injected fluid with overlying geologic media was investigated over a period of time by constructing axisymmetric, two-dimensional and three-dimensional, single-phase and multi-phase coupled fluid flow-deformation models. Fluid was injected into a geologic reservoir that is capped with an impermeable caprock layer. Numerical methods were used to simulate a hypothetical injection of a fluid into a typical geologic reservoir. Results from these analyses provided an insight into the overburden geologic response and flow behavior. Modeling results show that axisymmetric and three-dimensional models produce similar results for computed ground displacements for both, single-phase and multi-phase fluid flow modeling coupled with geomechanics.- CMG-GEM is a multi-phase fluid flow simulator, and water and $\mathrm{CO}_{2}$ were selected as two components in the fluid flow model. Water is a default component in CMGGEM. A small percentage (negligible composition) of $\mathrm{CO}_{2}$ was considered in the initialization and the model was assumed to be fully saturated with water. However, the water saturation can be controlled in CMG-GEM. Also, same relative permeability curves were used for both singlephase and multi-phase fluid flow models. In a single-phase fluid flow model, water was used as the injection component. In a multi-phase fluid flow analyses where modeling of $\mathrm{CO}_{2}$ injection is planned, the injection component is changed from water to $\mathrm{CO}_{2}$. The fluid pressure distribution is similar when both, axisymmetric and three-dimensional models were used. The relative permeability curves used in this study are in the similar range identified for different rock formations (Bennion and Bachu, 2005; Siriwardane et al., 2013).

Coupled flow and geomechanical modeling was performed to investigate the potential of caprock shear failure associated with underground $\mathrm{CO}_{2}$-injection in a multilayered geological system. In this study, geomechanical stress changes resulting from upward migration of the $\mathrm{CO}_{2}$ within the multilayered storage system were investigated. In the coupled fluid flow-deformation models, parametric analyses were performed to investigate the influence of geomechanical rock 
properties on rock failure due to shearing during a hypothetical $\mathrm{CO}_{2}$ injection for 5 years. MohrCoulomb failure criterion was used to simulate rock failure. The cohesion and angle of internal friction of the caprock, monitoring layer and the reservoir were varied to investigate the rock behavior. Results show that plastic strains developed in the caprock and the monitoring layer for certain values of cohesion and angle of internal friction $\left(\mathrm{c}=200 \mathrm{kPa}\right.$ and $\left.\phi=21.5^{\circ}\right)$ were used for the caprock and the monitoring layer. In this case the value of cohesion and angle of internal friction $\left(\mathrm{c}=5,000 \mathrm{kPa}\right.$ and $\left.\phi=21.5^{\circ}\right)$ was used for the reservoir rock.

In the 2-D, single-phase models a hypothetical inclined fault zone was considered in the caprock layer. Both Mohr-Coulomb and Druck-Prager failure criterions were used for the material in the fault zone to investigate the shear failure of rock during fluid injection. Parametric analyses were performed by changing the value of cohesion and angle of internal friction of the caprock in order to investigate the rock behavior during fluid injection.

\subsection{Conclusions}

- Computed ground deformations and pressure response due to $\mathrm{CO}_{2}$ injection were similar when axisymmetric and three-dimensional coupled single-phase fluid flow and geomechanical models were considered.

- Computed ground deformations and pressure response due to $\mathrm{CO}_{2}$ injection were similar when axisymmetric and three-dimensional coupled multi-phase fluid flow and geomechanical models were considered.

- Single-phase and multi-phase coupled fluid flow and geomechanical models have significant differences in modeling results of ground deformations and fluid pressure changes. In the current study, results from coupled multi-phase fluid flow and geomechanical models show higher ground displacements.

- Geomechanical properties such as cohesion, angle of friction and permeability show that these material properties have significant influence on shear failure of caprock layer.

- Lower the cohesion higher the magnitudes of plastic strains developed in the caprock.

- Lower the friction angle higher the magnitudes of plastic strains developed in the caprock. 
- Extent of shear failure damage zone (i.e., zone of plastic strains) is greater when the caprock permeability is higher. If the permeability of caprock layer is higher, the injected $\mathrm{CO}_{2}$ rises to the top of the reservoir and flows into the caprock region. The fluid flow in the caprock layer increases the fluid pressure causing changes in effective stresses and resulting in caprock damage.

- Inclined fault models were also considered to investigate shear failure of inclined fracture or a fault during fluid injection. Results show the development of plastic strains when injected fluid migrates to the fault zone. The magnitudes of equivalent plastic strains during a shear failure in the caprock layer can act as a proxy in identifying the extent of damage zone.

- In an inclined fault model, magnitudes of plastic strains are higher (about 30\%) in Drucker-Prager failure criteria than Mohr-Coulomb failure criteria.

- The extent of damage zone in the inclined fault model was large for the Drucker-Prager failure model compared to Mohr-Coulomb failure model. Plastic strains can be used as a measure to investigate the extent of the damage zone.

- The damage zone (failure region) due to fluid injection in the inclined fault model can be first noticed with the use of Drucker-Prager failure criteria when compared to MohrCoulomb failure criteria.

\subsection{Recommendations}

The following points are recommended for future research work:

- Consider stress-dependent permeability in the reservoir and leakage zone to analyze change in permeability with change in effective stresses when $\mathrm{CO}_{2}$ is injected.

- Investigate the influence of multiple leakage points on the pressure response and ground deformation behavior. Also perform three-dimensional modeling to investigate mechanical integrity of caprock seal layer.

- Consider the use of three-dimensional inclined fault models. 


\section{REFERENCES}

1. ABAQUS (2012). ABAQUS Manuals. ABAQUS version 6.12-1. Dassault Systems Simulia Corp (SIMULIA).

2. Bachu, S., Bonijoly, D., and Bradshaw, J. (2007). $\mathrm{CO}_{2}$ storage capacity estimation: methodology and gaps. International Journal of Greenhouse Gas Control 1(4), pp. 430443.

3. Barnes, D. A., Bacon, D. H., and Kelley, S. R. (2009). Geological sequestration of carbon dioxide in the Cambrian Mount Simon Sandstone: Regional storage capacity, site characterization, and large-scale injection feasibility, Michigan Basin. Environmental Geosciences, 16(3), pp. 163-183.

4. Bennion, B. and Bachu, S. (2005). Relative permeability characteristics for supercritical $\mathrm{CO}_{2}$ displacing water in a variety of potential sequestration zones in the Western Canada Sedimentary Basin. SPE 95547, Proceedings of the SPE Annual Technical Conference and Exhibition, Dallas, TX, Oct 9-12.

5. Berkowitz, B. (2002). Characterizing flow and transport in fractured geological media: A review. Advances in Water Resources 25, pp. 861.

6. Birkholzer, J., Zhou, Q., and Tsang, C. (2009). Large-scale impact of $\mathrm{CO}_{2}$ storage in deep saline aquifers: A sensitivity study on pressure response in stratified systems. International Journal of Greenhouse Gas Control 3(2), pp. 181-194.

7. Bryant, S.L., Laksminarsimham, S., and Pope, G.A. (2006). Buoyancy-dominated multiphase flow and its effect on geological sequestration of $\mathrm{CO}_{2}$. SPE99938, Society of Petroleum Engineers, Symposium on Improved Oil Recovery held in Tulsa, Oklahama, U.S.A., April 22-26.

8. Cappa, F. and Rutqvist, J. (2011). Modeling of coupled deformation and permeability evolution during fault reactivation induced by deep underground injection of $\mathrm{CO}_{2}$. International Journal of Greenhouse Gas Control 5, pp 336-346.

9. Computer Modeling Group (CMG). (2012). CMG-GEM Manuals. CMG-GEM Version 12. $\mathrm{CMG}$, Calgray, Alberta, Canada.

10. Chadwick, R.A., Zweigel, P., Gregerson, U., Kirby, G.A., Holloway, S., and Johannessen, P.N. (2004). Geological reservoir characterization of a $\mathrm{CO}_{2}$ storage site: the Utsira Sand, Sleipner, northern North Sea. Energy 29: 1371-81.

11. Chadwick, A., Arts, R., Bernstone, C., May, F., Thibeau, S., and Zweigel, P. (2008). Best practice for the storage of $\mathrm{CO}_{2}$ in saline aquifers: observations and guidelines from the SACS and $\mathrm{CO}_{2}$ STORE projects. British Geological Survey Occasional Publication, Nottingham, UK. 
12. Chang, K.W., Minkoff, S.E., and Bryant, S.L. (2008). Modeling leakage through faults of $\mathrm{CO}_{2}$ stored in an aquifer. SPE 115929. Proceedings of the SPE Annual Technical Conference and Exhibition, Denver, Colorado, U.S.A, September 21-24.

13. Chen, Z., Huan, G., and Ma, Y. (2006). Computational methods for multiphase flows in porous media. Society for Industrial and Applied Mathematics (SIAM), Philadelphia, Pennsylvania, U.S.A.

14. CO2CRC. (2008). Storage capacity estimation, site selection and characterisation for $\mathrm{CO}_{2}$ storage projects. Cooperative Research Centre for Greenhouse Gas Technologies, Canberra, CO2CRC Report No. RPTO8-1001.52.

15. Crockford, P. and Telmer, K. (2009). Exploring the fate of $\mathrm{CO}_{2}$ at British Columbia's planned Fort Nelson carbon capture and storage project. Geoscience Reports, $B C$ Ministry of Energy, Mines and Petroleum Resources, pp 1-4.

16. Das, D.B. and Hassanizadeh, S.M. (2005). Upscaling Multi-phase Flow in Porous Media, Netherlands, pp. 237-257.

17. Das, B.M. (2007). Principles of Foundation Engineering. Sixth Edition. Thomson publishers, Canada.

18. Desai, C.S. and Siriwardane, H.J. (1984) Constitutive Laws for Engineering Materials with Emphasis on Geologic Materials. Prentice-Hall, Inc. Englewood Cliffs, New Jersey, U.S.A.

19. Dewhurst, D.N., Yang, Y., and Aplin, A.C. (1999). Permeability and fluid flow in natural mudstones, In: Aplin, A.C., A.J. Fleet, and J.H.S. Macquaker (eds). Muds and mudstones: Physical and Fluid-Flow Properties, Geological Society, London, Special Publications No. 158, pp 23-44.

20. Ennis-King, J. and Paterson. L. (2005). Role of convective mixing in the long-term storage of carbon dioxide in deep saline formations. SPE 84322. Proceedings of the SPE Annual Technical Conference and Exhibition, Denver, Colorado, U.S.A, October 5-8.

21. Fischietto, N.E., Bowen, B.B., and Rupp, J. A. (2009). Facies analysis and reservoir characterization of the cambrian mount simon formation in the illinois basin: implications for $\mathrm{CO}_{2}$ sequestration and storage. Proceedings of the American Association of Petroleum Geologists (AAPG) Annual Convention and Exhibition, Denver, CO, USA, June 7-10.

22. Gourmelen, N., Angus, D., Shepeherd, A., Fisher, Q., Gouldson, A., \& Lesnic, D. (2011). Scrutinizing $\mathrm{CO}_{2}$ sequestration: A case study coupling InSAR and geomechanical modelling to monitor spatial and temporal characteristics of $\mathrm{CO}_{2}$ injection at In Salah, Algeria. Proceedings of the International Conference on Flows and Mechanics in Natural Porous Media from Pore to Field Scale, Pore2Field, Les Rencontres 
Scientifiques d'IFP Energies nouvelles; IFP Energies nouvelles, Rueil-Malmaison, France, November 16-18.

23. Griffith, C.A., Dzombak, D.A., and Lowry, G.V. (2011). Physical and chemical characteristics of potential seal strata in regions considered for demonstrating geological saline $\mathrm{CO}_{2}$ sequestration. Environmental Earth Sciences 64, pp.925-948.

24. He, Q., Mohaghegh, S., and Gholami, V. (2013). A field study on simulation of $\mathrm{CO}_{2}$ injection and ECBM production and prediction of $\mathrm{CO}_{2}$ storage capacity in unmineable coal seam. Journal of Petroleum Engineering.

25. Hellavang, H., Khattri, S.K., Fladmark, G.E., and Kvamme, B. (2005). $\mathrm{CO}_{2}$ storage in the Utsira Formation-Athena 3D reactive transport simulations. Basin Research, November 15.

26. Helwany, S. (2007). Applied Soil Mechanics: with ABAQUS Applications. John Wiley \& Sons, Inc.

27. Hickin, S. (2009). The role of quaternary geology in northeastern British Columbia's oil and gas industry: A summary. Geoscience reports. BC Ministry of Energy, Mines and Petroleum Resources, pp 25-37.

28. Hollaway, S. (2008). 4 Sequestration - The Underground Storage of. Carbon Dioxide. British Geological Survey, Keyworth, Nottingham NG212 5GG, UK.

29. Hosa, A., Esentia, M., Stewart, J., and Haszeldine, S. (2011). Injection of $\mathrm{CO}_{2}$ into saline formations: Benchmarking worldwide projects. Chemical Engineering Research and Design 89, pp. 1855-1864.

30. IEA Greenhouse gas R\&D programme (IEA GHG, 2008). Aquifer storage-Development Issues, November.

31. IPCC. (2005). IPCC Special Report on Carbon Dioxide Capture and Storage. Prepared by Working Group III of the Intergovernmental Panel on Climate Change [Metz, B, Davidson, O, de Coninck, H C, Loos, M and Meyer, L A (eds.)]. Cambridge University Press, Cambridge, United Kingdom and New York, NY, USA, pp. 442.

32. Koperna, G.J., Kuuskarna, V., and Riestenberg, D. (2011). The SECARB anthropogenic test: The first $\mathrm{U}>\mathrm{S}$ integrated $\mathrm{CO} 2$ capture, transportation and storage test. Presented at $28^{\text {th }}$ Annual International Pittsburgh Coal Conference, September 12-15.

33. Kumar, A., Noh, M., Pope, G.A., Sepehrnoori, K., Bryant, S., and Lake, L.W. (2004). Reservoir simulation of $\mathrm{CO}_{2}$ storage in deep saline aquifers. SPE 89343. Proceedings of the Fourteenth Symposium on Improved Oil Recovery, Tulsa, Oklahoma, U.S.A., April 17-21. 
34. Laundry, A. (2011). Spectra energy Fort Nelson carbon capture \& storage feasibility project. May 19. http://www.spectraenergy.com/Operations/New-Projects-and-OurProcess/New-Projects-in-Canada/Fort-Nelson-North-Processing

35. Leetaru, H.E., Morse, D.G., Frailey, S.M., and Finley, R. J. (2005). Mt. Simon sandstone as a carbon sequestration sinks in the Illinois Basin. American Association of Petroleum Geologists (AAPG) Annual Convention, Calgary, Alberta.

36. Litynski, J., Plasynski, S., Spangler, L., Finley, R., Steadman, E., Ball, D., Nementh, K. J., McPherson, B., and Myer, L. (2009). U.S. Department of Energy's regional carbon sequestration partnership program: Overview. Energy Procedia 1, pp. 3959-3967.

37. Liu, F., Lu, P., Zhu, C., and Xiao, Y. (2011). Coupled reactive flow and transport modeling of $\mathrm{CO}_{2}$ sequestration in the Mt. Simon sandstone formation, Midwest U.S.A. International Journal of Greenhouse Gas Control 5 (2), pp. 294-307.

38. Locke, J., Winschel, R., Bajura, R., Wilson, T., Siriwardane, H., Rauch, H., and Mohaghegh, S. (2011). $\mathrm{CO}_{2}$ sequestration in unmineable coal with Enhanced Coal Bed Methane Recovery: The Marshall County Project: Proceedings of the International Pittsburgh Coal Conference, Pittsburgh, PA, USA, September 12 - 15.

39. Lucier, A. and Zoback, M. (2008). Assessing the economic feasibility of regional deep saline aquifer $\mathrm{CO}_{2}$ injection and storage: A geomechanics-based workflow applied to the Rose Run sandstone in Eastern Ohio, USA. International Journal of Greenhouse Gas Control 2(2), pp. 230-247.

40. Mancini, E.A. and Goddard, D.A. (2006). Resource assessment of the in-place and potentially recoverable deep natural gas resource of the onshore interior salt basins, North central and Northeastern Gulf of Mexico. NETL, Department of Energy. November 15.

41. Martinez, M.J., Newell, P., Bishop, J. E., and Turner, D. Z. (2013). Coupled multi-phase flow and geomechanics model for analysis of joint reactivation during $\mathrm{CO}_{2}$ sequestration operations. International Journal of Greenhouse Gas Control 17, pp. 148-160.

42. Medina, R.C., Rupp. A.J., and Barnes, A.D. (2011). Effects of reduction in porosity and permeability with depth on storage capacity and injectivity in deep saline aquifers: A case study from the Mount Simon Sandstone aquifer. International Journal of Greenhouse Gas Control 5(1), pp. 146-456.

43. Michael, k., Golab, A., Shulakova, V., Ennis-king, J., Allinson, G., Sharma, S., and Aiken, T. (2010). Geologic storage of $\mathrm{CO}_{2}$ in saline aquifers-A review of the experience from existing storage operations. International Journal of Greenhouse Gas Control 4, pp. $659-667$. 
44. Minkoff, S.E., Stone, C.M., Bryant, S., Peszynska, M., and Wheeler, M.F. (2003). Coupled fluid flow and geomechanical deformation modeling. Journal of Petroleum Science and Engineering 38, pp. 37-56.

45. Morris, J.P., Detwiler, R.L., Friedmann, S.J., Vorobiev, O.Y., and Hao, Y. (2011a). The large-scale geomechanical and hydrogeological effects of multiple $\mathrm{CO}_{2}$ injection sites on formation stability. International Journal of Greenhouse Gas Control 5 (1), pp. 69-74.

46. Morris, J.P., Hao, Y., Foxall, W., and McNab, W. (2011b). A study of injection-induced mechanical deformation at the In Salah $\mathrm{CO}_{2}$ storage project. International Journal of Greenhouse Gas Control 5 (2), pp. 270-280.

47. Nacht, P.K., De Oliveira, M. F., Roehl, D.M., and Costa, A.M. (2010). Investigation of geological fault reactivation and opening. Asociacion Argentina de Mecanica Computacional 29, pp. 8687-8697.

48. Olivier, J.G.J., Janssens-Maenhout, G., and Peters, J.A.H.W. (2012). Trends in global global $\mathrm{CO}_{2}$ emmsions. Report, The Hague: PBL Netherlands Environmental Assessment Agency, Ispra: Joint Research Centre.

49. Preston, S., Monea, M., Jazrawki, W., Brown, K., Whittaker, S., White, D., Law, D., Chalaturnyk, R., and Rostron, B. (2005). IEA GHG Weyburn $\mathrm{CO}_{2}$ monitoring and storage project. Fuel Processing Technology 86, pp. 1547-1568.

50. Riddiford, F.A., Tourqui, A., Bishop, C.D., Taylor, B., and Smith, M. (2003). A cleaner development: The In Salah Gas Project, Algeria. Proceedings of the 6th International Conference on Greenhouse Gas Control Technologies. J. Gale and Y. Kaya, (eds.), October 1-4, Kyoto, Japan, I, pp. 601-606.

51. Ringrose, P., Atbi, M., Mason, D., Espinassous, M., Myhrer, Ø. Iding, M., Mathieson, A. and Wright, I. (2009). Plume development around well KB-502 at the In Salah $\mathrm{CO}_{2}$ storage site. European Association of Geoscientists and Engineers, First break 27, January.

52. Rodesta, T., Litynski, J., Plasynski, S., Spangler, L., Finley, R., Steadman, E., Ball, D., Hill, G., Mcpherson, B., Burton, E., and Vikara, D. (2011). U.S. Department of Energy's regional carbon sequestration partnership initiative: Update on validation and development phases. Energy Procedia 4, pp. 3457-3464.

53. Rohmer, J. and Bouc, O. (2010). A response surface methodology to address uncertainties in cap rock failure assessment for $\mathrm{CO}_{2}$ geological storage in deep aquifers. International Journal of Greenhouse Gas Control 4 (2), pp. 198-208.

54. Rutqvist, J., Wu, Y.S., Tsang, C.F., and Bodvarsson, G. (2002). A modeling approach for analysis of coupled multi-phase fluid flow, heat transfer, and deformation in fractured 
porous rock. International Journal of Rock Mechanicsn and Mining Science 39, pp. 429442.

55. Rutqvist, J., Birkholzer, J., Cappa, F., and Tsang, C. F. (2007). Estimating maximum sustainable injection pressure during geological sequestration of $\mathrm{CO}_{2}$ using coupled fluid flow and geomechanical fault-slip analysis. Energy Conversion and Management 48, pp. 1798-1807.

56. Rutqvist, J., Birkholzer, J., and Tsang, C. (2008). Coupled reservoir-geomechanical analysis of the potential for tensile and shear failure Associated with $\mathrm{CO}_{2}$ injection in multilayered reservoir-caprock system. International Journal of Rock Mechanics and Mining Science 45 (2), pp. 132-143.

57. Rutqvist, J., Vasco, D.W., and Myer, L. (2009). Coupled reservoir-geomechanical analysis of $\mathrm{CO}_{2}$ injection at In Salah, Algeria. Energy Procedia 1, pp. 1847-1854.

58. Rutqvist, J., Vasco, D.W., and Myer, L. (2010). Coupled reservoir-geomechanical analysis of $\mathrm{CO}_{2}$ injection and ground deformations at In Salah, Algeria. International Journal of Greenhouse Gas Control 4, pp. 255-230.

59. Shapiro, S.A. and Dinske, C. (2009). Scaling of seismicity induced by nonlinear fluidrock interaction. Journal of Geophysical Research 114.

60. Shi, J.Q., Sinayuc, C., Durucan, S., and Korre, A. (2012). Assessment of carbon dioxide plume behaviour within the storage reservoir and the lower caprock around the KB-502 injection well at In Salah. International Journal of Greenhouse Gas Control 7, pp 115126.

61. Siriwardane, H. and Gondle, R. (2011). Numerical modeling and monitoring of fluid flow and ground response during fluid injection. Proceedings of the $13^{\text {th }}$ International Association for Computer Methods and Advances in Geomechanics (IACMAG), Melbourne, Australia, May 9-11.

62. Siriwardane, H.J., Bowes, B.D., Bromhal, G.S., Gondle, R.K., Wells, A.W., and Strazisar, B.R. (2012). Modeling of $\mathrm{CBM}$ production, $\mathrm{CO}_{2}$ injection, and tracer movement at a field $\mathrm{CO}_{2}$ sequestration site. International Coalbed Journal of Coal Geology 96-97, pp. 120-136.

63. Siriwardane, H.J., Gondle, R., and Bromhal, G.S. (2013). Coupled flow and deformation modeling of carbon dioxide migration in the presence of a caprock fracture during injection. Energy \& Fuels 27(8), pp. 4232-4243.

64. Southwest Regional Carbon Sequestration Partnership (SECARB)-Development Phase (2013). National Energy Technology Laboratory, U.S. Department of Energy. October. 
65. Stevens, S.H., Kuuskraa, V.L., Gale, J., and Beecy, D. (2001). $\mathrm{CO}_{2}$ injection and sequestration in depleted oil and gas fields and deep coal seams: worldwide potential and costs. Environmental Geosciences 8(3), pp. 200-209.

66. Streit, E.J. and Hillis, R.R. (2004). Estimating fault stability and sustainable fluid pressures for underground storage of $\mathrm{CO}_{2}$ in porous rock. Australian School of Petroleum $(A S P)$, Adelaide, Australia. Energy 29, pp. 1445-1456.

67. Streit, E.J. and Siggins, A.F. (2005). Predicting, Monitoring and controlling geomechanical effects of $\mathrm{CO}_{2}$ injection. Greenhouse gas control technologies, Proceedings of the seventh International Conference on Greenhouse Gas Control Technologies; September 5-9.

68. Torp, T.A. and Gale, J. (2004). Demonstrating storage of $\mathrm{CO}_{2}$ in geological reservoirs: The Sleipner and SACS projects. Energy 29, pp. 1361-1369.

69. Tran, D., Settari. A, and Nghiem, L. (2004). New iterative coupling between a reservoir simulator and geomechanics module. SPE 78192, Proceedings of the SPE/ISRM Rock Mechanics Conference, Irving, Texas, U.S.A., October 20-23.

70. Tran, D., Nghiem, L., and Buchanan, L. (2005). An overview of iterative coupling between geomechanical deformation and reservoir flow. SPE 978979, Proceedings of the SPE International Thermal Operations and Heavy Oil Symposium, Calgary, Alberta, Canada, November 1-3.

71. Tran, D., Shrivastava, V., Nghiem, L., and Kohse, B. (2009). Geomechanical risk mitigation for $\mathrm{CO}_{2}$ sequestration in saline aquifers. SPE 125167, Proceedings of the SPE Annual Technical Conference and Exhibition, New Orleans, Louisiana, U.S.A., October 4-7.

72. Tran, D., Buchanan, L., and Nghiem, L. (2010). Improved gridding technique for coupling geomechanics to reservoir flow. SPE paper 115514. Proceedings of the SPE Annual Technical Conference and Exhibition, Denver, Colorado, U.S.A, September 2124.

73. U.S.D.O.E. (2007). Carbon Sequestration Atlas of the United States and Canada. United States Department of Energy.

74. U.S.D.O.E. (2012). Carbon Utilization and Storage Atlas of the United States, Edition 4. United States Department of Energy.

75. van der Meer, L.G.H. and van Wees, J.D. (2006). Limitations to storage pressure in finite saline aquifers, and the effect of $\mathrm{CO}_{2}$ solubility on storage pressure. SPE 103342 Proceedings of the SPE Annual Technical Conference and Exhibition, San Antonio, Texas, USA, September 24-27. 
76. Verdon, J.P., Kendall, J.M., White, D.J., and Angus, D.A (2011). Linking microseismic event observations with geomechanical models to minimize the risks of storing $\mathrm{CO}_{2}$ in geologic formations. Earth and Planetary Science letters 305, pp. 143-152.

77. Vidal-Gilbert, S., Tenthorey, E., Dewhurst, D., Ennis-King, J., Van Ruth, P., and Hillis, R. (2010). Geomechanical analysis of the Naylor Field, Otway Basin, Australia: Implications for $\mathrm{CO}_{2}$ injection and storage. International Journal of Greenhouse Gas Control 4 (5), pp. 827-839.

78. Vilarrasa, V., Bolster, D., Olivella, S., and Carrera, J. (2010). Coupled hydromechanical modeling of $\mathrm{CO}_{2}$ sequestration in deep saline aquifers. International Journal of Greenhouse Gas Control 4, pp. 910-919.

79. Vilarrasa, V., Olivella, S., and Carrera, J. (2011). Geomechanical stability of the caprock during $\mathrm{CO}_{2}$ sequestration in deep saline aquifers. Energy Procedia 4, pp. 5306-5313.

80. White, C.M., Smith, D.H., Jones, K.L., Goodman, A.L., Jikich, S.A., LaCount, R.b., DuBose, S.B., Ozdemir, E., Morsi, B.I., and Schroeder, K.T. (2005). Sequestration of carbon dioxide in coal with enhanced coalbed methane recovery-A review. Energy \& Fuels, An American Chemical Society Journal 19(3). March 22.

81. Wiprut, D. and Zoback, M.D. (2000). Fault reactivation and fluid flow along a previously dormant normal fault in the northern North Sea. Norwegian Petroleum Society Special Conference, 11, pp. 203-219.

82. Xu, Z., Fang, Y., Scheibe, T.D., and Bonneville, A. (2012). A fluid pressure and deformation analysis for geologic sequestration of carbon dioxide. Computers \& Geosciences 46, pp. 31-37.

83. Yang, F., Bai, B., Tang, D., Dunn-Norman, S., and Wronkiewicz, D. (2010). Comparison of completion and heterogeneity effect on $\mathrm{CO}_{2}$ sequestration in shallow and deep saline aquifers. SPE 131381. Proceedings of the SPE International Oil \& gas Conference and Exhibition in Beijing, China, June 8-10.

84. http://www.netl.doe.gov/research/coal/carbon-storage/carbon-storage-natcarb/ $\mathrm{CO}_{2-}$ storage-form.

85. www.CO2NOW.org 